Universidade de São Paulo

Instituto de Física

\title{
Complexidade e tomada de decisão
}

\author{
Eduardo Sangiorgio Dobay
}

Dissertação de mestrado apresentada ao Instituto de Física para a obtenção do título de Mestre em Ciências

Orientador:

Prof. Dr. Nestor Felipe Caticha Alfonso

\section{Comissão Examinadora:}

Prof. Dr. Nestor Felipe Caticha Alfonso (IF-USP)

Profa. Dra. Carmen Pimentel Cintra do Prado (IF-USP)

Prof. Dr. Ronald Dennis Paul Kenneth Clive Ranvaud (ICB-USP)

São Paulo 


\section{FICHA CATALOGRÁFICA}

Preparada pelo Serviço de Biblioteca e Informação do Instituto de Física da Universidade de São Paulo

Dobay, Eduardo Sangiorgio

Complexidade e tomada de decisão. São Paulo, 2014.

Dissertação (Mestrado) - Universidade de São Paulo. Instituto de Física. Depto. de Física Geral.

Orientador: Prof. Dr. Nestor Felipe Caticha Alfonso

Área de Concentração: Física Estatística

Unitermos: 1. Tomada de decisão; 2. Cadeias de Markov; 3. Modelos de aprendizagem; 4. Modelagem matemática.

USP/IF/SBI-101/2014 


\section{Agradecimentos}

Agradeço aos meus pais pelo apoio durante toda a graduação e a pós-graduação. Agradeço a todos os amigos que alimentaram meu interesse pela ciência e que estiveram disponíveis também durante os momentos de crise.

Agradeço ao Nestor Caticha pela orientação, pela paciência, pelas palavras de encorajamento, por seu tempo dedicado. Ao Marcus Vinícius Baldo e à Camila Victorino pela oportunidade de colaborar com este trabalho, à Carolina Feher pela troca de ideias.

Agradeço ao Conselho Nacional de Desenvolvimento Científico e Tecnológico (CNPq) e à Fundação de Amparo à Pesquisa do Estado de São Paulo (Fapesp) pelo auxílio financeiro, e à USP por toda a estrutura propiciada nestes anos. 



\section{Resumo}

Neste trabalho foi elaborada uma estrutura de modelos probabilísticos simples que pudessem descrever o processo de tomada de decisão de agentes humanos que são confrontados com a tarefa de prever elementos de uma sequência aleatória gerada por uma cadeia de Markov de memória $L$. Essa estrutura partiu de uma abordagem bayesiana em que o agente infere uma distribuição de probabilidades a partir de uma série de observações da sequência e de suas próprias respostas, considerando que o agente tenha uma memória de tamanho $K$.

Como resultado da abordagem bayesiana, o agente adota uma estratégia ótima que consiste na perseveração na alternativa mais provável dado o histórico das últimas tentativas; por conta disso e de observações experimentais de que humanos tendem a adotar nesse tipo de problema estratégias sub-ótimas, por exemplo a de pareamento de probabilidades (probability matching), foram desenvolvidas variações sobre esse modelo que tentassem descrever mais de perto o comportamento adotado por humanos. Nesse sentido, foram adotadas as variáveis de 'troca de resposta' (possível ação tomada pelo agente) e de 'recompensa' (possível resultado da ação) na formulação do modelo e foram adicionados parâmetros, inspirados em modelos de ação dopaminérgica, que permitissem um desvio da estratégia ótima resultante da abordagem bayesiana.

Os modelos construídos nessa estrutura foram simulados computacionalmente para diversos valores dos parâmetros, incluindo as memórias $K$ e $L$ do agente e da cadeia de Markov, respectivamente. Através de análises de correlação, esses resultados foram comparados aos dados experimentais, de um grupo de pesquisa do Instituto de Ciências Biomédicas da USP, referentes a tarefas de tomada de decisão envolvendo pessoas de diversas faixas etárias (de 3 a 73 anos) e cadeias de Markov de memórias 0, 1 e 2.

Nessa comparação, concluiu-se que as diferenças entre grupos etários no experimento podem ser explicadas em nossa modelagem através da variação da memória $K$ do agente - crianças de até 5 anos mostram um limite $K=1$, e as de até 12 anos mostram um limite $K=2$ - e da variação de um parâmetro de reforço de aprendizado - dependendo do grupo e da situação de decisão à qual os indivíduos eram expostos, o valor ajustado desse parâmetro variou de $10 \%$ para baixo até $30 \%$ para cima do seu valor original de acordo com a abordagem bayesiana. 



\section{Abstract}

In this work we developed a simple probabilistic modeling framework that could describe the process of decision making in human agents that are presented with the task of predicting elements of a random sequence generated by a Markov chain with memory $L$. Such framework arised from a Bayesian approach in which the agent infers a probability distribution from a series of observations on the sequence and on its own answers, and considers that the agent's memory has length $K$.

As a result of the Bayesian approach, the agent adopts an optimal strategy that consists in perseveration of the most likely alternative given the history of the last few trials; because of that and of experimental evidence that humans tend, in such kinds of problems, to adopt suboptimal strategies such as probability matching, variations on that model were developed in an attempt to have a closer description of the behavior adopted by humans. In that sense, the 'shift' (possible action taken by the agent on its response) and 'reward' (possible result of the action) variables were adopted in the formulation of the model, and parameters inspired by models of dopaminergic action were added to allow deviation from the optimal strategy that resulted from the Bayesian approach.

The models developed in that framework were computationally simulated for many values of the parameters, including the agent's and the Markov chain's memory lengths $K$ and $L$ respectively. Through correlation analysis these results were compared to experimental data, from a research group from the Biomedical Science Institute at USP, regarding decision making tasks that involved people of various ages ( 3 to 73 years old) and Markov chains of orders 0,1 and 2 .

In this comparison it was concluded that the differences between age groups in the experiment can be explained in our modeling through variation of the agent's memory length $K$ - children up to 5 years old exhibited a limitation of $K=1$, and those up to 12 years old were limited to $K=2-$ and through variation of a learning reinforcement parameter - depending on the group and the decision situation to which the candidates were exposed, the fitted value for that parameter ranged from $10 \%$ below to $30 \%$ above its original value according to the Bayesian approach. 



\section{Sumário}

Sumário ix

1 Decisões: um panorama geral 1

2 Caracterização matemática de decisões 5

2.1 Sequências binárias e cadeias de Markov . . . . . . . . . . . . 5

2.2 Uma visão do problema de decisão . . . . . . . . . . . . . . . . . . . 6

2.3 Caracterização da máquina . . . . . . . . . . . . . . . 7

2.4 Caracterização do agente . . . . . . . . . . . . . . 8

2.5 Desempenho do agente . . . . . . . . . . . . . . 9

$2.5 .1 \quad$ Erro médio . . . . . . . . . . . . . . . . . . 10

2.5.2 Estimativa da distribuição . . . . . . . . . . . . . . . . 13

2.5.3 De volta à minimização do erro . . . . . . . . . . . . . . 16

2.6 Uma mudança de variáveis . . . . . . . . . . . . . . . . . . . . . . . 19

2.6.1 Revisitando o erro e sua minimização . . . . . . . . . . . . . . 20

2.6 .2 Estimativa das probabilidades . . . . . . . . . . . . . 22

2.6.3 O aprendizado como uma série de correções . . . . . . . . . . . 24

3 Simulações e resultados $\quad 27$

3.1 Descrição dos algoritmos utilizados . . . . . . . . . . . . . . . . 27

3.2 Observações iniciais . . . . . . . . . . . . . . . . . . . . . . . 29

3.3 Perturbações sobre o aprendizado . . . . . . . . . . . . . . . 37

3.4 Resultados experimentais . . . . . . . . . . . . . . . . . . . 39

3.4.1 Descrição do experimento . . . . . . . . . . . . . . . . 39

3.4 .2 Breve resumo dos resultados . . . . . . . . . . . . . . . . 40

3.5 Confronto com os resultados experimentais . . . . . . . . . . . . . . 41

3.5.1 Metodologia . . . . . . . . . . . . . . . 41

3.5.2 Resultados e discussão da comparação . . . . . . . . . . . . . . 44

4 Conclusões $\quad 73$

$\begin{array}{ll}\text { Glossário } & 75\end{array}$

$\begin{array}{ll}\text { Bibliografia } & 77\end{array}$ 



\section{Capítulo 1}

\section{Decisões: um panorama geral}

O estudo de decisões é um assunto amplo e visto como objeto de interesse, por diferentes pontos de vista, em diversas áreas do conhecimento. Um dos objetivos principais das Ciências Econômicas, por exemplo, é estudar, num contexto de gestão de bens e recursos, o comportamento de agentes humanos, de modo que a decisão não pode deixar de ser objeto central de estudo - em particular, há interesse em conhecer as melhores decisões possíveis para se tomar em cada cenário. Outras áreas, como Direito e Medicina, possuem momentos de tomada de decisão em pontos cruciais de sua metodologia de trabalho prático. Em um outro lado, a Neurociência e a Psicologia buscam razões pelas quais pessoas tomam certos tipos de decisões.

Um resultado muito presente é o contraste entre a maneira como pessoas deveriam tomar decisões e a maneira como realmente tomam decisões. Um dos problemas por trás disso é a suposição (errônea) de que pessoas tomam decisões de maneira racional; pelo contrário, crenças, vieses e preocupações pessoais podem afetar tanto o julgamento das opções disponíveis quanto a decisão em si.

Nas primeiras tentativas de quantificar o estudo da tomada de decisões, estudaram-se muitos problemas com apostas em jogos de azar. Uma abordagem comum consistia em calcular o valor esperado do prêmio - a média dos prêmios possíveis ponderados pela probabilidade de ocorrência de cada situação. No século 18, conforme contam Martin (2004) e Savage (1972), Nicolas Bernoulli encontrou uma situação, que nomeou paradoxo de São Petersburgo, na qual essa abordagem se mostrava problemática:

Um jogo consiste de um prêmio inicial de 2 dólares e uma sequência de lançamentos de uma moeda honesta. Se o resultado for coroa, o jogo acaba e o jogador recebe o prêmio; se for cara, o prêmio é duplicado e o jogo continua. O prêmio final $P$ depende do número $n$ de caras que apareceram em sequência: $P=2 \cdot 2^{n}$. A probabilidade de que $n$ lançamentos seguidos resultem em cara e o seguinte em coroa é $(1 / 2)^{n+1}$. Desta maneira, o prêmio esperado é

$$
E(P)=\sum_{n=0}^{\infty}\left(2 \cdot 2^{n}\right) \cdot\left(\frac{1}{2}\right)^{n+1}=1+1+1+\cdots=\infty
$$

O problema dessa abordagem está na contradição entre o valor esperado infinito do prêmio e a observação de que as pessoas em geral não estão dispostas a pagar altas quantias para poder entrar nesse jogo, o que sugere que o prêmio esperado não é uma boa medida da desejabilidade de uma aposta. 
Daniel Bernoulli propôs, para resolver esse impasse, o emprego de uma função de utilidade, que estabelece uma escala de desejabilidade entre os resultados. Essa escala responde melhor à pergunta sobre as vantagens e desvantagens da aposta: o resultado a ser analisado passa a ser a utilidade esperada em vez do prêmio esperado. Porém, como aponta Martin (2004), a escolha dessa escala requer certo cuidado para garantir que a utilidade esperada seja finita em todos os casos.

Kahneman e Tversky (1979) fizeram entrevistas com diversos indivíduos e identificaram problemas nas conclusões extraídas da teoria de utilidade introduzida por Bernoulli e aprimorada por von Neumann e Morgenstern. Há diversos conjuntos de problemas que, mesmo sendo equivalentes do ponto de vista dessa teoria, podem ser formulados de maneiras diferentes de modo a influenciar a preferência das pessoas entre as opções apresentadas. Nos casos estudados ocorre muito frequentemente uma inversão na preferência da população ao alterar a formulação do problema para outro que tenha exatamente o mesmo prêmio esperado e a mesma utilidade esperada. A alternativa desenvolvida pelos autores foi a teoria da perspectiva (prospect theory), que leva em conta efeitos observados em escolhas na vida real - como assimetria entre perdas e ganhos, e aversão ao risco ou busca pelo risco.

O foco de tais trabalhos está em problemas nos quais um agente deve tomar uma única decisão frente a um único problema, cujas regras são totalmente claras quando o problema é posto ao agente.

Em uma outra classe de problemas, o agente toma decisões repetidas frente ao mesmo problema, porém sem conhecer a princípio as probabilidades subjacentes. Desta forma, o interesse é em maximizar a soma dos resultados a longo prazo, e não em maximizar o resultado de uma iteração; além disso, espera-se que o agente utilize os resultados para aprender sobre o problema, e que com o passar do tempo ele se vá se aproximando de uma estratégia melhor para suas decisões dentro do problema.

Um exemplo dessa classe é o experimento descrito em Behrend e Bitterman (1961), realizado com um conjunto de peixes. No momento da alimentação, eram mostradas a cada sujeito duas cápsulas, das quais apenas uma, determinada aleatoriamente pelo controlador da experiência, continha comida. O peixe era incentivado a tocar uma das duas em busca de comida; após a escolha, o conteúdo da cápsula escolhida era liberado para o peixe e a outra opção era retirada. Quando o aparecimento de comida em uma das cápsulas era mais frequente do que na outra, os sujeitos desenvolveram uma tendência a persistir sempre na cápsula mais frequente - essa é a melhor estratégia possível (conhecida como perseveração) para o caso em que o padrão externo é aleatório. Quando o experimento foi conduzido de uma maneira na qual os peixes eram guiados a fornecer a resposta certa, a tendência era de visitar cada cápsula com probabilidade 
correspondente à frequência de aparecimento de comida nela - estratégia conhecida como pareamento de probabilidades (probability matching).

Segundo tal trabalho, o único outro animal em que se observa o pareamento de probabilidades é o ser humano. Victorino (2012) realizou um experimento com voluntários submetidos a tarefas de escolha binária (em que se apresentam duas alternativas, como no exemplo anterior), em que se puderam observar os dois tipos de estratégia - o pareamento de probabilidades e a perseveração na alternativa mais frequente - além de estratégias intermediárias.

Bogacz et al. (2006) apresenta e compara uma série de modelos para descrever o processo humano de tomada de decisões em um outro tipo de problema de escolhas binárias, em que a cada tentativa há informação suficiente para se escolher a resposta correta, mas há um tempo de reação até que tal informação seja compreendida pelo sujeito; a relação entre tempo de reação e acurácia é um dos interesses de tal trabalho.

O presente trabalho é uma tentativa de um novo tipo de modelagem, que descreva o problema de Victorino (2012) e busque identificar qualitativamente o desvio das estratégias adotadas pelos sujeitos em relação à estratégia ótima. A estratégia ótima será construída a partir do próximo capítulo; os resultados desse experimento serão descritos mais detalhadamente na seção 3.4. Em seguida, será feita uma comparação entre o experimento e a modelagem aqui desenvolvida. 

Capítulo 2

Caracterização matemática de decisões

\subsection{Sequências binárias e cadeias de Markov}

Uma sequência binária é uma sequência que tem apenas dois tipos de elementos ou símbolos. Os elementos podem ser quaisquer: números, objetos utilizados como estímulos, "esquerda" e "direita"; em nosso estudo, representaremos os dois elementos pelos números 0 e 1.

Uma cadeia de Markov é, informalmente falando, uma sequência que representa a evolução temporal de um objeto que transita entre vários estados de maneira probabilística: a transição de um estado para o outro ocorre com uma probabilidade que depende apenas do estado do qual o objeto parte e do estado para o qual ele vai. Por exemplo, suponha um certo modelo climático para um certo lugar no qual a probabilidade de chuva em um dia qualquer dependa da chuva do dia anterior da seguinte maneira: se choveu no dia anterior, a probabilidade de chuva no dia é de $50 \%$ e, se não choveu, a probabilidade de chuva é de $30 \%$. Nesse exemplo, "choveu" e "não choveu" são os estados possíveis, e a regra que estabelecemos constitui um conjunto de probabilidades de transição entre esses dois estados, exatamente o que se precisa para descrever uma cadeia de Markov.

Definindo mais rigorosamente, dado um espaço de probabilidades $(\Omega, \mathscr{B}, P)$ - constituído por um espaço amostral $\Omega$, um conjunto $\mathscr{B}$ de eventos e uma medida $P$ de probabilidades -, uma cadeia de Markov é uma sequência de variáveis aleatórias $X_{1}, X_{2}, X_{3}, \ldots$ tais que, para quaisquer $x_{1}, x_{2}, \ldots \in \Omega$,

$$
P\left(X_{n}=x \mid X_{n-1}=x_{n-1}, \ldots, X_{2}=x_{2}, X_{1}=x_{1}\right)=P\left(X_{n}=x \mid X_{n-1}=x_{n-1}\right) .
$$

Os elementos do nosso exemplo, nessa linguagem, podem ser traduzidos da seguinte forma: o espaço amostral, $\Omega$, contém os valores "choveu" e "não choveu", que são os resultados possíveis para uma pergunta do tipo "choveu no dia $n$ ?”. A resposta para essa pergunta é representada por $x_{n}$.

Se colocarmos mais condições no nosso modelo, supondo que a probabilidade de chover hoje dependa da chuva de ontem e de anteontem, as probabilidades de transição de estado dependerão dos dois últimos estados, não apenas do último - e, por isso, não valerá a modelagem que imaginamos em termos de uma cadeia de Markov.

Podemos, porém, usar o seguinte artifício para transformar esse novo problema em uma cadeia de Markov tradicional: a cada instante $t$ consideramos como personagem principal não o último estado $S_{t}$ do sistema, mas sim o $\operatorname{par}\left(S_{t-1}, S_{t}\right)$ dos dois últimos 
estados do sistema. Para evitar confusões devidas ao múltiplo uso da palavra 'estado', vamos chamar o 'estado de passo único' $S_{t}$ de um 1-estado do sistema, e $\left(S_{t-1}, S_{t}\right)$ de um 2-estado do sistema.

Dessa maneira, em vez de dizer que o sistema realiza uma transição de $S_{t}$ para $S_{t+1}$, dizemos que ele realiza uma transição de $\left(S_{t-1}, S_{t}\right)$ para $\left(S_{t}, S_{t+1}\right)$. Portanto, todas as possíveis transições que o sistema realiza são do tipo $\left(s, s^{\prime}\right) \rightarrow\left(s^{\prime}, s^{\prime \prime}\right)$; qualquer transição do tipo $\left(s, s^{\prime}\right) \rightarrow\left(\bullet, s^{\prime \prime}\right)$, com $\bullet \neq s^{\prime}$, é probida e portanto o elemento de matriz correspondente é nulo.

Esse raciocínio se estende facilmente para modelos em que a probabilidade de transição para um estado $x_{t}$ depende dos últimos $L$ estados, $x_{t-1} \ldots x_{t-L}$ : o $L$-estado que devemos utilizar em uma cadeia de Markov é a $L$-upla $\left(x_{t-L}, \ldots, x_{t-1}\right)$, da qual só se pode realizar transições para os estados $\left(x_{t-L+1}, \ldots, x_{t-1}, x_{t}\right)$.

É importante notar que essa regra continua apresentando uma simetria de translação temporal: a distribuição de $X_{t}$, dados $X_{t-1}, \ldots, X_{t-L}$, é igual à distribuição de $X_{t+\delta}$, dados $X_{n+\delta-1}, \ldots, X_{n+\delta-L}$.

Com essa estrutura conseguimos consolidar a definição do que chamaremos de cadeia de Markov de memória $L$ ou de ordem $L$. O caso $L=1$ representa a cadeia de Markov tradicional, e $L=0$ representa uma sequência de variáveis aleatórias independentes, igualmente distribuídas de acordo com uma distribuição discreta de probabilidades.

\subsection{Uma visão do problema de decisão}

Suponhamos que uma pessoa esteja interagindo com uma máquina que gera uma sequência binária e que essa pessoa deva tentar prever, a cada passo, qual será o próximo elemento da sequência. Num possível exemplo dessa situação, um programa de computador apresenta ao usuário a opção de clicar em um dentre dois botões que apareçam na tela, e, após a ação do usuário, responde se o botão clicado era o correto.

O usuário não sabe, a princípio, qual regra a máquina utiliza para construir a sequência, e, portanto, se quiser atingir um melhor desempenho, precisa analisar os resultados das tentativas anteriores para tentar descobrir algo sobre a regra e com isso construir uma estratégia melhor para suas próximas tentativas. Este agente pode ser incentivado a buscar um melhor desempenho através de diversos estímulos - continuando o exemplo anterior, uma possibilidade é que o programa de computador seja construído como um jogo e que cada acerto dê algum tipo de retorno positivo ao usuário (uma pontuação e/ou alguma espécie de prêmio virtual); isso o instiga a buscar uma estratégia para maximizar sua pontuação e seus prêmios. 
Nem sempre essa busca por um maior desempenho acaba na melhor estratégia possível nem no entendimento do padrão da sequência gerada pela máquina: diversos fatores podem levar uma pessoa a adotar uma estratégia que seja pouco favorável - como influências emocionais ou convicções pessoais -, além de, como observa Kahneman (2011), haver desvios cognitivos.

Essa "perversão" muitas vezes está ligada ao uso de regras probabilísticas. Em uma máquina determinística, dado um determinado conjunto de condições iniciais, é possível prever perfeitamente quais elementos irão compor a sequência gerada. Uma máquina probabilística não gera os elementos diretamente: ela gera uma distribuição de probabilidades e sorteia aleatoriamente um dos elementos possíveis seguindo essa distribuição.

Vale também lembrar que a melhor estratégia possível pode não resultar num desempenho de $100 \%$; ainda mais, se a regra usada pela máquina para escolher o próximo elemento for probabilística, certamente o desempenho ótimo será menor que 100\%: não há estratégia que garanta coincidência total com uma sequência probabilística.

\subsection{Caracterização da máquina}

Consideremos uma versão um pouco mais específica do problema de decisão que está sendo apresentado. Suponhamos que a sequência gerada pela máquina seja uma cadeia de Markov com memória de $L$ passos, ou seja, que a distribuição de probabilidades para o símbolo atual seja uma função dos $L$ símbolos anteriores. Por ser uma cadeia de Markov, sabemos que essa função não depende do instante em que estamos, ou seja, a dependência com os últimos $L$ elementos é sempre a mesma.

As seguintes notações serão adotadas:

- A máquina gera a cada instante $t$ um símbolo $x_{t}$, que pode ter um dos valores $\{0,1\}$. Esse símbolo é o valor assumido pela variável aleatória $X_{t}$.

- Como o tempo é discretizado no processo que estamos estudando, a palavra instante poderá ser substituida por iteração, ou também por rodada, visto que a interação entre o agente e a máquina torna o problema análogo a um jogo.

- $\eta_{1}^{L}$ representa o conjunto dos últimos $L$ símbolos, ou seja, $\left(x_{t-1} \ldots x_{t-L}\right)$. Pela nossa descrição anterior, esse conjunto caracteriza o estado da máquina, de sorte que as probabilidades de transição dependem unicamente de $\eta_{1}^{L}$ :

$$
P\left(X_{t}=x_{t} \mid X_{t-1}=x_{t-1}, \ldots, X_{t-L}=x_{t-L}\right)=P\left(x_{t} \mid x_{t-1}, \ldots, x_{t-L}\right) \equiv P\left(x_{t} \mid \eta_{1}^{L}\right)
$$


Portanto, se, no instante $t$ quisermos saber qual o símbolo $x_{t}$ que será gerado pela máquina, devemos consultar a distribuição de probabilidades $P\left(x_{t} \mid \eta_{1}^{L}\right)$.

É importante notar que uma cadeia de Markov de ordem $L$ pode ter probabilidades de transição tais que a distribuição seja indiferente a alguns dos $x_{t-i}, 1 \leq i \leq L$, isto é, tais que

$$
P\left(x_{t} \mid x_{t-1}, \ldots, x_{t-i}, \ldots, x_{t-L}\right)
$$

tenha o mesmo valor qualquer que seja o valor de $x_{t-i}$. Quando essa condição for satisfeita por todo um intervalo de valores consecutivos de $i$ que inclua $L-$ digamos, $\left\{i \in \mathbb{Z} \mid L^{\prime}<i \leq L\right\}-$, a cadeia pode ser repensada como sendo de memória $L^{\prime}$. Para evitar ambiguidades e imprecisões, suporemos que, quando esse tipo de situação ocorre, a ordem da cadeia será considerada como sendo $L^{\prime}$ e não $L$.

\subsection{Caracterização do agente}

Sob a inspiração das cadeias de Markov, vamos imaginar que as respostas do agente sejam baseadas no que ocorreu (tanto suas próprias respostas quanto os símbolos emitidos pela máquina) no passado recente, e que tal informação se restrinja aos últimos $K$ passos. Digamos também que isso possa ser feito através de uma distribuição de probabilidades - ou seja, que o agente use a informação sobre o passado recente para determinar a probabilidade de escolher cada uma das respostas possíveis. Essa distribuição é uma função que recebe o conjunto dos resultados dos últimos $K$ passos e devolve um objeto que indica as probabilidades de o usuário escolher 0 ou 1. Frequentemente iremos nos referir a esse conjunto de últimos resultados (dos últimos $K$ passos, ou de outro número dependendo do contexto) simplesmente como o passado (de tamanho $K$ ).

Apesar de isso indicar que o comportamento do agente é, em geral, imprevisível pois, mesmo determinadas todas as condições que podem influenciar sua escolha, não é possível prever com certeza qual será a decisão final do agente -, esse modelo também permite descrever comportamentos determinísticos, através de probabilidades que valem zero ou um. Esse tipo de descrição pode ser interpretado como uma tabela que descreve que ação tomar para cada uma das possibilidades de passado - e cujas entradas podem ser traduzidas em palavras como algo parecido com "se os últimos 3 valores forem 0,1 e 0 , escolha 1". Naturalmente, se quisermos descrever em palavras o comportamento probabilístico que foi mencionado há pouco, teremos algo um pouco mais complexo como "se os últimos 3 valores forem 0,1 e 0 , faça um sorteio de tal forma que em $30 \%$ das vezes resulte em 0 e em $70 \%$ das vezes resulte em 1"; ou, de forma um pouco mais precisa, evitando problemas de uma interpretação frequentista das probabilidades, "faça um sorteio que resulte em 0 ou 1 com probabilidades (respectivamente) de $30 \%$ e $70 \%$ ". 
Para deixar clara a distinção entre a distribuição de probabilidades que gera os símbolos da máquina e a distribuição de probabilidades que gera as respostas do agente, vamos denotar esta última pela letra $Q$ e manter a primeira com a letra $P$.

Vamos chamar de $y_{t}$ a resposta do agente no instante $t$, ou seja, a resposta que o agente imagina como uma boa estimativa para $x_{t}$ antes de conhecer o verdadeiro valor de $x_{t}$. Consideremos também que $y_{t}$ é o resultado da variável aleatória $Y_{t}$, cuja distribuição de probabilidades é aquela representada pela letra $Q$. Pelas considerações acima, $Q$ tem a forma

$$
Q\left(Y_{t}=y_{t} \mid X_{t-1}=x_{t-1}, Y_{t-1}=y_{t-1}, \ldots, X_{t-K}=x_{t-K}, Y_{t-K}=y_{t-K}\right),
$$

que abreviaremos como $Q\left(y_{t} \mid x_{t-1}, y_{t-1}, \ldots, x_{t-K}, y_{t-K}\right)$. Por analogia à abreviação que introduzimos anteriormente, $\left(x_{t-1} \ldots x_{t-L}\right) \equiv \eta_{1}^{L}$, denotemos $\left(y_{t-1} \ldots y_{t-K}\right) \equiv \xi_{1}^{K}$, de modo a compactar ainda mais a forma da distribuição $Q$ :

$$
Q\left(y_{t} \mid \eta_{1}^{K} \xi_{1}^{K}\right)
$$

Note-se que, se supusermos que $K<L$, ou seja, que a memória do agente é menor que a da máquina, o agente não consegue acumular dados suficientes para inferir corretamente a distribuição $P$. Ele consegue inferir uma distribuição incompleta, que corresponde à marginalização da distribuição $P$ para os últimos $K$ passos.

\subsection{Desempenho do agente}

Uma forma simples de avaliar o desempenho do agente em suas tentativas de prever os resultados da máquina é introduzir a função indicadora de erro:

$$
\varepsilon(y, x)= \begin{cases}1 & \text { se } x \neq y(\text { erro }) \\ 0 & \text { se } x=y \text { (acerto) }\end{cases}
$$

em que $y$ é a resposta do agente e $x$ é o resultado da máquina. O resultado dessa função é a "quantidade de erro" correspondente a uma iteração $t$ : somando o resultado dessa função $\varepsilon\left(y_{t}, x_{t}\right)$ aplicado a uma sequência de rodadas $t_{1} \leq t \leq t_{2}$, obtém-se o número total de erros cometido pelo agente nesse conjunto de rodadas.

Esse valor não traz muita informação sobre o problema, pois é um resultado local, para apenas uma iteração do problema; devemos buscar uma estimativa global para o desempenho do agente, e a seguir abordaremos algumas das possibilidades. 


\subsubsection{Erro médio}

Vamos tomar a função indicadora de erro para uma rodada e calcular sua média sobre todas as situações possíveis. Essa média terá a forma

$$
\varepsilon_{m}=\sum_{x, y, \eta_{1}^{L}, \xi_{1}^{K}} \varepsilon(y, x) p\left(y, x, \eta_{1}^{L}, \xi_{1}^{K}\right)
$$

em que $p\left(y, x, \eta_{1}^{L}, \xi_{1}^{K}\right)$ é a probabilidade conjunta de ocorrência do passado $\eta_{1}^{L}$ da máquina, do passado $\xi_{1}^{K}$ do agente, da resposta $y$ do agente e do resultado $x$ da máquina. Vamos supor daqui em diante, por simplicidade, que $K \leq L$.

Nosso objetivo agora é entender a distribuição de probabilidades do lado direito. Podemos desmembrar a probabilidade conjunta da seguinte maneira, lembrando que $x \mathrm{e}$ $y$ são independentes:

$$
\begin{aligned}
p\left(y, x, \eta_{1}^{L}, \xi_{1}^{K}\right) & =Q\left(y \mid \eta_{1}^{L}, \xi_{1}^{K}\right) P\left(x \mid \eta_{1}^{L}, \xi_{1}^{K}\right) p\left(\eta_{1}^{L}, \xi_{1}^{K}\right) \\
& =Q\left(y \mid \eta_{1}^{L}, \xi_{1}^{K}\right) P\left(x \mid \eta_{1}^{L}, \xi_{1}^{K}\right) p\left(\eta_{1}^{K} \eta_{K+1}^{L} \xi_{1}^{K}\right) \\
& =Q\left(y \mid \eta_{1}^{L}, \xi_{1}^{K}\right) P\left(x \mid \eta_{1}^{L}, \xi_{1}^{K}\right) p\left(\eta_{K+1}^{L} \mid \eta_{1}^{K} \xi_{1}^{K}\right) p\left(\eta_{1}^{K} \xi_{1}^{K}\right)
\end{aligned}
$$

Considerando agora que o comportamento do agente não influencia de maneira nenhuma os resultados da máquina, e também que ele é restrito a tudo o que aconteceu apenas nos últimos $K$ passos, reduzimos a equação anterior a

$$
p\left(y, x, \eta_{1}^{L}, \xi_{1}^{K}\right)=Q\left(y \mid \eta_{1}^{K}, \xi_{1}^{K}\right) P\left(x \mid \eta_{1}^{L}\right) P\left(\eta_{K+1}^{L} \mid \eta_{1}^{K}\right) p\left(\eta_{1}^{K} \xi_{1}^{K}\right) .
$$

Lembramos que o que nos interessa é verificar o que acontece com essa distribuição no contexto das somatórias em (2.1). A somatória sobre $\eta_{1}^{L}$ pode ser decomposta em duas: uma sobre $\eta_{1}^{K}$ e outra sobre $\eta_{K+1}^{L}$. Reintroduzindo nessa equação a forma (2.3) e alterando a ordem das somatórias, temos

$$
\begin{aligned}
\varepsilon_{m} & =\sum_{x, y, \eta_{1}^{K}, \xi_{1}^{K}} \sum_{\eta_{K+1}^{L}} \varepsilon(y, x) p\left(y, x, \eta_{1}^{L}, \xi_{1}^{K}\right) \\
& =\sum_{x, y, \eta_{1}^{K}, \xi_{1}^{K}} \varepsilon(y, x) Q\left(y \mid \eta_{1}^{K}, \xi_{1}^{K}\right)\left(\sum_{\eta_{K+1}^{L}} P\left(x \mid \eta_{1}^{L}\right) P\left(\eta_{K+1}^{L} \mid \eta_{1}^{K}\right)\right) p\left(\eta_{1}^{K} \xi_{1}^{K}\right)
\end{aligned}
$$

Nosso modelo de agente supõe que a informação que ele é capaz de acumular se limite às últimas $K$ iterações. Isso significa que, ao olhar para os últimos $K$ resultados gerados pela máquina, ele não consegue determinar o estado atual dela - o vetor dos resultados $\left(x_{t-1}, \ldots, x_{t-L}\right)$, que constitui o estado composto da máquina na interpretação equivalente de uma cadeia de Markov de memória 1. 
Desta maneira, o termo que aparece destacado entre parênteses tem um significado claro: é a média das probabilidades de transição para estados com $X_{t}=x_{t}$ tomada sobre os possíveis estados da máquina que coincidam com os últimos $K$ resultados. Essa média corresponde à marginalização sobre as variáveis $x_{K+1}, \ldots, x_{L}$ que constituem a fatia $\eta_{K+1}^{L}$ do passado, e também é conhecida como $P\left(X_{t}=x_{t} \mid \eta_{1}^{K}\right)$. O caso $x_{t}=1$ será abreviado como $p_{\eta}$, em que $\eta$ representa $\eta_{1}^{K}$ :

$$
p_{\eta}=p_{\eta}\left(\eta_{1}^{K}\right)=\sum_{\eta_{K+1}^{L}} P\left(x=1 \mid \eta_{1}^{L}\right) P\left(\eta_{K+1}^{L} \mid \eta_{1}^{K}\right)=P\left(X_{t}=1 \mid \eta_{1}^{K}\right) .
$$

Não é necessário fazer outra definição para $x_{t}=0$ pois 0 e 1 são resultados complementares:

$$
P\left(X_{t}=0 \mid \eta_{1}^{K}\right)=1-P\left(X_{t}=1 \mid \eta_{1}^{K}\right)=1-p_{\eta} .
$$

De forma análoga, mas sem a necessidade de marginalizar, definiremos $q_{\eta \xi}$ para denotar a probabilidade com que o agente escolhe $y_{t}=1$ dado o passado constituído por $\eta_{1}^{K}$ e $\xi_{1}^{K}$ :

$$
q_{\eta \xi}=Q\left(Y_{t}=1 \mid \eta_{1}^{K} \xi_{1}^{K}\right)
$$

de forma que $1-q_{\eta \xi}$ representa a probabilidade análoga para $y_{t}=0$. O paralelo entre $q_{\eta \xi}$ e $p_{\eta}$ sugere que haja alguma espécie de correlação entre os dois, e a seguir verificaremos esse fato.

Com essas abreviações, podemos reescrever a expressão (2.4) para o erro como

$$
\begin{aligned}
\varepsilon_{m}= & \sum_{x, y, \eta_{1}^{K}, \xi_{1}^{K}} \varepsilon(y, x) Q\left(y \mid \eta_{1}^{K}, \xi_{1}^{K}\right) P\left(x \mid \eta_{1}^{K}\right) p\left(\eta_{1}^{K} \xi_{1}^{K}\right) \\
=\sum_{\eta_{1}^{K}, \xi_{1}^{K}} & {\left[Q\left(y=1 \mid \eta_{1}^{K}, \xi_{1}^{K}\right) P\left(x=0 \mid \eta_{1}^{K}\right)\right.} \\
& \left.\quad+Q\left(y=0 \mid \eta_{1}^{K}, \xi_{1}^{K}\right) P\left(x=1 \mid \eta_{1}^{K}\right)\right] p\left(\eta_{1}^{K} \xi_{1}^{K}\right)
\end{aligned}
$$

(eliminando os termos $\operatorname{com} x=y$ pois $\varepsilon(y, x)$ se anula nesses casos)

$$
=\sum_{\eta_{1}^{K}, \xi_{1}^{K}}\left[q_{\eta \xi}\left(1-p_{\eta}\right)+\left(1-q_{\eta \xi}\right) p_{\eta}\right] p\left(\eta_{1}^{K} \xi_{1}^{K}\right) \text {. }
$$

A partir dessa forma, podemos proceder à tentativa de encontrar os "melhores" valores de $q_{\eta \xi}$ que o agente pode usar - ou seja, os valores de $q_{\eta \xi}$ que minimizam a expressão do erro. Temos pela frente, então, um problema de otimização da função $\varepsilon_{m}$ com as variáveis $\left\{q_{\eta \xi}\right\}$, sendo cada uma no domínio [0,1]. Como há $2^{K}$ valores possíveis tanto para $\eta_{1}^{K}$ quanto para $\xi_{1}^{K}$, trata-se de um problema de $2^{2 K}$ variáveis, ou seja, no domínio $[0,1]^{2 K}$. 
O método geral para fazer essa otimização envolve o cálculo das derivadas de $\varepsilon_{m}$ em relação a cada um dos $q_{\eta \xi}$ (isto é, para cada um dos possíveis valores de $\eta$ e de $\xi$ ) no interior do domínio, além da análise do comportamento da função na fronteira do domínio. Para isso, vamos reescrever a expressão do erro deixando em evidência os fatores $q_{\eta \xi}$ :

$$
\varepsilon_{m}=\sum_{\eta_{1}^{K}, \xi_{1}^{K}}\left[q_{\eta \xi}\left(1-2 p_{\eta}\right)+p_{\eta}\right] p\left(\eta_{1}^{K} \xi_{1}^{K}\right) .
$$

Como a função a ser minimizada é linear em todas as variáveis $q$, todas as derivadas parciais em relação a essas variáveis são constantes. Isso significa que todos os mínimos ou máximos da função estão na fronteira do domínio, que é constituída por todas as $2^{2 K}$-uplas que só contêm zeros e uns. Outro fato notável é o de que o coeficiente de $q_{\eta \xi}$ não depende de $\xi$, mas apenas de $\eta$, e portanto a análise é idêntica para todos os $q_{\eta \xi}$ com o mesmo valor de $\eta$.

Porém, nos casos em que $p_{\eta}=1 / 2$, o coeficiente de $q_{\eta \xi}$ é nulo; portanto, o erro é efetivamente independente das variáveis $q$ correspondentes. A interpretação disso é clara: após o passado $\eta$, os resultados $x=0$ e $x=1$ são igualmente prováveis, condição em que é impossível a existência de uma estratégia que garanta um desempenho melhor que $50 \%$.

Em um mesmo problema podem coexistir as duas situações: pode ocorrer $p_{\eta}=1 / 2$ para alguns valores de $\eta$ e $p_{\eta} \neq 1 / 2$ para outros valores de $\eta$. Uma vez que não é possível fazer nenhuma otimização para $p_{\eta}=1 / 2$, vamos prosseguir esta análise apenas para os $\eta$ tais que $p_{\eta} \neq 1 / 2$. Ela se divide em duas partes:

(a) Se $p_{\eta}<1 / 2$, então o coeficiente das variáveis $q$ correspondentes é positivo, de modo que $\varepsilon_{m}$ é crescente nessas variáveis. Portanto, o valor de $q$ que minimiza o erro está na fronteira inferior, ou seja, é 0 .

(b) Se $p_{\eta}>1 / 2$, os coeficientes correspondentes de $q$ são negativos, tornando o erro decrescente em relação a $q$; então, ele é minimizado por $q=1$, na fronteira superior do domínio.

Dessa discussão, concluímos que minimizar o erro consiste em minimizar cada uma das parcelas da soma em (2.9), ou seja, cada uma das expressões

$$
q_{\eta \xi}\left(1-2 p_{\eta}\right)+p_{\eta}
$$

em relação a $q_{\eta \xi}$. A solução pode ser escrita como

$$
q_{\eta \xi}=q^{o}\left(p_{\eta}\right):=\theta\left(2 p_{\eta}-1\right),
$$


em que $q^{o}$ ( $q$ ótimo) é definida por essa equação e $\theta$ é a função degrau (de Heaviside), definida por

$$
\theta(x)= \begin{cases}0 & \text { se } x<0 \\ 1 / 2 & \text { se } x=0 \\ 1 & \text { se } x>0\end{cases}
$$

Porém, ao resolver esse problema da perspectiva do agente, não se sabe o valor de $p_{\eta}$ - o máximo que se pode ser é uma estimativa de sua distribuição, levantada a partir das observações já feitas. Cada possível valor de $p_{\eta}$ determina um valor de $q_{\eta \xi}$ que soluciona o problema. Podemos imaginar duas maneiras de proceder nessa situação: uma delas é minimizar essa expressão substituindo $p_{\eta}$ por um único valor que representa a distribuição (como a média, mediana ou moda da distribuição); outra é minimizar a média dessa expressão (com relação à sua distribuição). Ambas as maneiras requerem que tenhamos uma estimativa da distribuição.

\subsubsection{Estimativa da distribuição}

A distribuição real de $p_{\eta}$ pode ser calculada a partir da matriz de transição da cadeia de Markov, pois corresponde à marginalização da distribuição das probabilidades de transição ignorando os passos anteriores aos $K$ últimos passos. Porém, esse dado não é acessível da perspectiva do agente; o melhor que o agente pode fazer é estimar essa distribuição a partir de suas observações. A primeira abordagem para isso será através de inferência bayesiana.

O objetivo do agente é estimar a probabilidade $p_{\eta}$ de ocorrência de um símbolo $x=1$ após um passado $\eta$. Partindo da distribuição a priori que estabelecermos para a situação inicial antes de qualquer observação, tomaremos iterativamente cada observação e aplicaremos o teorema de Bayes até que tenhamos inserido toda a informação conhecida na distribuição, ou seja, todas as observações feitas até o instante que está sendo considerado. O resultado final será uma distribuição que pode ser representada por uma densidade: $P\left(p_{\eta}=p\right), p \in[0,1]$.

Esse procedimento pode ser encarado de maneira indutiva: munidos da distribuição inicial e da regra que inclui cada pedaço de informação na distribuição, podemos dizer qual será a distribuição após um número determinado de atualizações. Como a regra de atualização é do tipo

$($ distribuição a posteriori $)=$ constante $\times($ distribuição a priori $) \times($ verossimilhança $)$,

a distribuição 'final' é igual, a menos de uma constante de normalização, à distribuição inicial multiplicada pelo produto das verossimilhanças. 
Considerando cada passado como um objeto independente dos demais passados, a informação inicial sobre as probabilidades de ocorrência de cada símbolo após um passado $\eta$ é vazia. O princípio da indiferença nos orienta, então, a supor uma distribuição de probabilidades a priori uniforme no intervalo $[0,1]$. Representando essa distribuição como uma densidade, essa suposição pode ser escrita como

$$
P_{\text {priori }}\left(p_{\eta}=p\right)=\text { constante. }
$$

Para fazer o passo indutivo, vamos introduzir a seguinte notação: para um dado passado $\eta, \mu$ denota o número de vezes que foi observada a sequência $\eta$, e $j$ representa o número de vezes que essa sequência foi seguida do símbolo $x=1$. Nesse estágio, chamaremos a distribuição atualizada de $P\left(p_{\eta}=p \mid \mu, j\right)$.

Na próxima observação, o resultado $x^{\prime}$ da observação do símbolo $x$ poderá ser 0 ou 1 . Caso seja 1 , o valor da variável $j$ aumenta de 1 ; caso seja 0 , o valor de $j$ permanece o mesmo - resumindo, o valor de $j$ passa para $j+x^{\prime}$. Em ambos os casos, o valor de $\mu$ aumenta de 1.

Após incluir essa informação na distribuição, teremos a distribuição $P\left(p_{\eta}=p \mid\right.$ $\left.\mu+1, j+x^{\prime}\right)$. Esse procedimento de inclusão é a aplicação do teorema de Bayes:

$$
P\left(p_{\eta}=p \mid \mu+1, j+x^{\prime}\right) \propto \underbrace{P\left(p_{\eta}=p \mid \mu, j\right)}_{\text {distribuição a priori }} \underbrace{P\left(x^{\prime} \mid p_{\eta}=p, \mu, j\right)}_{\text {verossimilhança }},
$$

em que a constante de proporcionalidade pode ser obtida ao final, para normalizar a distribuição obtida. A verossimilhança representa a probabilidade de obter o símbolo $x^{\prime}$ dado que $p_{\eta}=p$, ou seja, dado que a probabilidade de obter 1 é $p$ e a probabilidade de obter 0 é $1-p$; portanto, seu valor é

$$
\begin{cases}1-p & \text { se } x^{\prime}=0 \\ p & \text { se } x^{\prime}=1\end{cases}
$$

Logo, se foram feitas $\mu$ observações do passado $\eta$, das quais $j$ foram seguidas por um símbolo $x=1$, o produto das verossimilhanças será $p^{j}(1-p)^{\mu-j}$. Esse produto, a menos de uma constante de normalização, é igual à função densidade da distribuição:

$$
P\left(p_{\eta}=p \mid \mu, j\right)=\frac{1}{N_{\mu, j}} p^{j}(1-p)^{\mu-j},
$$

sendo $N_{\mu, j}$ uma constante de normalização. Essa é a conhecida distribuição beta, com parâmetros $(j+1, \mu-j+1)$ segundo sua definição tradicional:

$$
P(\operatorname{Beta}(\alpha, \beta)=x) \propto x^{\alpha-1}(1-x)^{\beta-1}, x \in[0,1] .
$$



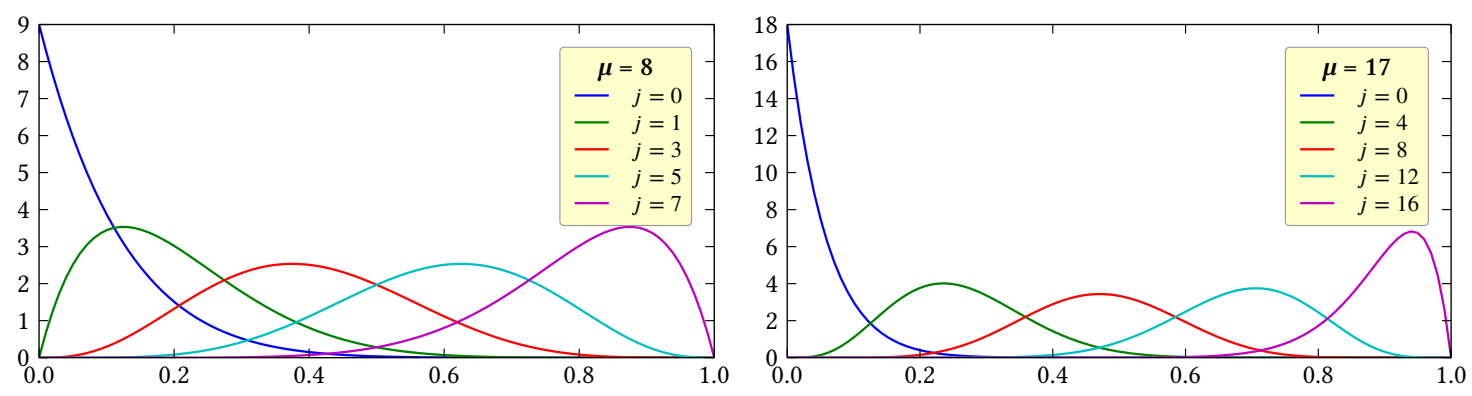

Figura 2.1: Gráficos da distribuição de $p_{\eta}$ (2.16), para dois valores de $\mu$ (8 e 17) e cinco valores de $j$ para cada $\mu$.

A constante de normalização, $N_{\mu, j}$, pode ser escrita em termos da função beta de Euler,

$$
\mathrm{B}(\alpha, \beta)=\int_{0}^{1} t^{\alpha-1}(1-t)^{\beta-1} d t=\frac{\Gamma(\alpha) \Gamma(\beta)}{\Gamma(\alpha+\beta)}=\frac{(\alpha-1) !(\beta-1) !}{(\alpha+\beta-1) !}
$$

(em que $\Gamma$ representa a função gama de Euler), da seguinte forma:

$$
N_{\mu, j}=\int_{0}^{1} p^{j}(1-p)^{\mu-j} d p=\mathrm{B}(j+1, \mu-j+1)=\frac{j !(\mu-j) !}{(\mu+1) !},
$$

A média dessa distribuição é

$$
\begin{aligned}
\langle p\rangle_{\mu, j} & =\int_{0}^{1} p \cdot P\left(p_{\eta}=p \mid \mu, j\right) d p=\frac{1}{N_{\mu, j}} \int_{0}^{1} p^{j+1}(1-p)^{\mu-j} d p \\
& =\frac{N_{\mu+1, j+1}}{N_{\mu, j}}=\frac{j+1}{\mu+2} .
\end{aligned}
$$

A moda, ou valor mais provável, é o valor $p^{*}$ de $p$ que maximiza $P\left(p_{\eta}=p \mid \mu, j\right)$. Podemos encontrá-la impondo o anulamento da derivada da distribuição:

$$
\left.\frac{d}{d p} P\left(p_{\eta}=p \mid \mu, j\right)\right|_{p=p^{*}}=0
$$

substituindo a forma funcional da distribuição (2.13), essa imposição equivale a

$$
\left(p^{*}\right)^{j-1}\left(1-p^{*}\right)^{\mu-j-1}\left[j\left(1-p^{*}\right)-(\mu-j) p^{*}\right]=0,
$$

de onde sai o resultado

$$
p^{*}=\frac{j}{\mu} .
$$

Não tão rápido! Se $j=0$ ou $j=\mu$, esta conta não está totalmente correta. No entanto, a solução acima reproduz perfeitamente os resultados que são obtidos nessas condições. Vamos considerar que $\mu \geq 1$, pois $\mu=0$ corresponde à distribuição a priori, que é uniforme - portanto não faz sentido falar em 'valor de $p$ mais provável' nesse caso. 
- Se $j=0$, a distribuição se reduz a $P(p)=(1-p)^{\mu}$, estritamente decrescente em $[0,1]$. Portanto, a moda está no extremo inferior do domínio: $p^{*}=0$;

- se $j=\mu$, a distribuição é $P(p)=p^{\mu}$, que é estritamente crescente em $[0,1]$. Portanto, a moda é o extremo superior, $p^{*}=1$.

\subsubsection{De volta à minimização do erro}

A partir da distribuição de $p_{\eta}$ (2.13), nossa tarefa é encontrar os valores de $q_{\eta \xi}$ que minimizam o erro esperado de cada passado $\eta \xi$, ou seja, que minimizam (2.10). Conforme discutido anteriormente, a solução que minimiza esse erro para um $p_{\eta}$ bem definido é a função $q^{o}$ descrita em (2.11). A partir disso, estudaremos duas abordagens diferentes para nossa tarefa:

Otimização da média Calcular $q^{o}$ em um valor específico de $p_{\eta}$ que represente a distribuição como um todo - o valor médio, $\left\langle p_{\eta}\right\rangle$. Representamos esse resultado por $q^{D}=q^{o}\left(\left\langle p_{\eta}\right\rangle\right)$.

Média das otimizações Calcular a média de $q^{o}$ na distribuição de $p_{\eta}$, ou seja, $q^{B}=$ $\left\langle q^{o}\left(p_{\eta}\right)\right\rangle$.

Na estratégia de otimização da média, as soluções para os $q^{D}$ são discretas - apenas 0 e 1, o que estabelece para o agente um comportamento determinístico frente a cada possibilidade de passado. A única exceção ocorrerá quando houver empate entre as duas escolhas, ou seja, quando o agente tiver observado que ambas ocorrem com a mesma frequência; nesse caso, o agente realizará um sorteio imparcial entre elas.

Aplicando a definição de $q^{D}$, e considerando as variáveis $j$ e $\mu$ referentes ao passado $\eta \xi$, podemos escrever essa solução como

$$
q^{D}=q^{o}\left(\left\langle p_{\eta}\right\rangle\right)=\theta\left(2\left\langle p_{\eta}\right\rangle-1\right)=\theta\left(2 \frac{j+1}{\mu+2}-1\right)=\theta\left(\frac{2 j-\mu}{\mu+2}\right)
$$

e, notando que a função degrau de Heaviside depende apenas do sinal de seu argumento, independendo do módulo, podemos escrever

$$
q^{D}=\theta(2 j-\mu)
$$

Essa equação resume o significado dessa estratégia: se o número de observações de $x=1$ for maior do que a metade das observações $(2 j>\mu$, ou $j>\mu / 2)$, o agente escolhe sempre $y=1$ (com probabilidade $q=1$ ). Se for menor que a metade, o agente escolhe sempre 
$y=0(y=1$ com probabilidade $q=0)$. Em caso de empate, se ocorrer exatamente $2 j=\mu$, o agente faz um sorteio com probabilidade igual para os dois lados $(q=1 / 2)$.

$\mathrm{Na}$ estratégia de média das otimizações, o comportamento resultante do agente é (em geral) probabilístico pois os valores de $q^{B}$ podem assumir qualquer valor entre 0 e 1. Isso discorda da nossa solução ótima em que todos os $q_{\eta \xi}$ devem ter valores 0 ou 1 , mas é de nosso interesse também ter parâmetros para modelar agentes com estratégias sub-ótimas. Podemos expressar essa solução como

$$
q^{B}=\left\langle q^{o}\left(p_{\eta}\right)\right\rangle=\int_{0}^{1} q^{o}(p) P\left(p_{\eta}=p \mid \mu, j\right) d p=\int_{0}^{1} \theta(2 p-1) P\left(p_{\eta}=p \mid \mu, j\right) d p .
$$

Como a função $\theta$ só assume os três valores $\{0,1 / 2,1\}$ e o valor $1 / 2$ só é assumido em um único ponto, o valor da integral resume-se ao valor da integral no conjunto em que essa função vale 1. Ou seja, só entrarão na integral os pontos $p>1 / 2$ que tornam o argumento da função $\theta$ positivo. Portanto,

$$
q^{B}=\int_{1 / 2}^{1} P\left(p_{\eta}=p \mid \mu, j\right) d p=\frac{1}{N_{\mu, j}} \int_{1 / 2}^{1} p^{j}(1-p)^{\mu-j} d p .
$$

Essa integral pode ser calculada analiticamente de maneira direta, pois o integrando é um polinômio. Ela também pode ser expressa em termos da função beta incompleta, definida por

$$
\mathrm{B}_{s}(\alpha, \beta)=\int_{0}^{s} t^{\alpha-1}(1-t)^{\beta-1} d t
$$

(tomando $s=1 / 2$ ) ou da função beta incompleta regularizada, definida como

$$
I_{s}(\alpha, \beta)=\frac{\mathrm{B}_{s}(\alpha, \beta)}{\mathrm{B}(\alpha, \beta)} .
$$

Considerando, como em (2.16), que $N_{\mu, j}=\mathrm{B}(j+1, \mu-j+1)=\mathrm{B}(\mu-j+1, j+1)$ (a função beta é simétrica em seus argumentos), e fazendo uma mudança de variável $1-p \rightarrow p$, podemos escrever

$$
\begin{aligned}
q^{B} & =\frac{1}{N_{\mu, j}} \int_{0}^{1 / 2} p^{\mu-j}(1-p)^{j} d p \\
& =\frac{\mathrm{B}_{1 / 2}(\mu-j+1, j+1)}{\mathrm{B}(\mu-j+1, j+1)}=I_{1 / 2}(\mu-j+1, j+1) .
\end{aligned}
$$

A distribuição de $p_{\eta}$ é também bem aproximado por uma distribuição gaussiana, e a aproximação melhora à medida que $\mu$ cresce. Para isso, lembremos que a distribuição gaussiana de média $x_{0}$ tem como função densidade

$$
f(x)=\frac{1}{\sqrt{2 \pi \sigma^{2}}} \exp \left[-\frac{\left(x-x_{0}\right)^{2}}{2 \sigma^{2}}\right],
$$


de forma que seu logaritmo,

$$
\log (f(x))=-\log \sqrt{2 \pi \sigma^{2}}-\frac{\left(x-x_{0}\right)^{2}}{2 \sigma^{2}}
$$

é um polinômio cuja primeira derivada se anula em $x=x_{0}$ e cuja segunda derivada é igual a $-1 / \sigma^{2}-$ isso é suficiente para aproximar em torno de $x_{0}$ qualquer função que tenha um máximo local em $x_{0}$. Usaremos essas propriedades para aproximar nossa distribuição

$$
P\left(p_{\eta}=p \mid \mu, j\right)=\frac{1}{N_{\mu, j}} p^{j}(1-p)^{\mu-j}
$$

por uma gaussiana: primeiramente vamos tomar seu logaritmo,

$$
g(p):=\log \left(P\left(p_{\eta}=p \mid \mu, j\right)\right)=-\log \left(N_{\mu, j}\right)+j \log p+(\mu-j) \log (1-p),
$$

e escrever seu polinômio de Taylor em torno de seu ponto de máximo. O ponto de máximo é a moda, $p^{*}=j / \mu$ (que atende à condição $g^{\prime}\left(p^{*}\right)=0$ ). A segunda derivada será

$$
g^{\prime \prime}(p)=-\frac{j}{p^{2}}-\frac{(\mu-j)}{(1-p)^{2}},
$$

e portanto a variância, dada por $-1 / g^{\prime \prime}\left(p^{*}\right)$, será

$$
\sigma^{2}=\frac{j(\mu-j)}{\mu^{3}}
$$

Ou seja, a distribuição de $p_{\eta}$ é aproximada pela distribuição gaussiana

$$
f(p)=\frac{1}{\sqrt{2 \pi \sigma^{2}}} \exp \left[-\frac{(p-j / \mu)^{2}}{2 \sigma^{2}}\right]
$$

(com a variância $\sigma^{2}$ dada acima na equação 2.27). Para obter dessa distribuição uma nova estimativa $q^{G}$ para $q_{\eta \xi}$, devemos repetir para ela a operação feita em (2.20), lembrando que o domínio da distribuição gaussiana estende-se ao infinito.

$$
q^{G}=\left\langle q^{o}\left(p_{\eta}\right)\right\rangle_{f}=\int_{-\infty}^{\infty} \theta(2 p-1) f(p) d p=\int_{1 / 2}^{\infty} f(p) d p .
$$

A função erro, definida como

$$
\operatorname{erf}(x)=\frac{2}{\sqrt{\pi}} \int_{0}^{x} \exp \left(-s^{2}\right) d s
$$

permite escrever o valor dessa integral como

$$
q^{G}=\int_{\frac{1 / 2-j / \mu}{\sigma \sqrt{2}}}^{\infty} \frac{\exp \left(-x^{2}\right)}{\sqrt{2 \pi \sigma^{2}}} d x \cdot \sigma \sqrt{2}=\frac{1}{2}\left[\lim _{x \rightarrow \infty} \operatorname{erf}(x)-\operatorname{erf}\left(\frac{1 / 2-j / \mu}{\sigma \sqrt{2}}\right)\right] ;
$$

usando, por fim, sua propriedade $\lim _{x \rightarrow \infty} \operatorname{erf}(x)=1$, obtemos

$$
q^{G}=\frac{1}{2}\left[1+\operatorname{erf}\left(\frac{j-\mu / 2}{\mu \sigma \sqrt{2}}\right)\right]
$$

Na figura 2.2 podemos comparar os três estimantes $q^{D}, q^{B}$ e $q^{G}$. 

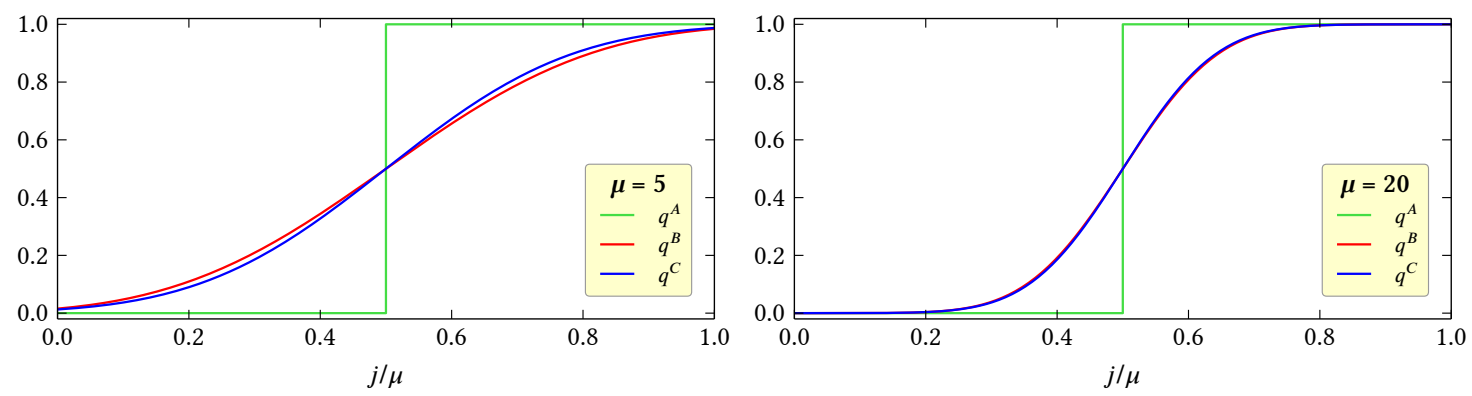

Figura 2.2: Gráficos dos estimantes $q^{D}, q^{B}$ e $q^{G}$ contra a razão $j / \mu$, para certos valores de $\mu$.

\subsection{Uma mudança de variáveis}

Uma outra descrição deste problema é motivada pelo sistema de recompensas presente em cérebros de animais: muitos comportamentos de um animal são resultados de um processo de aprendizado, no qual cada ação pode ser seguida de um feedback externo que pode ser tomado como uma recompensa ou punição à ação. A interpretação desse feedback no sistema neurológico como recompensa ou punição pode levar a uma modificação na probabilidade com que o animal adota aquele comportamento.

Por isso, vamos agora reformular o problema em termos de outras variáveis: a variável de recompensa $\rho_{t}$, que indica 1 se o agente acertou o símbolo gerado pela máquina no instante $t\left(y_{t}=x_{t}\right)$, e 0 se ele errou; e a variável de troca $\sigma_{t}$, que indica 1 se o agente mudou sua resposta no instante seguinte $\left(y_{t+1} \neq y_{t}\right)$, e 0 se ele manteve sua resposta. Formalmente, podemos definir essas variáveis como

$$
\rho_{t}=\left\{\begin{array}{ll}
1 & \text { se } x_{t}=y_{t} \\
0 & \text { se } x_{t} \neq y_{t}
\end{array} \quad \sigma_{t}= \begin{cases}1 & \text { se } y_{t+1} \neq y_{t} \\
0 & \text { se } y_{t+1}=y_{t}\end{cases}\right.
$$

Além disso, é importante verificar como se dá a equivalência entre a informação dada pelas variáveis $(x, y)$ e a informação dada pelas variáveis $(\rho, \sigma)$ :

- Em uma sequência de respostas do agente, podemos determinar todas a partir da primeira se soubermos se o agente trocou ou não de resposta em cada uma das rodadas seguintes; ou seja, o conjunto de variáveis $\left(y_{t}, y_{t+1}, \ldots, y_{t+k-1}, y_{t+k}\right)$ pode ser substituído pelo conjunto $\left(\sigma_{t}, \sigma_{t+1}, \ldots, \sigma_{t+k-1}\right)$ juntamente com a variável $y_{t}$.

- Conhecendo cada resposta do agente, é possível saber qual foi o símbolo gerado pela máquina se soubermos também o valor da variável de recompensa daquele instante; portanto, toda a informação contida no conjunto $\left(x_{t}, x_{t+1}, \ldots, x_{t+k-1}, x_{t+k}\right)$ pode ser obtida a partir do conjunto do item anterior se utilizarmos as variáveis $\left(\rho_{t}, \rho_{t+1}, \ldots, \rho_{t+k-1}, \rho_{t+k}\right)$. 
Ou seja, os dois conjuntos

$$
\left(\begin{array}{lllll}
x_{t} & x_{t+1} & \cdots & x_{t+k-1} & x_{t+k} \\
y_{t} & y_{t+1} & \cdots & y_{t+k-1} & y_{t+k}
\end{array}\right) \quad \text { e } \quad\left(\begin{array}{cccccc} 
& \rho_{t} & \rho_{t+1} & \cdots & \rho_{t+k-1} & \rho_{t+k} \\
y_{t} & \sigma_{t} & \sigma_{t+1} & \cdots & \sigma_{t+k-1} &
\end{array}\right)
$$

contêm a mesma informação. Isso é representado de outra forma na figura 2.3.

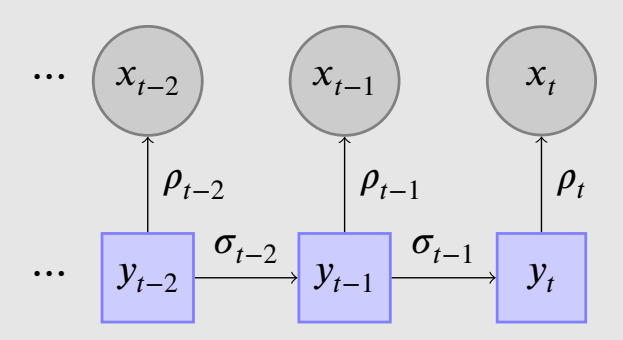

Figura 2.3: Relação entre as variáveis $(x, y)$ e as variáveis $(\rho, \sigma)$. As setas indicam como a tradução pode ser feita no sentido $(\rho, \sigma) \rightarrow(x, y)$.

\subsubsection{Revisitando o erro e sua minimização}

Nosso foco será, novamente, verificar a estratégia ótima que um agente pode adotar quando confrontado com o mesmo problema de decisão exposto neste capítulo; porém consideraremos que o agente raciocina em termos das variáveis $(\rho, \sigma)$ em vez de em termos de $(x, y)$. Isso significa que o agente raciocina em termos não de probabilidades de responder com $y=0$ ou $y=1$, mas de probabilidades de mudar de resposta em relação à resposta anterior, baseando-se em seus acertos e erros correspondentes. Continuaremos supondo que o agente tem uma memória de tamanho $K$, e que portanto o conjunto de variáveis que influenciam em sua decisão se restringe ao que aconteceu nas $K$ últimas iterações. Lembramos que nosso objetivo final não é encontrar a melhor estratégia possível, mas sim encontrar elementos para entender os mecanismos que agem por trás das decisões.

Vamos, então, retomar a discussão que já foi feita sobre o cálculo do erro e sua minimização, substituindo as variáveis $(x, y)$ pelas $(\rho, \sigma)$, em busca de resultados análogos aos já obtidos. Nosso primeiro passo será reescrever a expressão geral do erro (2.7). Vamos, antes, copiá-la deixando explícitos os índices temporais:

$$
\varepsilon_{m}=\sum_{x_{t}, y_{t}, \eta_{1}^{K}, \xi_{1}^{K}} \varepsilon\left(y_{t}, x_{t}\right) Q\left(y_{t} \mid \eta_{1}^{K}, \xi_{1}^{K}\right) P\left(x_{t} \mid \eta_{1}^{K}\right) p\left(\eta_{1}^{K} \xi_{1}^{K}\right)
$$

Da direita para a esquerda:

1. O conjunto de variáveis $\left(\eta_{1}^{K} \xi_{1}^{K}\right)$ corresponde a $\left(\rho_{t-K} \ldots \rho_{t-1}, \sigma_{t-K} \ldots \sigma_{t-2}, y_{t-K}\right)$; mas usaremos simplesmente a letra $I$ para representar a informação aí contida. Futuramente, quando precisarmos ser mais explícitos, escreveremos esse conjunto como $\left(y_{t-K}, \sigma_{t-2}^{t-K}, \rho_{t-1}^{t-K}\right)$. 
2. As probabilidades de $x_{t}$ e $y_{t}$ na realidade são a decomposição de uma probabilidade conjunta de $\left(x_{t}, y_{t}\right)$ condicionada a $\eta_{1}^{K} \xi_{1}^{K}$. Esta equivale à informação $I$ que definimos no item anterior; as variáveis $\left(x_{t}, y_{t}\right)$ são substituídas por $\left(\rho_{t}, \sigma_{t-1}\right)$, pois, dado $I$, contêm a mesma informação. Ficamos, então, com $P\left(\rho_{t}, \sigma_{t-1} \mid I\right)$, que pode ser decomposta em um produto:

$$
P\left(\rho_{t} \mid \sigma_{t-1}, I\right) P\left(\sigma_{t-1} \mid I\right) .
$$

3. A função indicadora de erro $\varepsilon\left(y_{t}, x_{t}\right)$ fica muito simples, pois é o 'contrário' da variável de recompensa:: $1-\rho_{t}$.

Ou seja, o erro médio será reescrito como

$$
\varepsilon_{m}=\sum_{\rho_{t}^{t-K}, \sigma_{t-1}^{t-K}, y_{t-K}}\left(1-\rho_{t}\right) P\left(\rho_{t} \mid \sigma_{t-1}, I\right) P\left(\sigma_{t-1} \mid I\right) p(I)
$$

Claramente os termos com $\rho_{t}=1$ se anulam; a soma se restringe, então, aos termos em que $\rho_{t}=0$. Vamos olhar com mais detalhe e separar os termos com os diferentes valores de $\sigma_{t-1}$, que indicam as possíveis ações do agente:

$$
\begin{aligned}
\varepsilon_{m}=\sum_{\rho_{t-1}^{t-K}, \sigma_{t-2}^{t-K}, y_{t-K}}\left[P\left(\rho_{t}=0 \mid \sigma_{t-1}=0, I\right) P\left(\sigma_{t-1}=0 \mid I\right)\right. \\
\left.+P\left(\rho_{t}=0 \mid \sigma_{t-1}=1, I\right) P\left(\sigma_{t-1}=1 \mid I\right)\right] p(I)
\end{aligned}
$$

As probabilidades que envolvem apenas $\sigma_{t-1}$ são comportamentos do agente: representam a estratégia que o agente usa para escolher se muda ou não de resposta. Denotaremos por $q_{s}$ a probabilidade com que o agente muda de resposta:

$$
\begin{aligned}
q_{s} & :=P\left(\sigma_{t-1}=1 \mid I\right)=P\left(\sigma_{t-1}=1 \mid \rho_{t-1}^{t-K} \sigma_{t-2}^{t-K} y_{t-K}\right) \\
1-q_{s} & =P\left(\sigma_{t-1}=0 \mid I\right) .
\end{aligned}
$$

As outras duas probabilidades são um parâmetro que pode ser estimado pelo agente a fim de moldar sua estratégia, em total analogia com o que foi feito nas variáveis $(x, y)$. Denotaremos

$$
p_{0}:=P\left(\rho_{t}=0 \mid \sigma_{t-1}=1, I\right)=P\left(\rho_{t}=0 \mid \sigma_{t-1}=1, \rho_{t-1}^{t-K} \sigma_{t-2}^{t-K} y_{t-K}\right),
$$

que é a probabilidade que o agente tem de errar após ter mudado de resposta. A probabilidade de acertar após ter mantido a mesma resposta, $P\left(\rho_{t}=1 \mid \sigma_{t-1}=0, I\right)$ é igual a esta, pois em ambas as situações a condição para o acerto é que o símbolo gerado pela máquina seja igual ao símbolo dado como resposta pelo agente no instante anterior. 
No entanto, precisamos da probabilidade de errar após ter mantido a mesma resposta, que há de ser o complementar da que acabamos de obter, ou seja,

$$
\begin{aligned}
p_{0} & =P\left(\rho_{t}=0 \mid \sigma_{t-1}=1, I\right) \\
1-p_{0} & =P\left(\rho_{t}=0 \mid \sigma_{t-1}=0, I\right)
\end{aligned}
$$

Assim podemos chegar à seguinte expressão para o erro:

$$
\begin{aligned}
\varepsilon_{m} & =\sum_{\rho_{t-1}^{t-K}, \sigma_{t-2}^{t-K}, y_{t-K}}\left[\left(1-p_{0}\right)\left(1-q_{s}\right)+p_{0} q_{s}\right] p\left(\rho_{t-1}^{t-K} \sigma_{t-2}^{t-K} y_{t-K}\right) \\
& =\sum_{\substack{\rho_{t-1}^{t-K}, \sigma_{t-2}^{t-K}, y_{t-K}\\
}}\left[1-p_{0}+\left(2 p_{0}-1\right) q_{s}\right] p\left(\rho_{t-1}^{t-K} \sigma_{t-2}^{t-K} y_{t-K}\right),
\end{aligned}
$$

sem esquecer que $p_{0}$ e $q_{s}$ trazem em si a dependência de $I=\rho_{t-1}^{t-K} \sigma_{t-2}^{t-K} y_{t-K}$. Note que a expressão é muito próxima à obtida em (2.9):

$$
\varepsilon_{m}=\sum_{\eta_{1}^{K}, \xi_{1}^{K}}\left[q_{\eta \xi}\left(1-2 p_{\eta}\right)+p_{\eta}\right] p\left(\eta_{1}^{K} \xi_{1}^{K}\right) .
$$

Portanto, podemos nos valer dos mesmos métodos para achar estratégias do agente que minimizem o erro. A expressão entre colchetes é linear em $q_{s}$ e assim os valores ótimos de $q_{s}$ são os extremos $q_{s}=0$ ou 1 , dependendo do sinal do coeficiente de $q_{s}$ :

$$
\begin{cases}q_{s}=0 & \text { se o coeficiente for positivo, } p_{0}>1 / 2 \\ q_{s}=1 & \text { se o coeficiente for negativo, } p_{0}<1 / 2\end{cases}
$$

ou, definindo a função $q_{s}^{o}\left(q_{s}\right.$ ótimo),

$$
q_{s}^{o}\left(p_{0}\right)=\left\{\begin{array}{ll}
1 & \text { se } p_{0}<1 / 2 \\
0 & \text { se } p_{0}>1 / 2
\end{array}\right\}=\theta\left(1-2 p_{0}\right)
$$

Assim, fossem conhecidos todos os valores de $p_{0}$, a estratégia ótima para este problema seria agir sempre com $\sigma=0$ (manter a mesma resposta), se $q_{s}=0$; ou $\sigma=1$ (mudar de resposta) se $q_{s}=1$. Porém, como já vimos, o melhor que conseguimos fazer é estimar uma distribuição para cada $p_{0}$. Vamos a essa estimativa.

\subsubsection{Estimativa das probabilidades}

Vamos seguir a abordagem bayesiana para estimar uma distribuição para $p_{0}$. O primeiro passo é supor uma distribuição uniforme a priori, já que não há nenhuma informação para supor o contrário; depois de um certo número de iterações, quando o agente já 
possui uma informação $I$, o agente toma a ação $\sigma_{t-1}$ e obtém o feedback $\rho_{t}$. A ação $\sigma_{t-1}$ não adiciona nenhuma informação sobre a variável $p_{0}$; mas, unindo-a a $\rho_{t}$, temos uma porção de informação suficiente para dizer algo sobre $p_{0}$, que é uma probabilidade de $\rho_{t}$ condicionada a $\sigma_{t-1}$. Vejamos através do teorema de Bayes como atualizar a distribuição de $p_{0}$ dado $I$ com a nova informação:

$$
\begin{aligned}
P\left(p_{0} \mid \rho_{t}, \sigma_{t-1}, I\right) & =\frac{1}{N} P\left(p_{0} \mid \sigma_{t-1}, I\right) P\left(\rho_{t} \mid \sigma_{t-1}, p_{0}, I\right) \\
& =\frac{1}{N} P\left(p_{0} \mid I\right) P\left(\rho_{t} \mid \sigma_{t-1}, p_{0}, I\right)
\end{aligned}
$$

A verossimilhança pode ser calculada de acordo com a seguinte tabela, usando diretamente a definição (2.37) de $p_{0}$ :

\begin{tabular}{ccc}
$\sigma_{t-1}$ & $\rho_{t}$ & $P\left(\rho_{t} \mid \sigma_{t-1}, p_{0}, I\right)$ \\
\hline 0 & 0 & $1-p_{0}$ \\
0 & 1 & $p_{0}$ \\
1 & 0 & $p_{0}$ \\
1 & 1 & $1-p_{0}$
\end{tabular}

Essa tabela nos dá um resultado: o de que a verossimilhança não depende dos valores específicos de cada variável $\sigma_{t-1}, \rho_{t}$, mas sim da relação entre as duas - de igualdade ou de diferença. Por isso, nessa formulação do problema será conveniente contar o número de vezes em que ocorre $\sigma_{t-1}=\rho_{t}$ versus o número de vezes em que ocorre $\sigma_{t-1} \neq \rho_{t}$. Nomeando as variáveis da mesma maneira que antes, $j$ representará a contagem de vezes em que ocorreu $\rho_{t} \neq \sigma_{t-1}$, e $\mu-j$ representará a contagem de vezes em que ocorreu $\rho_{t}=\sigma_{t-1}$; essas contagens são sempre condicionadas ao histórico $\sigma_{t-2}^{t-K} \rho_{t-1}^{t-K} y_{t-K}$. É importante ressaltar que esse acoplamento entre as duas variáveis sugere uma tendência no agente de associar os erros a uma mudança de resposta ou à manutenção da resposta anterior, dependendo do valor correspondente de $p_{0}$.

Já temos todos os elementos para chegar à distribuição estimada de $p_{0}$ : resta agora multiplicar a distribuição a priori pela sequência de verossimilhanças, exatamente como fizemos para chegar até (2.13). Pela discussão que fizemos acima, chegaremos exatamente à mesma distribuição, mudando apenas a interpretação dos parâmetros:

$$
P\left(p_{0}=p \mid \mu, j\right)=\frac{1}{N_{\mu, j}} p^{j}(1-p)^{\mu-j}
$$

$\operatorname{com} N_{\mu, j}$ definido por (2.16). 


\subsubsection{O aprendizado como uma série de correções}

A média da distribuição que acabamos de obter é a média que obtivemos em (2.17):

$$
\left\langle p_{0}\right\rangle_{\mu, j} \equiv E\left(p_{0} \mid \mu, j\right)=\frac{j+1}{\mu+2} .
$$

A cada nova informação que o agente recebe - ou seja, a cada vez que o agente toma uma ação e verifica se recebeu uma recompensa -, temos um novo valor para $j$ e para $\mu$ : $\mu$ sempre aumenta de 1 , e $j$ pode aumentar de 1 ou não se alterar; podemos representar a variação de $j$ por $x$ (que vale 1 se $\rho_{t} \neq \sigma_{t-1}$, e 0 caso contrário), de forma que sempre podemos considerar que ocorre a transição $(\mu, j) \rightarrow(\mu+1, j+x)$. Lembremos que essas variáveis, assim como a distribuição, se referem a um específico dentre os valores possíveis para o histórico específico dos $K$ últimos passos.

Nessa transição, a média muda de $(j+1) /(\mu+2)$ para $(j+x+1) /(\mu+3)$. A variação da média é, portanto,

$$
\begin{aligned}
E\left(p_{0} \mid \mu+1, j+x\right)-E\left(p_{0} \mid \mu, j\right) & =\frac{j+x+1}{\mu+3}-\frac{j+1}{\mu+2} \\
& =\frac{x}{\mu+3}+(j+1) \frac{(\mu+2)-(\mu+3)}{(\mu+2)(\mu+3)} \\
& =-\frac{j+1}{(\mu+2)(\mu+3)}+x \frac{1}{\mu+3}
\end{aligned}
$$

Lembrando que o significado de $p_{0}$ é a probabilidade com a qual o agente erra após mudar de resposta (ou acerta após manter a resposta), podemos interpretar esse resultado da seguinte maneira: o primeiro termo, sempre negativo, é o 'esquecimento' que leva a distribuição em direção a $p_{0}=0$, ou seja, ao acoplamento entre mudar de resposta e acertar. O segundo pode ser nulo ou positivo, e representa uma espécie de estímulo que leva a distribuição em direção a $p_{0}=1$, ou seja, a um maior acoplamento entre manter a resposta e acertar. Podemos entender o esquecimento como um processo contínuo, eventualmente perturbado por estímulos abruptos de aprendizado, conforme ilustrado na figura 2.4. No entanto, como veremos a seguir, é necessário cuidado com essa interpretação.

Podemos reescrever a variação da média como

$$
\begin{aligned}
E\left(p_{0} \mid \mu+1, j+x\right)-E\left(p_{0} \mid \mu, j\right) \equiv \Delta E & =\frac{1}{\mu+3}\left(-\frac{j+1}{\mu+2}+x\right) \\
& =\frac{1}{\mu+3}\left(-E\left(p_{0} \mid \mu, j\right)+x\right)
\end{aligned}
$$

Assim, podemos reescrever $E\left(p_{0} \mid \mu+1, j+x\right) \equiv E^{\prime}$ em função de $E\left(p_{0} \mid \mu, j\right) \equiv E$ :

$$
E^{\prime}=E+\Delta E= \begin{cases}\left(1-\frac{1}{\mu+3}\right) E & \text { se } x=0 \\ \left(1-\frac{1}{\mu+3}\right) E+\frac{1}{\mu+3} & \text { se } x=1\end{cases}
$$




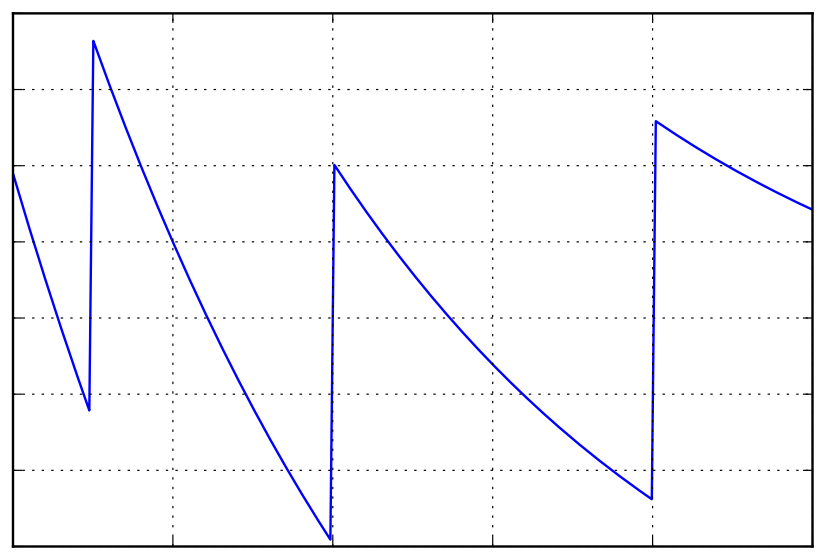

FIGURA 2.4: Exemplo de dinâmica de esquecimento com estímulos abruptos de aprendizado.

Esse resultado, ilustrado no gráfico da figura 2.5, mostra que o modelo é simétrico quanto à relação entre $\rho_{t}$ e $\sigma_{t-1}$, representada por $x=0$ (iguais) ou $x=1$ (diferentes). Uma informação $x=1$ altera o valor de $\left\langle p_{0}\right\rangle$ exatamente da mesma forma que uma informação $x=0$ altera o valor de $\left\langle 1-p_{0}\right\rangle$.

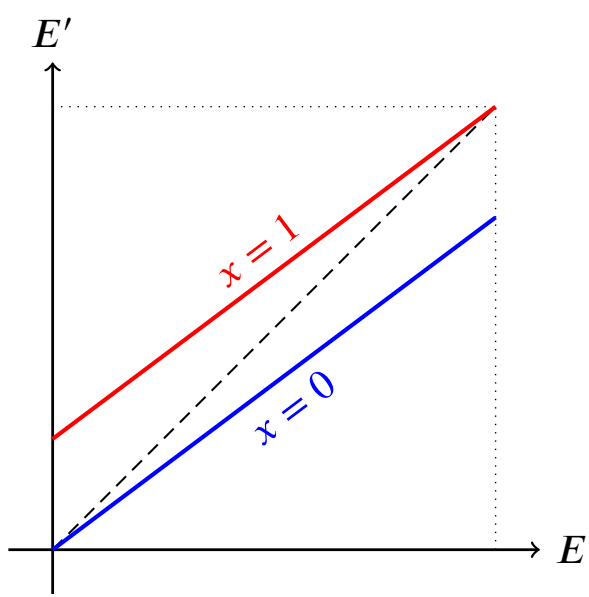

Figura 2.5: Efeito da atualização da distribuição no valor médio, que vai de $E$ a $E^{\prime}$ quando a informação x é recebida. A diagonal tracejada indica a reta $E^{\prime}=E$. Observe que para $x=0$ o valor médio decresce, enquanto para $x=1 \mathrm{o}$ valor médio aumenta.

Portanto, se alterarmos o sentido das variáveis do problema de modo que os significados de $x=0$ e $x=1$ se invertam, bem como de $j$ e $\mu-j$, e de $p_{0}=0$ e $p_{0}=1$, a forma funcional dessa variação permanece, o que significa que nossa interpretação é simétrica e portanto não há preferência no modelo por um ou outro acoplamento. Com efeito, quando a sequência à qual o modelo tenta se ajustar tem uma taxa de alternância alta (por exemplo, 010010100101010101 ...), ou seja, alta probabilidade de que o símbolo 
seguinte seja diferente do anterior, esperamos que o acoplamento entre acertar e mudar de resposta seja maior do que quando a sequência favorece longas sequências de símbolos iguais (por exemplo, 01111111100000000 ...); o modelo deve ser igualmente capaz de se ajustar aos dois tipos de sequências.

A magnitude de ambos os termos diminui à medida que vão sendo apresentados mais exemplos, ou seja, as correções se tornam cada vez menores, de modo que a dificuldade de introduzir mudanças bruscas no sistema cresce com o tempo. Isso indica que a adaptabilidade a mudanças de regra no meio do jogo não é um forte do modelo. 


\section{Capítulo 3}

\section{Simulações e resultados}

$\mathrm{Na}$ análise deste tipo de problema, é de grande importância o uso de métodos numéricos; alguns procedimentos se tornariam tarefas imensamente mais difíceis ou mesmo impossíveis sem cálculos computacionais. Neste projeto foram largamente usadas simulações computacionais para reproduzir o comportamento que estabelecemos como modelo para o agente; com esse objetivo, foi escrito um programa em linguagem $\mathrm{C}++$.

Além disso, para o desenvolvimento do presente trabalho tem grande importância o trabalho de Victorino (2012). Descreveremos na seção 3.4 os procedimentos nele adotados, e, em seguida, relacionaremos seus resultados aos resultados de nossas simulações.

\subsection{Descrição dos algoritmos utilizados}

Por trás da modelagem da máquina, há uma cadeia de Markov de memória $L$, com 2 estados possíveis; ela é traduzida em uma cadeia de Markov de memória 1, com $2^{L}$ estados possíveis - todas as combinações de $L$ estados escolhidos entre os 2 possíveis para a cadeia original. Cada uma dessas combinações corresponde a um passado $\eta$ na nossa descrição anterior; esse passado pode, então, ser descrito por um índice numérico com $0 \leq \eta<2^{L}$. Assim, as variáveis indexadas por $\eta-$ as contagens $j$ e $\mu$, e as probabilidades $p$ de obter o símbolo $x=1$ - são representadas no programa por matrizes (unidimensionais) de comprimento $2^{L}$.

Para a simulação das transições de estados no processo markoviano, foi escolhido o gerador de números pseudo-aleatórios xorshift (Marsaglia, 2003). A cada iteração, o gerador é chamado e do resultado por ele emitido se extrai um valor aleatório dentre 0 e 1, que será o símbolo emitido pela máquina nessa iteração. A distribuição entre 0 e 1 não é uniforme: ela é ditada pelo valor de $p$ no estado $\eta$ atual. Após o sorteio, a variável que representa o estado atual é atualizada, de modo a 'esquecer' a informação do $K$-ésimo último símbolo e incluir a informação do novo símbolo.

As técnicas para a simulação do comportamento do agente são essencialmente as mesmas. Ele possui uma memória de tamanho $K$, o que significa que ele mantém como estado $\eta \xi$ um número que representa um coletivo de variáveis das $K$ últimas rodadas; essas variáveis podem ser $x$ (neste caso chamamos o estado apenas de $\eta$ ), pares $(x, y)$ ou $(\rho, \sigma)$. Essas três possibilidades atribuem diferentes significados à variável $q$ que representa a probabilidade com que o agente toma uma certa ação: "escolher $x=1$ " nos dois casos que incluem a variável $x$, ou "mudar de resposta" no caso das variáveis $\rho, \sigma$. A 
diferença entre os casos $x$ e $x, y$ é a presença ou não das respostas passadas do próprio agente no estado - o histórico ao qual essa probabilidade se condiciona.

Em qualquer dessas três situações, o agente indexa pelo estado as variáveis $j, \mu-$ contagens de ocorrência de eventos - e a probabilidade $q$, estimada a partir destas duas últimas. Vimos anteriormente três formas diferentes de realizar essa estimativa, que denominamos $q^{D}$ (discreta), $q^{B}$ (distribuição beta) e $q^{G}$ (distribuição gaussiana).

A cada rodada, o agente escolhe uma resposta, usando uma das estimativas para a probabilidade $q$. Após comparar com o símbolo gerado pela máquina, ele segue à etapa de aprendizado: usa esse resultado para atualizar as variáveis $j, \mu$ e $q$ associadas ao estado $\eta$ $(\eta \xi)$, atualizando também o estado para a próxima rodada.

O programa escrito permite selecionar os seguintes parâmetros para executar a simulação:

- Para a máquina:

- o tamanho $L$ da memória do processo markoviano;

- todas as probabilidades de transição relevantes para o processo.

- Para o agente:

- o tamanho $K$ da memória do agente;

- o conjunto $V$ de tipos de variáveis em termos das quais o agente raciocina $x,(x, y)$ ou $(\rho, \sigma)$;

- qual estimativa $q^{E}, E \in\{D, B, G\}$, o agente deve usar para a probabilidade $q$;

Daqui em diante, para nos referir a um agente com essas características, usaremos a notação $(K ; V ; E)$ para indicar a espécie do agente.

Se considerarmos o processo interno à maquina (com memória de $L$ passos) como uma cadeia de Markov, teremos de trabalhar com o conjunto de $L$-estados, que contém todas as $2^{L}$ possíveis combinações de $L$ estados de passo único (1-estados); especificar todas as probabilidades de transição necessitaria de uma matriz $2^{L} \times 2^{L}$.

No entanto, já comentamos na seção 2.1 que nem todas as transições são possíveis, por causa do vínculo entre o $L$-estado de partida e o de chegada; há apenas dois $L$-estados de chegada possíveis para cada $L$-estado de partida (correspondendo a $x=0$ ou $x=1$ para o último instante). Além disso, as probabilidades para esses dois estados de chegada são complementares, de forma que podemos especificar apenas uma das duas e daí calcular a outra - convencionamos especificar as probabilidades para $x=1$, coerentemente com a 
escolha para $p_{\eta}$. Dessa forma, o processo markoviano está completamente especificado se fornecermos as probabilidades de se obter $x=1$ após cada $L$-upla de símbolos, o que resulta em uma lista de apenas $2^{L}$ elementos. As $L$-uplas são listadas em ordem lexicográfica.

Assim, se um processo for especificado com $L=2$ e as probabilidades $[0.7,0,0.5$, $0.25]$, devemos entender que

$$
\begin{array}{ll}
P(00 \rightarrow 1)=0.7 & P(00 \rightarrow 0)=1-0.7=0.3 \\
P(01 \rightarrow 1)=0 & P(01 \rightarrow 0)=1-0=1 \\
P(10 \rightarrow 1)=0.5 & P(10 \rightarrow 0)=1-0.5=0.5 \\
P(11 \rightarrow 1)=0.25 & P(11 \rightarrow 0)=1-0.25=0.75
\end{array}
$$

\subsection{Observações iniciais}

Uma das primeiras observações que se podem extrair dessas simulações é a evolução no tempo dos erros e acertos do agente, à medida que ele aprende. Podemos imaginar algumas diferentes maneiras de graficar o desempenho do agente ao longo do tempo:

(a) associar a cada instante $t$ o número total de erros realizados até esse instante, $E(t)$. Essa representação permite ver diretamente o 'ritmo' dos acertos e erros - um aumento na percepção da inclinação média significa que o agente passou a errar mais vezes.

(b) associar a cada $t$ a taxa de erros acumulada até esse instante, $E(t) / t$, que corresponde, no gráfico do item anterior, à inclinação da reta que liga a origem ao ponto $(t, E(t))$. Essa representação mostra a evolução da fração total de erros, mas não mostra diretamente a evolução direta do ritmo de acertos.

(c) unindo o melhor dos dois mundos, calcular as médias móveis, tomando para cada ponto a inclinação média do gráfico do item (a) no intervalo (de um tamanho prédeterminado) precedente. Esse tamanho deve ser suficientemente longo para absorver variações muito bruscas devidas à aleatoriedade das sequências, mas suficientemente curto para caracterizar uma informação local. A inclinação média corresponde à soma dos erros realizados no intervalo selecionado dividida pelo tamanho do intervalo, ou seja, à média do erro realizado por instante de tempo.

Para comparar essas diferentes possibilidades, vamos iniciar observando resultados contra um mesmo tipo de máquina, que funciona com uma cadeia de Markov sem 
memória, ou seja, um processo que gera o número $1 \mathrm{com}$ probabilidade $p$ e o número 0 com probabilidade $1-p$, independentemente do histórico. Adotaremos $p=0,3$ nos seguintes exemplos. Na figura 3.1, a métrica (a) de contagem de erros $E(t)$ é usada para mostrar a evolução do desempenho das espécies de agentes aqui estudadas contra essa máquina. Essa figura une diferentes execuções do programa, que entre si tiveram os parâmetros da máquina mantidos, e os parâmetros do agente alterados - mantendo o tamanho da memória do agente em um passo.

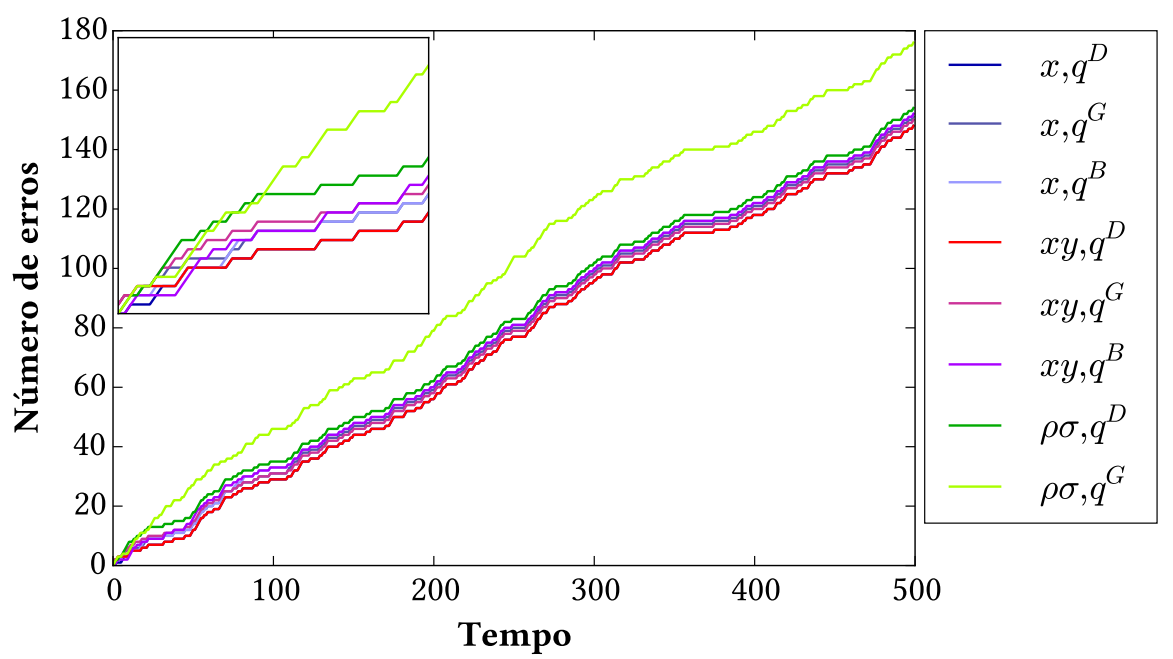

Figura 3.1: Comparação entre o desempenho de agentes de memória 1, mas diferentes espécies, contra uma mesma sequência, usando a métrica de contagem de erros $E(t)$.

Na métrica (a), é possível diferenciar agentes que erram com mais ou menos frequência através da inclinação média das suas curvas de número de erros. No exemplo mostrado na figura 3.1, todos os agentes $(x)$ e $(x, y)$ se acumulam. Há diferenças entre eles no início da execução do algoritmo (reproduzido em detalhe no canto superior esquerdo da figura), mas após um tempo todos passam à mesma estratégia - com isso, as curvas se tornam cópias paralelas a partir desse ponto; elas não se igualam pois há diferença no número de erros cometidos até então.

As métricas (b) e (c) têm em comum o fato de devolverem taxas de erro e não contagens. Portanto, os resultados dessas métricas não devem apresentar uma tendência de crescimento linear, mas sim uma flutuação estável em torno de um valor, visto que a tendência linear dos gráficos de contagens é estável. Na figura 3.2 mostramos um gráfico de comparação entre os valores dessas métricas para o agente $(1 ; x ; D)$; abaixo dele, uma representação unidimensional dos erros e acertos do agente ao longo das iterações, com acertos e erros representados pelas cores verde e vermelho, respectivamente. 
Na figura 3.2, vemos que o gráfico de $E(t) / t$ tem a maior das estabilidades. Isso não é inesperado, pois na realidade essa grandeza corresponde à média do erro nas $t$ primeiras iterações, e o erro tem uma tendência linear como vimos anteriormente; o esperado é de fato que a média fique mais estável quanto maior o número de dados.

A maior variação é a da média móvel, que foi calculada, para cada $t$, como a taxa de erros para os últimos $n=50$ instantes - valores menores de $n$, como $n=20$, resultam em variações ainda maiores. (Note que a média móvel só pode ser calculada a partir de $t=50$.) Uma visualização mais clara é obtida pelos alisamentos da sequência de médias móveis, a um parâmetro $\alpha \in(0,1]$ : se $M_{t}$ representa a média móvel no instante $t$, o alisamento $\bar{M}_{t}$ é

$$
\bar{M}_{t}=\alpha M_{t}+(1-\alpha) \bar{M}_{t-1}
$$

Ou seja, o parâmetro $\alpha$ determina a proporção da "mistura" entre cada valor da sequência e o resumo dos anteriores; $\alpha=1$ reproduz a sequência original, e, quanto mais próximo de 0 , mais forte é o alisamento e menor é a flutuação em torno do valor inicial da sequência.

De fato, notamos que a média alisada se aproxima mais da taxa de erros $E(t) / t$ quando se diminui $\alpha$; porém, cada uma das métricas atende a um compromisso diferente, e por isso não é interessante alisar muito fortemente a sequência: a média móvel mostra as oscilações que a taxa de erros não é capaz de captar. O diagrama unidimensional de acertos e erros mostra claramente a distribuição temporal entre acertos e erros, porém não é capaz de mostrar os padrões numéricos entre a proporção de acertos e erros.

Os dados apresentados até aqui não são suficientes para comparar a eficiência dos agentes. Eles representam uma única instância de uma única cadeia de Markov, em uma

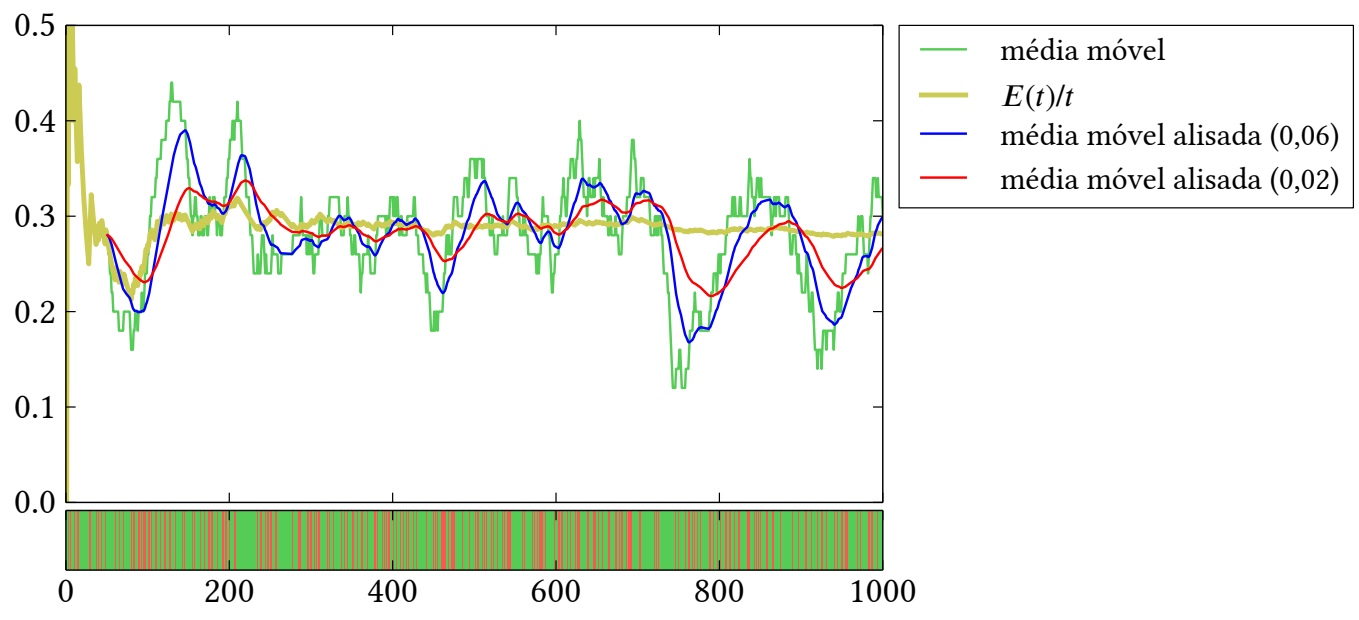

Figura 3.2: Comparação entre as métricas de taxa de erros para uma execução do algoritmo. 
única experiência do agente. Os resultados poderiam ser diferentes se o agente observasse a sequência novamente, com as mesmas hipóteses, mas fizesse diferentes "escolhas" nas situações em que sua resposta é determinada por uma distribuição de probabilidades. Seriam também diferentes se o agente observasse outra realização do mesmo processo markoviano - os parâmetros seriam os mesmos, porém a sequência assumiria valores diferentes. Mais drasticamente, os resultados também mudariam caso esses parâmetros fossem alterados.

Em suma, ao repetir a execução do algoritmo, mantendo iguais todos os parâmetros (da máquina e do agente), o desempenho do agente varia. Para entender melhor esse efeito, vamos decompor essa aleatoriedade nas suas duas componentes: a aleatoriedade do agente e a da máquina.

Isolamos na figura 3.3 a variação do desempenho de um agente ao usar a mesma estratégia para 'jogar o jogo' repetidas vezes, sendo mantida fixa a sequência gerada pela máquina. Lembre-se de que a sequência de respostas do agente pode variar, tanto pelo desconhecimento inicial sobre a máquina quanto pelo uso de estratégias probabilísticas e não determinísticas na modelagem do agente. Para facilitar a visualização, a escala entre os gráficos só foi mantida no eixo horizontal - a diferença entre as escalas dos eixos verticais não adiciona nenhuma informação sobre a dispersão das taxas de erro.

Verifica-se que os agentes que usam estratégias envolvendo o estimante $q^{D}$ têm variância menor em seu desempenho, já que nesses casos o agente converge para estratégias em que todas as probabilidades de suas ações são 0 ou 1; ou seja, seu comportamento é essencialmente determinístico, sendo a variação devida apenas às escolhas aleatórias nas primeiras iterações em que ainda não há informação suficiente.

Em comparação com os que usam apenas $x$, os agentes que usam as variáveis $x, y \mathrm{em}$ suas estimativas tendem a ter uma variância maior, que pode ser explicada simplesmente pelo fato de haver mais parâmetros a serem estimados - o número de instâncias possíveis do passado passa de 2 a 4. Já que, a cada iteração, o agente atualiza a estimativa para a distribuição de apenas um parâmetro por vez, o tempo até a convergência de todas as distribuições para valores determinísticos é maior, e portanto o agente passa mais tempo dependendo de resultados probabilísticos.

Pela mesma razão, agentes com memória maior demoram mais até atingir um regime estacionário em relação à taxa de erros. A cada passo de memória que se adiciona, o número de parâmetros a estimar dobra (apenas parâmetros $x$ ) ou quadruplica (parâmetros $x y$ ou $\rho \sigma$ ); o tempo para que a estratégia do agente convirja para uma consideravelmente próxima da ótima aumenta na mesma proporção.

Na figura 3.4, mostra-se o desempenho do agente quando a sequência gerada pela máquina varia a cada repetição do jogo, mantendo porém os mesmos parâmetros do 


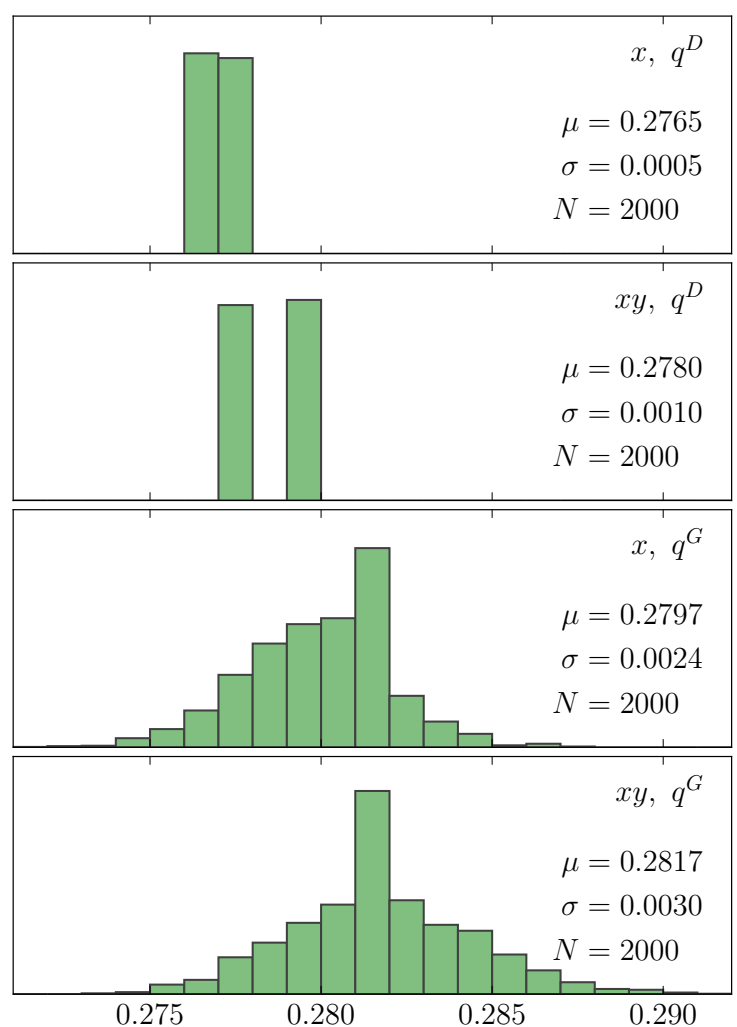

(a) Cadeia sem memória

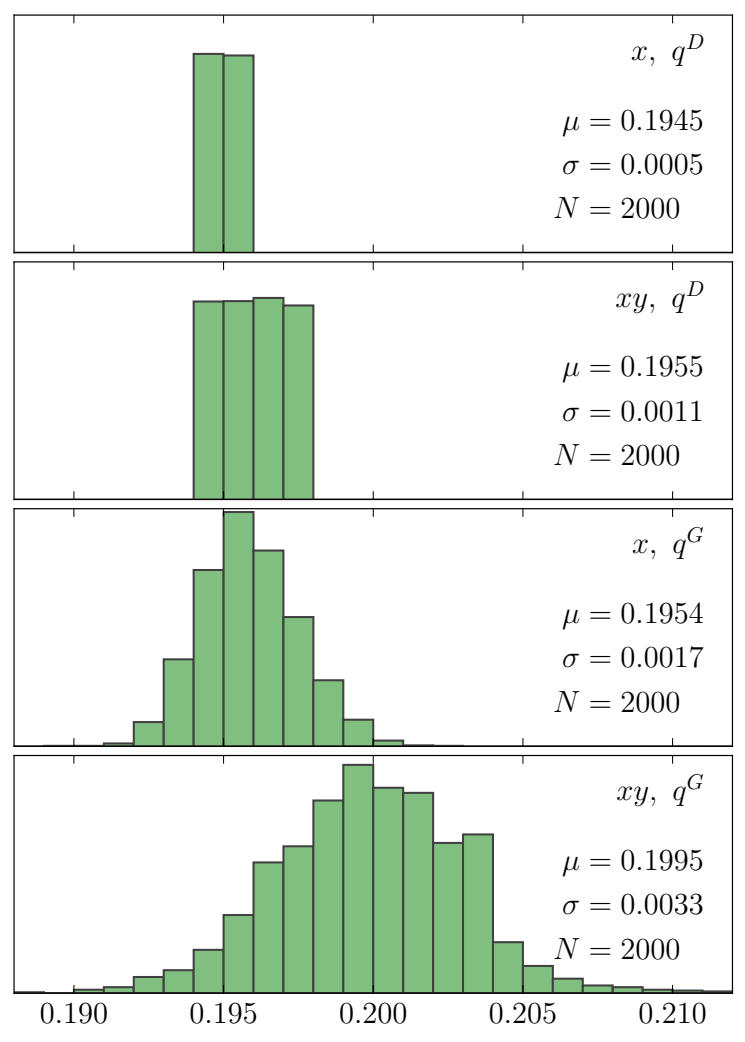

(b) Cadeia de memória 1

Figura 3.3: Histogramas das quantidades de erro acumuladas após 1000 iterações. Cada coluna contém os resultados de 2000 execuções da simulação para cada tipo de agente, mantendo-se fixa a sequência de símbolos gerada pela máquina. Os eixos verticais não estão na mesma escala.

processo markoviano. Em ambas as figuras, os histogramas representam a distribuição das taxas finais de erro (razão entre número de erros e número de iterações) após um mesmo número de iterações, em 2000 execuções do algoritmo. Os mesmos gráficos foram elaborados para os mesmos agentes contra outro tipo de sequência: uma cadeia de Markov de memória 1, com probabilidades [0.7,0].

Separando a variabilidade dos resultados em duas componentes distintas - uma devida ao agente e outra à maquina -, vemos que não é adequado desprezar totalmente a contribuição da variabilidade das respostas do agente, salvo possivelmente para os agentes que usam as estimativas do tipo $q^{D}$. Porém é também afirmável que a variabilidade da máquina é mais significativa do que a do agente - o desvio padrão das taxas de erro aumenta cerca de 5 vezes quando se permite variação da sequência da máquina.

Com isso, conclui-se que não é estatisticamente significativo comparar o desempenho de agentes diferentes baseados em apenas uma execução do algoritmo. Daqui em diante, 

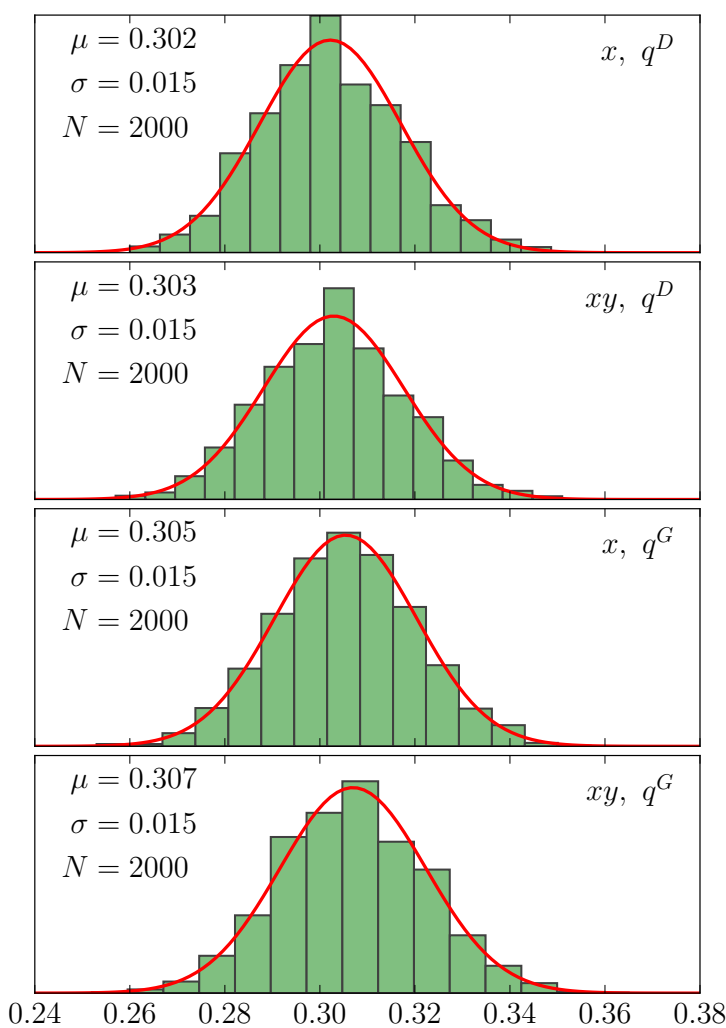

(a) Cadeia sem memória
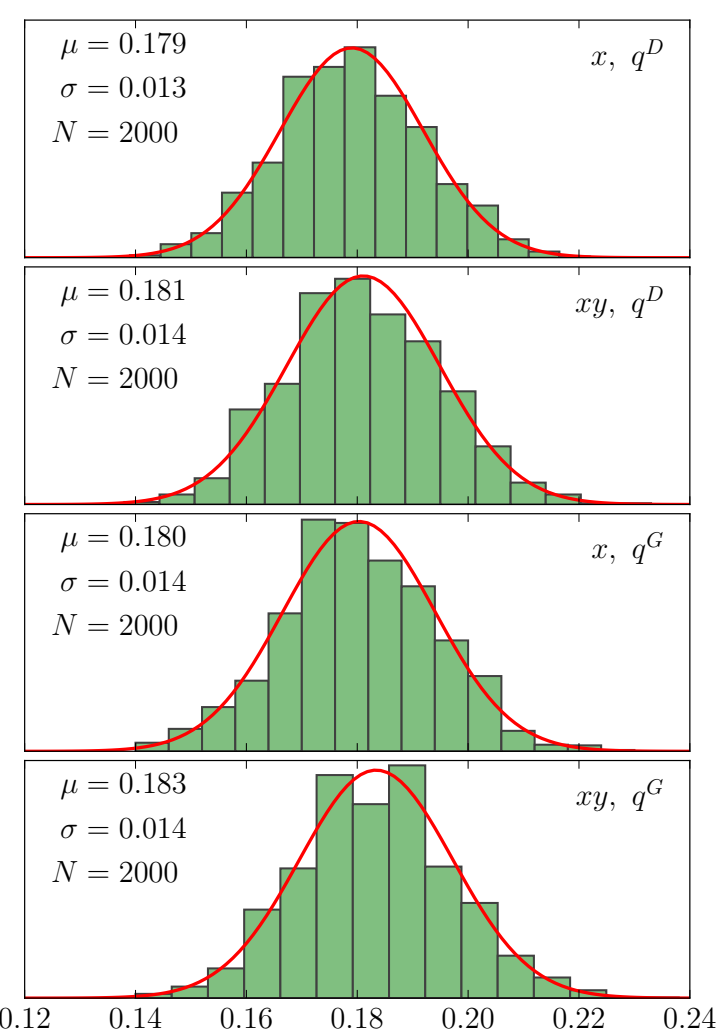

(b) Cadeia de memória 1

Figura 3.4: Histogramas das quantidades de erro acumuladas após 1000 iterações. Cada coluna contém os resultados de 2000 execuções da simulação para cada espécie de agente, mantendo-se fixos os parâmetros que caracterizam a cadeia de Markov gerada pela máquina. Os eixos verticais não estão na mesma escala.

nossas análises serão baseadas em médias de um alto número de execuções de cada simulação, observando o desempenho do agente contra uma cadeia de Markov como um todo, e não apenas instâncias particulares dela.

Na sequência, feita a discussão sobre como os resultados devem ser obtidos e interpretados, executamos o algoritmo para uma ampla gama de tipos de cadeias de Markov, obtendo uma primeira visualização das predições que se podem extrair da teoria desenvolvida. Primeiramente, para cadeias de ordem zero, que dependem de um par de probabilidades complementares $1-p$ e $p$ de obter, respectivamente, 0 e 1 , representamos na figura 3.5 os resultados finais para a taxa de erros em simulações com diferentes valores de $p$.

Para os agentes com o melhor desempenho possível, ou seja, que adotam a estratégia de perseveração, o gráfico da taxa final de erros deve ser simétrico em relação ao eixo 

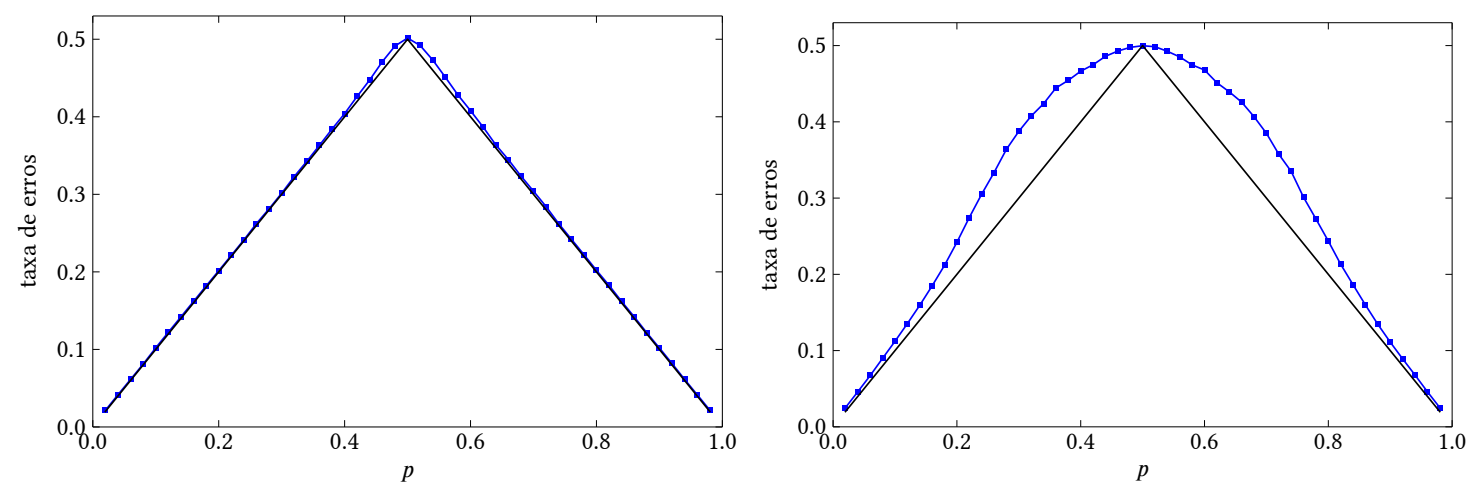

Figura 3.5: Resultado do algoritmo para diversas cadeias de memória zero, variando o valor de $p$ : taxas de erro versus $p$, para os agentes $(1 ; x ; D) e(1 ; \rho, \sigma ; D)$.

$p=1 / 2$ : o nome de cada símbolo deve ser irrelevante para o agente e portanto uma troca de $p$ por $1-p$ (que corresponde a tomar o mesmo processo porém invertendo o nome dos dois símbolos) não deve alterar a taxa de sucesso.

Nas extremidades $p=0$ ou 1 - situação em que a sequência consiste apenas de zeros ou apenas de uns e portanto a estratégia ótima garante $100 \%$ de acerto -, a taxa de erros deve tender a zero. No centro, $p=1 / 2$, a taxa de erros deve ser $1 / 2$ - a sequência tende a frequências iguais de zeros e uns, e portanto a melhor estratégia é escolher persistir em uma das duas opções, garantindo $50 \%$ de acerto a longo prazo. Entre o centro e a extremidade esquerda, a estratégia ideal para o agente é escolher sempre zero, pois é a alternativa mais provável; assim, a taxa de erros será igual a taxa de aparecimento de uns, que é $p$, e portanto há um crescimento linear da extremidade até o centro. No lado direito, teremos um espelho do lado esquerdo, devido à simetria que descrevemos.

Vemos no gráfico de desempenho dos agentes $(x)$ que nossas previsões se aplicam muito bem; vemos também que para os agentes $(\rho, \sigma)$ o desempenho é pior. Uma das diferenças é na velocidade do aprendizado: ao executar o algoritmo por 100000 iterações em vez de 1000 , ou mesmo por 10000 , nota-se uma melhoria no desempenho (conforme figura 3.6); porém, ainda permanece um desvio na região mais próxima do centro. No entanto, não há muito interesse em analisar simulações com um número tão alto de iterações, tendo em vista que em situações reais em geral não é possível ter amostras tão grandes de respostas.

Consideremos agora uma cadeia de memória 1, em que a probabilidade de aparecimento do símbolo 1 é $p$ caso o símbolo anterior seja 0 , e $q$ caso o anterior seja 1. Espera-se a seguinte simetria: se os papéis dos dois símbolos forem invertidos, a taxa de sucesso do agente deve ser a mesma, pois o agente não tem preferência pelo nome dos símbolos. $\mathrm{Na}$ 


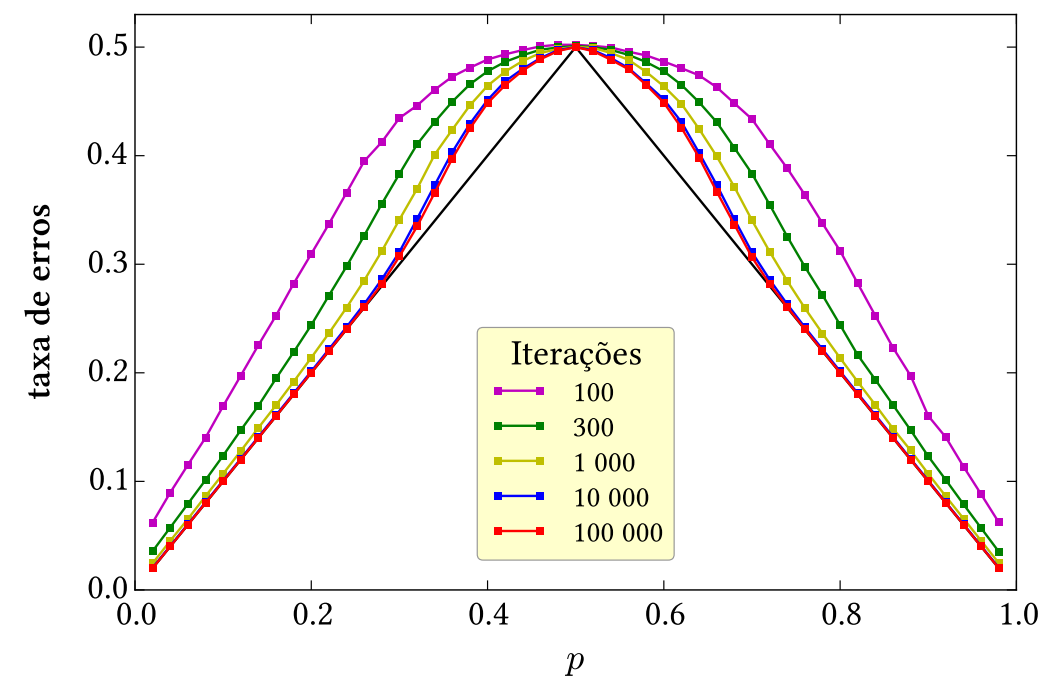

Figura 3.6: Resultado da figura 3.5 apenas para os agentes $(\rho, \sigma)$, comparando resultados após números diferentes de iterações.

situação inicial, temos as seguintes probabilidades de transição:

$$
\begin{aligned}
& P(0 \rightarrow 1)=p \\
& P(0 \rightarrow 0)=1-p \\
& P(1 \rightarrow 1)=q \\
& P(1 \rightarrow 0)=1-q
\end{aligned}
$$

Ao inverter os papéis, trocamos do lado esquerdo todos os zeros por uns e todos os uns por zeros:

$$
\begin{aligned}
& P(1 \rightarrow 0)=p \\
& P(1 \rightarrow 1)=1-p \\
& P(0 \rightarrow 0)=q \\
& P(0 \rightarrow 1)=1-q
\end{aligned}
$$

Desta forma, a taxa de sucesso para o par de probabilidades $(p, q)$ deve ser igual à taxa para o par $(1-q, 1-p)$. Isso significa que a reta $p+q=1(p=1-q)$ deve ser um eixo de simetria do plano $(p, q)$ em relação às taxas de sucesso (ou de erro).

Mostramos na figura 3.7 taxas de erro dos agentes $(x)$ e $(\rho, \sigma)$ num mapa de cores sobre o plano $(p, q)$, nos mesmos procedimentos que foram feitos para ordem zero. De fato observa-se nesses gráficos a simetria esperada pela equivalência entre cadeias pela troca de nomes dos símbolos (o eixo de simetria foi representado na figura). Os dois apresentam as mesmas tendências gerais, porém o agente $(\rho, \sigma)$ tem taxas de erro mais elevadas em mais regiões do plano. 

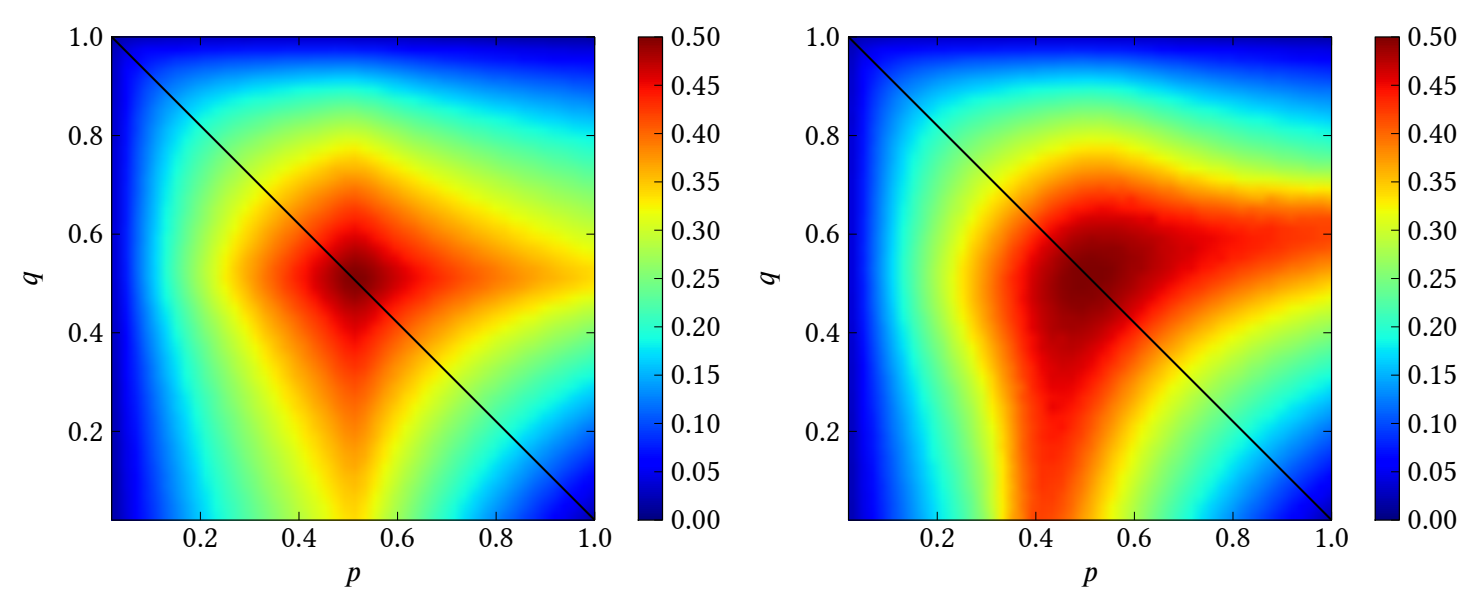

Figura 3.7: Resultado do algoritmo para diversas cadeias de memória 1, variando os valores de $p$ e $q$. As taxas de erro são representadas pela escala de cores sobre o espaço $(p, q)$. As figuras referem-se respectivamente aos agentes $(1 ; x ; D) e(1 ; \rho, \sigma ; D)$.

\subsection{Perturbações sobre o aprendizado}

Na equação 2.44, estabelecemos a atualização da distribuição de probabilidades como uma série de correções incrementais, compostas por dois termos: um de 'esquecimento', sempre negativo, e outro de 'estímulo' ou 'reforço', positivo ou nulo. Vamos reescrever essa equação porém introduzindo os coeficientes $c_{0}$ e $c_{1}$ nesses dois termos, a fim de estudar o efeito de perturbações no aprendizado do agente:

$$
\Delta E=-c_{0} \frac{j+1}{(\mu+2)(\mu+3)}+c_{1} x \frac{1}{\mu+3}
$$

O caso $c_{0}=1=c_{1}$ recai na equação original que deduzimos para o aprendizado bayesiano.

A motivação desse estudo está na possibilidade de fazer um paralelo com o sistema de recompensa do cérebro humano. Um dos protagonistas do sistema de recompensa é o neurotransmissor dopamina; a maioria das situações de recompensa está associada a um aumento no nível de dopamina no cérebro. A variação do nível de dopamina tem duas partes: as liberações, que aumentam o nível, e as absorções, que o diminuem. Assim, se a equação 3.4 for uma descrição razoável de um processo que envolve o balanço dopaminérgico, podemos associar $c_{0}$ à taxa de absorção e $c_{1}$ à taxa de liberação do neurotransmissor. Esse processo é análogo ao representado na figura 2.4.

Como falamos em perturbações e não alterações arbitrárias nesses coeficientes, vamos nos restringir a alterar a magnitude dos coeficientes no entorno dos valores originais, sem alterar seus sinais. Alterar $c_{0}$ e $c_{1}$ simultaneamente (isto é, mantendo-os iguais entre si) corresponde a uma correção no ritmo do aprendizado; alterar $c_{0}$ e $c_{1}$ independentemente 
quebra a simetria entre os dois diferentes tipos de exemplo $\left(\rho_{t}=\sigma_{t-1}\right.$ e $\left.\rho_{t} \neq \sigma_{t-1}\right)$ ao mudar a relação entre as partes negativa e positiva da correção $\Delta E$. Alterações de apenas $c_{0}$ têm uma simetria com alterações de apenas $c_{1}$ : podemos transformar alterações de um tipo em uma combinação de uma alteração do outro tipo com uma correção no ritmo do aprendizado.

Para verificar o efeito de perturbações nesses parâmetros, foram feitas simulações para um conjunto suficiente de valores desses parâmetros, e tomadas médias para 1000 execuções com cada valor. Na figura 3.8 são apresentados gráficos das taxas de erros finais (médias) contra os valores dos parâmetros variados.
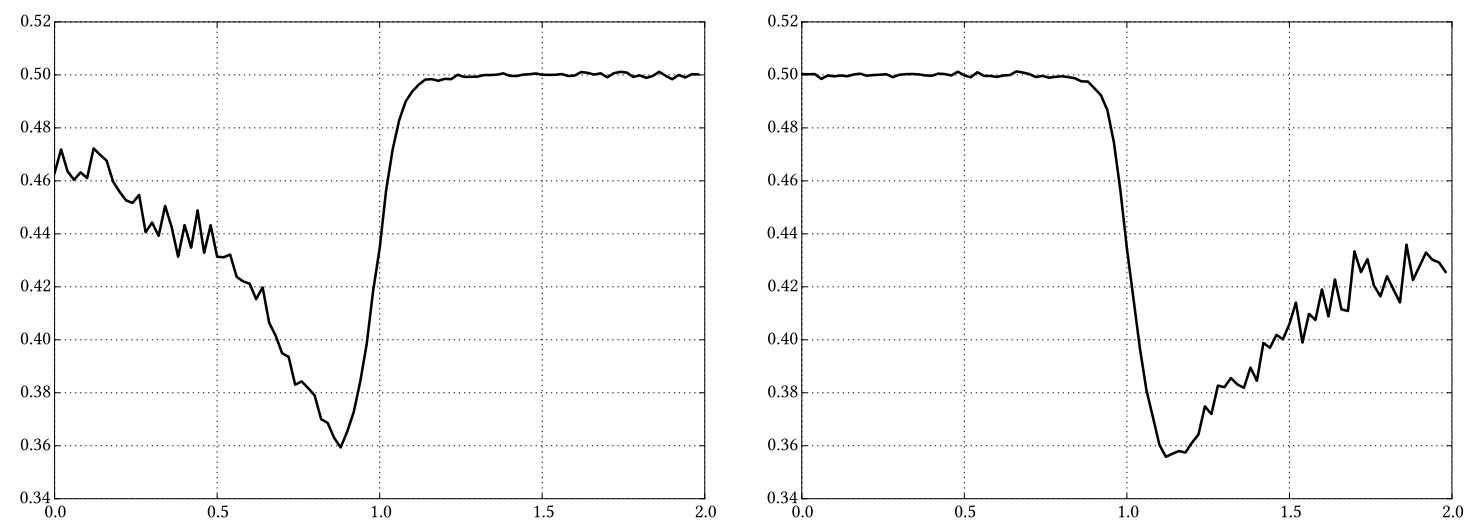

(a) Variando $c_{0} \operatorname{com} c_{1}=1$

(b) Variando $c_{1} \operatorname{com} c_{0}=1$

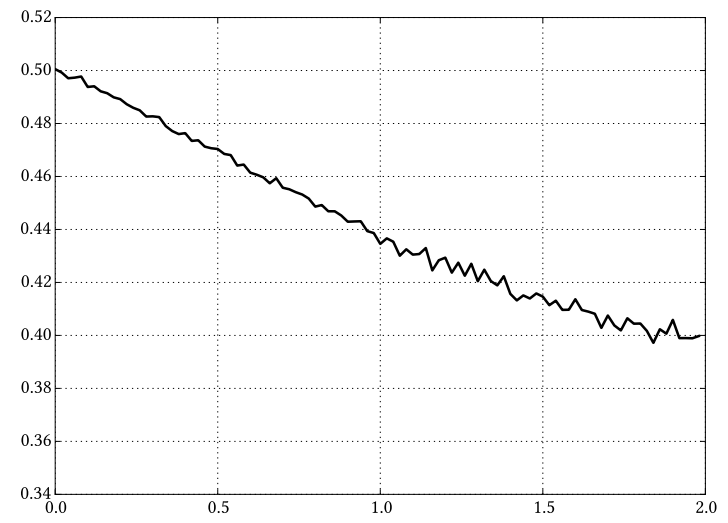

(c) Variando $c_{0}=c_{1}$ conjuntamente

FiguRA 3.8: Variação do erro dos agentes contra sequências binárias aleatórias (com distribuição de probabilidades 70:30 entre os dois elementos) ao se variarem os parâmetros $c_{0}$ e $c_{1}$ conjuntamente $e$ separadamante. 
Da figura, vemos que alterações que quebram a simetria entre os tipos de resultado (igualdade ou diferença entre $\rho$ e $\sigma$ ), ou seja, alterações apenas em $c_{1}$ ou apenas em $c_{0}$, tendem a prejudicar muito mais rapidamente o desempenho do agente, além de haver uma simetria entre aumento de $c_{1}$ e diminuição de $c_{0}$ (e vice-versa). Por outro lado, alterações no ritmo do aprendizado conseguem 'sobreviver' num intervalo bem maior dos valores do parâmetro $c=c_{0}=c_{1}$ pois seu efeito na acurácia é mais suave.

\subsection{Resultados experimentais}

No trabalho realizado pelo grupo do professor Marcus Vinícius Baldo do ICB-USP e descrito em Victorino (2012), foi realizado um experimento no qual voluntários foram submetidos a tarefas de decisões binárias repetidas. A seguir fazemos uma descrição dos procedimentos e descrevemos os resultados aí obtidos, a fim de situar as possibilidades de comparação com os resultados que obtivemos até este ponto no presente trabalho. A comparação é feita em seguida, na seção 3.5.

\subsubsection{Descrição do experimento}

Após uma explicação inicial sobre o experimento, cada voluntário passou por três tarefas diferentes de decisão, cada uma com até 300 tentativas. Os voluntários eram de variadas idades - desde 3 até mais de 70 anos -, e para as crianças o número de tentativas foi diminuído para 150 devido ao cansaço que a atividade poderia provocar nelas caso fosse muito extensa.

A cada tentativa são apresentadas ao voluntário duas alternativas em um programa de computador (dois quadrados cinzas idênticos, um à esquerda e outro à direita). O indivíduo deve escolher uma das duas para tentar prever em qual das duas será apresentado um estímulo visual (um círculo preto) associado a uma recompensa - figurinhas colecionáveis de álbuns para as crianças; 5 centavos no caso dos adultos. O prêmio obtido é acumulado e o total acumulado até o momento é também mostrado na tela do computador.

A posição dos estímulos de recompensa a cada tentativa foi definida previamente por três diferentes regras probabilísticas programadas no computador, denominadas M0, M1 e M2 e correspondentes a cadeias de Markov de memórias 0, 1 e 2, respectivamente. Tais regras estão descritas na tabela 3.1. As três tarefas de decisão às quais cada candidato foi submetido correspondem a essas três regras, de modo que todos os candidatos foram avaliados perante os mesmos tipos de cadeias. 
TABela 3.1: Descrição das matrizes de transição utilizadas para cada um dos tipos de tarefa de decisão.

\begin{tabular}{cc} 
Tarefa & Probabilidades de transição \\
\hline M0 & $P(1)=0,3$ \\
\hline M1 & $P(0 \rightarrow 1)=0,7$ \\
& $P(1 \rightarrow 1)=0$ \\
\hline M2 & $P(00 \rightarrow 1)=0,7$ \\
& $P(01 \rightarrow 1)=0$ \\
& $P(10 \rightarrow 1)=0,3$ \\
& $P(11 \rightarrow 1)=1$
\end{tabular}

\subsubsection{Breve resumo dos resultados}

A variedade entre os candidatos permitiu usar os dados para analisar as diferenças de estratégias decisionais entre crianças, adultos e jovens. Percebeu-se que crianças mais jovens, de até 5 anos, tendem à prospecção (investigação das possibilidades), alternando frequentemente suas escolhas; idosos tendem à perseveração numa mesma alternativa; $\mathrm{e}$ adultos jovens (cerca de 20-25 anos) adotam com frequência a estratégia nomeada como "win-stay/lose-shift" (ganhar - permanecer; perder - mudar), que seria uma espécie de intermediário entre a prospecção e a perseveração, mostrando-se como uma estratégia mais eficiente em ambientes desconhecidos.

A análise do tipo de estratégia pode ser feita com a ajuda de gráficos que medem correlações (temporais) entre variáveis do problema. Uma possibilidade é mostrada no gráfico da figura 3.9, que mostra a correlação entre a probabilidade de mudar de resposta após acertar e a probabilidade de mudar após errar e cujo significado foi discutido na seção anterior. Outra possibilidade são as correlações entre as séries de respostas e de gabaritos, que serão discutidas na seção 3.5.

Observou-se que as diferentes estratégias adotadas pelos indivíduos estão ligadas a comportamentos que buscam mais perseveração ou mais prospecção. Concluiu-se que a diferença entre faixas etárias se deve à diferença no estágio de desenvolvimento do sistema nervoso de cada indivíduo - por exemplo, a falta de uma noção bem desenvolvida de acúmulo de recompensas em crianças mais novas é motivo para que nelas não se manifeste a estratégia de perseveração. 
Idade: $3.9-71.2$

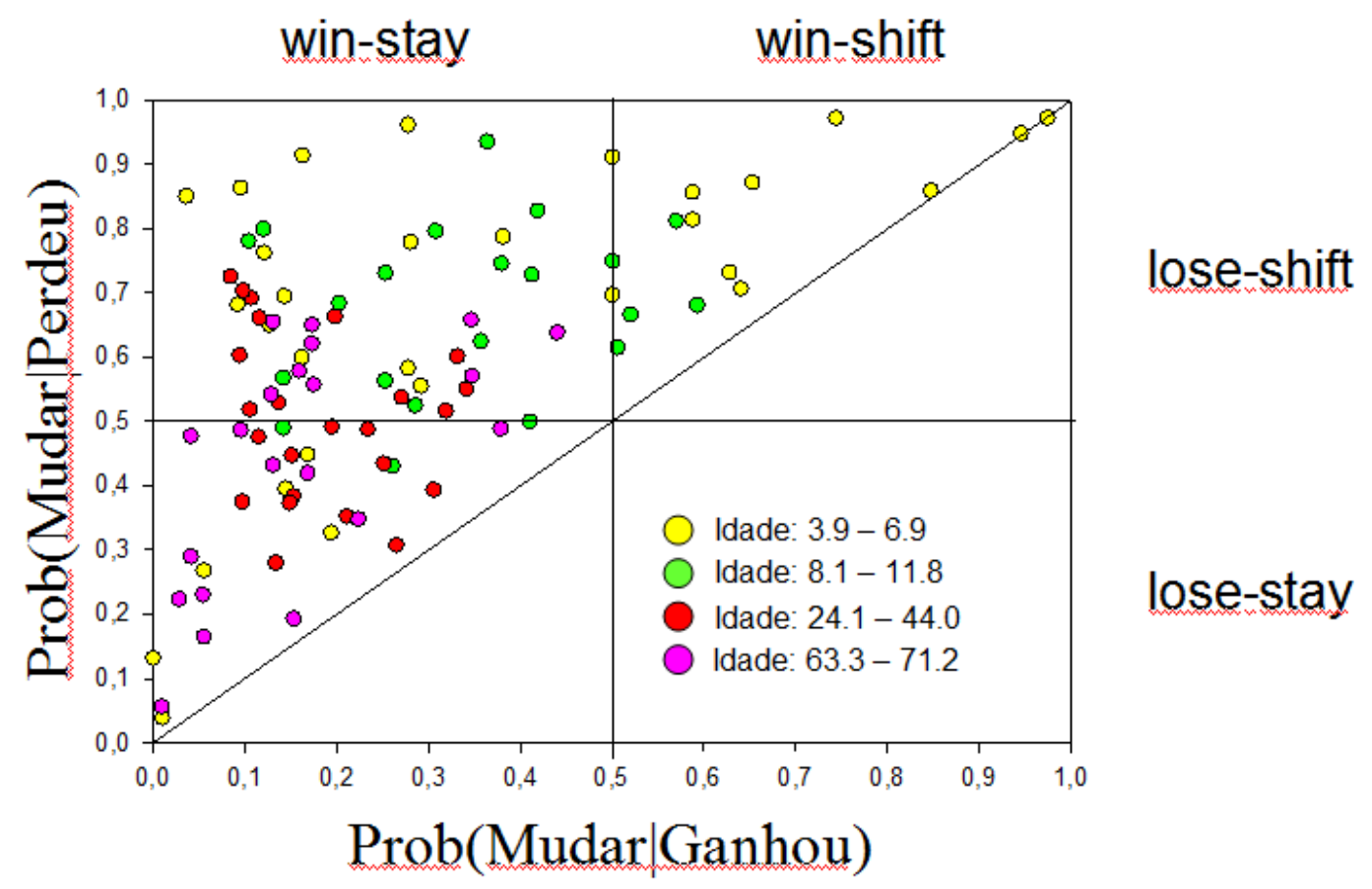

Figura 3.9: Correlação, para cada voluntário de todas as faixas etárias, entre a probabilidade de mudar após um acerto e a probabilidade de mudar após um erro (Victorino, 2012).

\subsection{Confronto com os resultados experimentais}

\subsubsection{Metodologia}

Dada a ampla variedade de modelos que podem ser obtidos variando-se os parâmetros estabelecidos para o agente (comprimento da memória, conjunto de variáveis utilizadas, método usado para a estimativa das probabilidades, modulação dos coeficientes do aprendizado), a taxa de erros do confronto com uma sequência específica não deve ser tomada como única métrica de comparação entre os agentes simulados e os sujeitos do experimento. Uma técnica possível é a análise de correlação entre as sequências de respostas do agente e do 'gabarito'.

Lembrando que os valores das sequências são apenas os números 0 e 1 , expressaremos a correlação entre dois valores como +1 caso eles sejam iguais e -1 caso sejam diferentes:

$$
\operatorname{corr}(x, y)=(2 x-1)(2 y-1)= \begin{cases}+1 & \text { se } x=y \\ -1 & \text { se } x \neq y\end{cases}
$$


Correlações serão tomadas entre valores de uma mesma sequência $\left(x_{t}\right)_{t=1}^{N}$, caso em que serão chamadas de autocorrelações, ou entre valores de duas sequências diferentes $\left(x_{t}\right)_{t=1}^{N}$ e $\left(y_{t}\right)_{t=1}^{N}$, sendo aí chamadas de correlações cruzadas.

Chamamos de correlação de ordem $K$ a média aritmética das correlações entre os pares de valores com índices distando entre si $K$ unidades. A autocorrelação de ordem $K$ da sequência $\left(x_{t}\right)$, por exemplo, será a média das correlações entre os pares $\left(x_{1}, x_{1+K}\right)$, $\left(x_{2}, x_{2+K}\right), \ldots,\left(x_{N-K}, x_{N}\right)$, e será denotada por

$$
\operatorname{ACorr}_{K}(x)=\operatorname{Corr}_{K}(x, x)=\frac{1}{N-K} \sum_{t=1}^{N-K} \operatorname{corr}\left(x_{t}, x_{t+K}\right) \text {, }
$$

em que adotamos a convenção de usar corr com inicial minúscula para indicar correlação entre valores e Corr com inicial maiúscula para indicar correlação entre sequências.

A correlação cruzada entre $\left(x_{t}\right)$ e $\left(y_{t}\right)$ requer mais atenção pois temos de distinguir os pares em que o índice de $x$ é anterior ao de $y$ daqueles em que o índice de $x$ é posterior ao de $y$. A primeira possibilidade gera a correlação cruzada de y com o passado de $x$ :

$$
\operatorname{Corr}_{K}(x, y)=\frac{1}{N-K} \sum_{t=1}^{N-K} \operatorname{corr}\left(x_{t}, y_{t+K}\right) ;
$$

a segunda gera a correlação cruzada de $x$ com o passado de y:

$$
\operatorname{Corr}_{K}(y, x)=\frac{1}{N-K} \sum_{t=1}^{N-K} \operatorname{corr}\left(y_{t}, x_{t+K}\right) .
$$

Com essas definições, podemos observar algumas propriedades de nossas métricas de correlação:

- O valor 1 para uma correlação entre duas sequências indica total coincidência entre

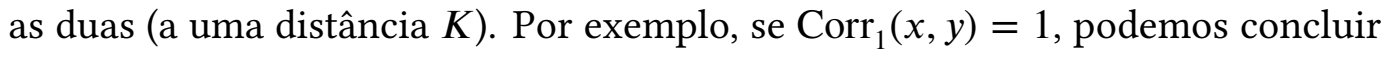
que cada valor da série $y$ é exatamente igual ao valor anterior da série $x$. (Se $\operatorname{Corr}_{1}(y, x)=1$, então cada valor da série $y$ é igual ao valor seguinte da série $x$.) Em particular, a autocorrelação de ordem zero $\operatorname{Corr}_{0}(x, x)$ é sempre 1 .

Em contrapartida, o valor -1 indica total oposição. $\mathrm{O}$ valor 0 indica equilíbrio entre as coincidências e oposições no conjunto dos elementos considerados.

- $\operatorname{Corr}_{0}(x, y)$ corresponde à métrica de acertos (isto é, o complemento da métrica de erros) que temos utilizado até agora, a menos de uma transformação linear de escala - do intervalo $[-1,1]$ para o intervalo $[0,1]$. 
Na figura 3.10 mostramos um exemplo de gráfico de correlação para um certo agente confrontado com uma certa máquina. São mostradas três curvas: as autocorrelações da sequência $x$ de respostas do agente, as autocorrelações da sequência de símbolos $y$ da máquina e as correlações cruzadas entre as duas. Nas abscissas são representadas as diferentes ordens de correlação (de 0 até 10 ), e nas ordenadas os valores das correlações para as ordens correspondentes. Devido às flutuações estatísticas que já mencionamos antes ao analisar o comportamento dos agentes, as curvas dos agentes simulados representam valores médios para 100 execuções - foram tomadas médias aritméticas ponto a ponto das curvas de correlação de cada execução.

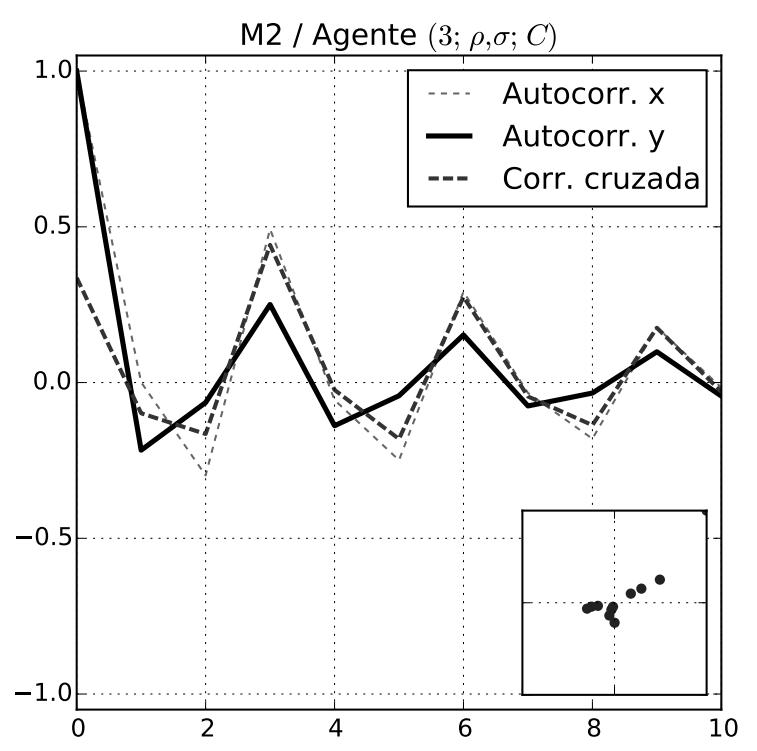

Figura 3.10: Exemplo de gráfico de correlação para um agente confrontado com uma máquina. São mostradas as curvas de autocorrelação das duas sequências de respostas e a curva de correlação cruzada do agente em relação ao passado da máquina.

Ao comparar os resultados de agentes simulados e humanos pela análise de correlação, concentraremos nossa atenção nos seguintes aspectos dos gráficos:

- perfil geral de amplitude das curvas: valores mínimos e máximos, rapidez de decaimento;

- período das (eventuais) oscilações das curvas;

- maior ênfase no formato das curvas apenas até ordens de correlação mais baixas (3 ou 4) - a contribuição das correlações de ordens superiores tende a ser menos relevante após esse ponto, além de tais correlações carregarem informação já presente nas ordens mais baixas; 
Também na figura 3.10 foi feita uma representação mais compacta de parte desses resultados - o gráfico menor mostra a autocorrelação de $y$ contra a autocorrelação de $x$; cada ponto tem coordenadas $\left(\operatorname{ACorr}_{K}(x), \operatorname{ACorr}_{K}(y)\right)$. As escalas dos eixos foram omitidas para não poluir a visualização; ambas são iguais à escala vertical do gráfico maior, de $-1 \mathrm{a}+1$.

Esta representação mais compacta permite uma percepção mais imediata dos contrastes e semelhanças entre os dois padrões de correlação. Mesmo com a flutuação estatística nos pontos da sequência $x$, ainda é possível com ela comparar os padrões das figuras nos gráficos $x y$ para diversos agentes contra um mesmo tipo de máquina.

\subsubsection{Resultados e discussão da comparação}

Devemos primeiramente ressaltar que nosso objetivo não é obter resultados quantitativamente corretos que permitam uma comparação numérica entre os modelos simulados e os sujeitos do experimento. Vemos este modelo como uma primeira tentativa de abordar o problema, e os resultados qualitativos desta comparação como subsídio para futuros trabalhos que dêem continuidade a este; esperamos poder fornecer alguma visão no sentido de selecionar quais aspectos do modelo devem ser mantidos e quais devem ser alterados.

Dito isto, buscamos comparar os resultados das simulações de diferentes modelos de agentes com os resultados do experimento com diferentes sujeitos, e inferir para cada classe de sujeitos qual a descrição mais adequada dentro do nosso repertório de modelos. Uma vez que o experimento de Victorino (2012) mostrou-se sensível apenas à faixa etária dos voluntários, e considerando que a análise das respostas de um único sujeito não tem grande significado devido às flutuações estatísticas, nossa comparação terá como base os grupos resultantes da mesma divisão em faixas etárias, de acordo com a tabela 3.2.

TABEla 3.2: Distribuição dos sujeitos do experimento entre as faixas etárias consideradas. Dados de Victorino (2012).

\begin{tabular}{rccccccccc} 
GRUPO & 1 & 2 & 3 & 4 & 5 & 6 & 7 & 8 & 9 \\
\hline FAIXA ETÁRIA (ANOS) & $3-4$ & $4-5$ & $6-7$ & $8-9$ & $10-12$ & $20-25$ & $40-45$ & $60-65$ & $70-75$ \\
IDADE MÉDIA (ANOS) & 3,9 & 5,0 & 6,9 & 8,1 & 11,8 & 24,1 & 44,0 & 63,3 & 71,2 \\
NÚMERO DE INDIVÍDUOS & 9 & 9 & 12 & 10 & 11 & 12 & 12 & 11 & 11
\end{tabular}

O ideal seria poder determinar qual o modelo de agentes que melhor se ajusta a cada grupo de indivíduos, considerando as respostas dos agentes e dos indivíduos às três tarefas de decisão. Porém, dados a simplicidade dos modelos e os objetivos que foram propostos, não devemos esperar que necessariamente um mesmo modelo de agente se ajuste igualmente bem a um grupo de sujeitos quando confrontado com sequências de 
ordens diferentes. Dentre os desvios que podem ocorrer em relação a essa expectativa, podemos apontar, por exemplo, que diferentes estratégias sejam selecionadas pelo cérebro para a abordagem de cada problema, dependendo de diversos fatores, dos mais objetivos (como o tipo de sequência) até mais subjetivos como elementos da percepção de cada indivíduo. Outra possibilidade é que as estratégias adotadas pelos agentes humanos sejam uma combinação de estratégias "instintivas" - que não são conscientizadas pelos indivíduos e devem ser conceitualmente mais próximas do tipo de estratégia adotada pelos agentes em nossos modelos - e estratégias deliberadas e conscientes, que podem variar muito entre indivíduos e não têm como ser modeladas no escopo deste trabalho.
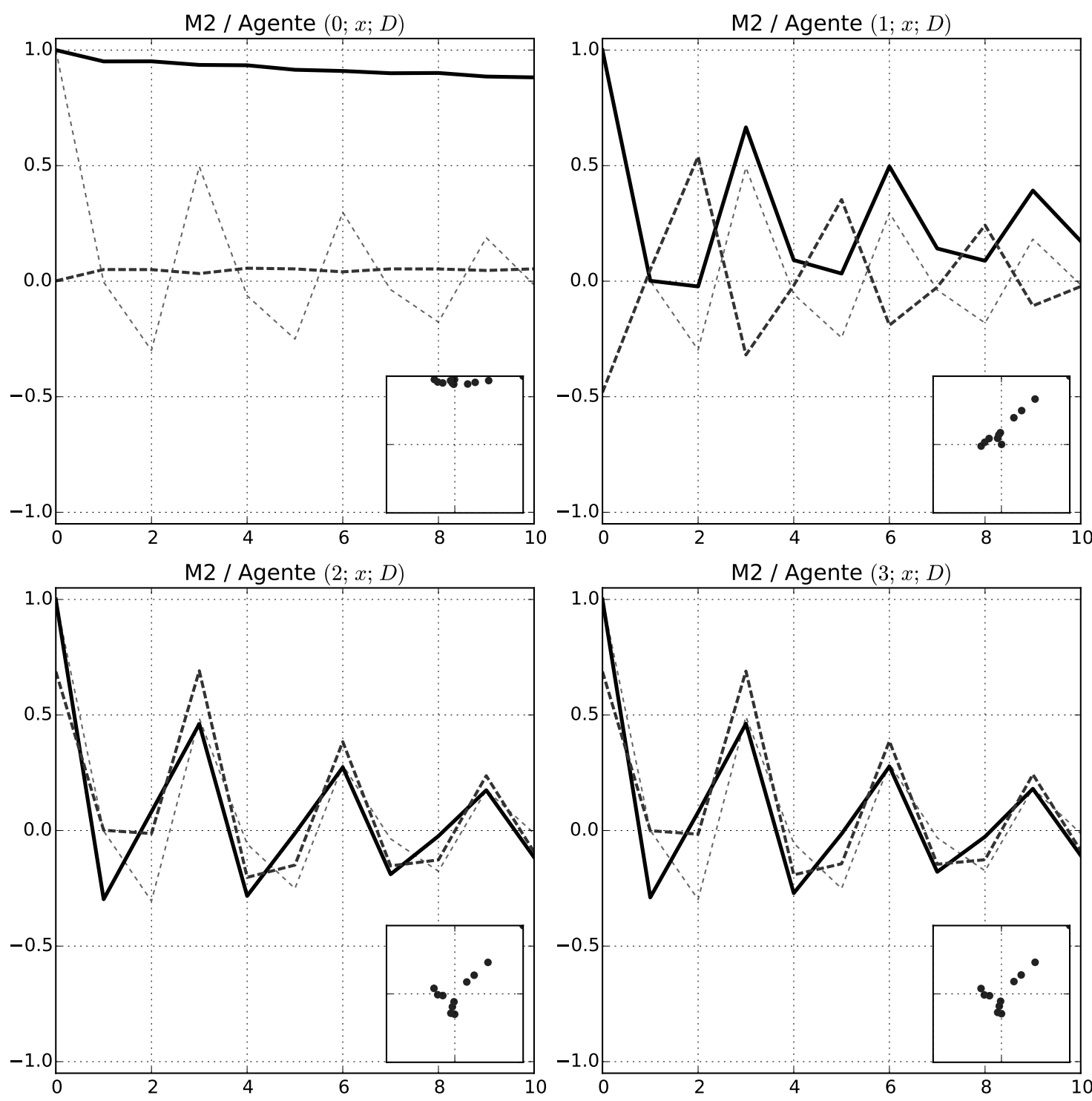

Figura 3.11: Curvas de correlação para simulações de agentes $(K ; x ; D)$ contra sequências M2. 


\section{Sequências M2}

Iniciaremos com a análise das tarefas de decisão perante sequências geradas por M2. Nas figuras 3.11, 3.12 e 3.13, mostramos os gráficos de correlação para os agentes dos tipos $(K ; x ; D),(K ; \rho, \sigma ; D)$ e $(K ; \rho, \sigma ; G)$, com $K=0,1,2,3$. Nota-se que as diferenças entre as estimativas tipo $D$ e $G$ para os agentes $\rho, \sigma$ não são muito profundas, porém os dois modelos reagem diferentemente quando se variam as constantes de aprendizado $c_{0}$ e $c_{1}$, como veremos a seguir através de alguns exemplos. As legendas, iguais à da figura 3.10, foram omitidas daqui em diante para minimizar interferências na visualização.
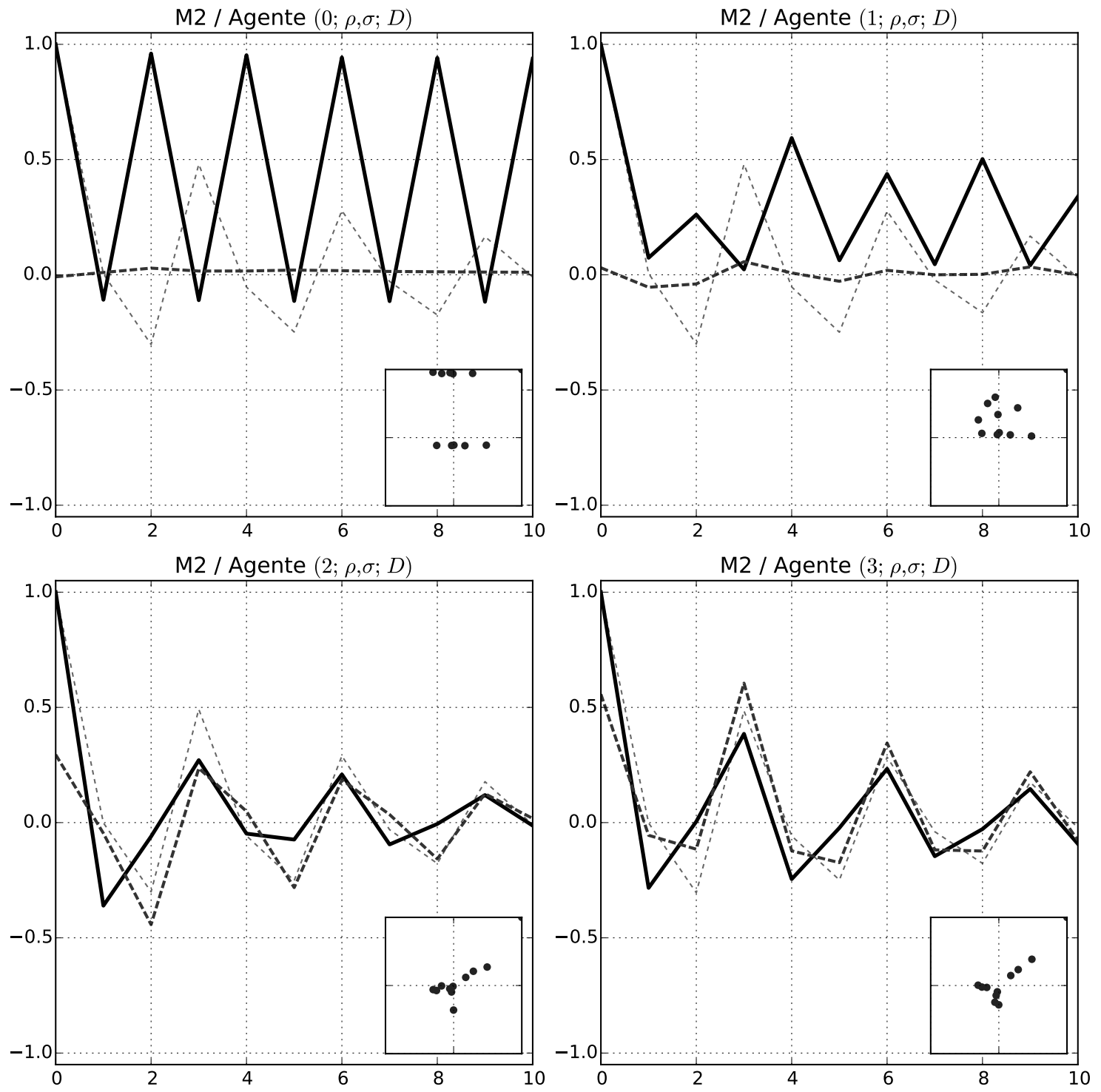

Figura 3.12: Curvas de correlação para simulações de agentes $(K ; \rho, \sigma ; D)$ contra sequências M2. 

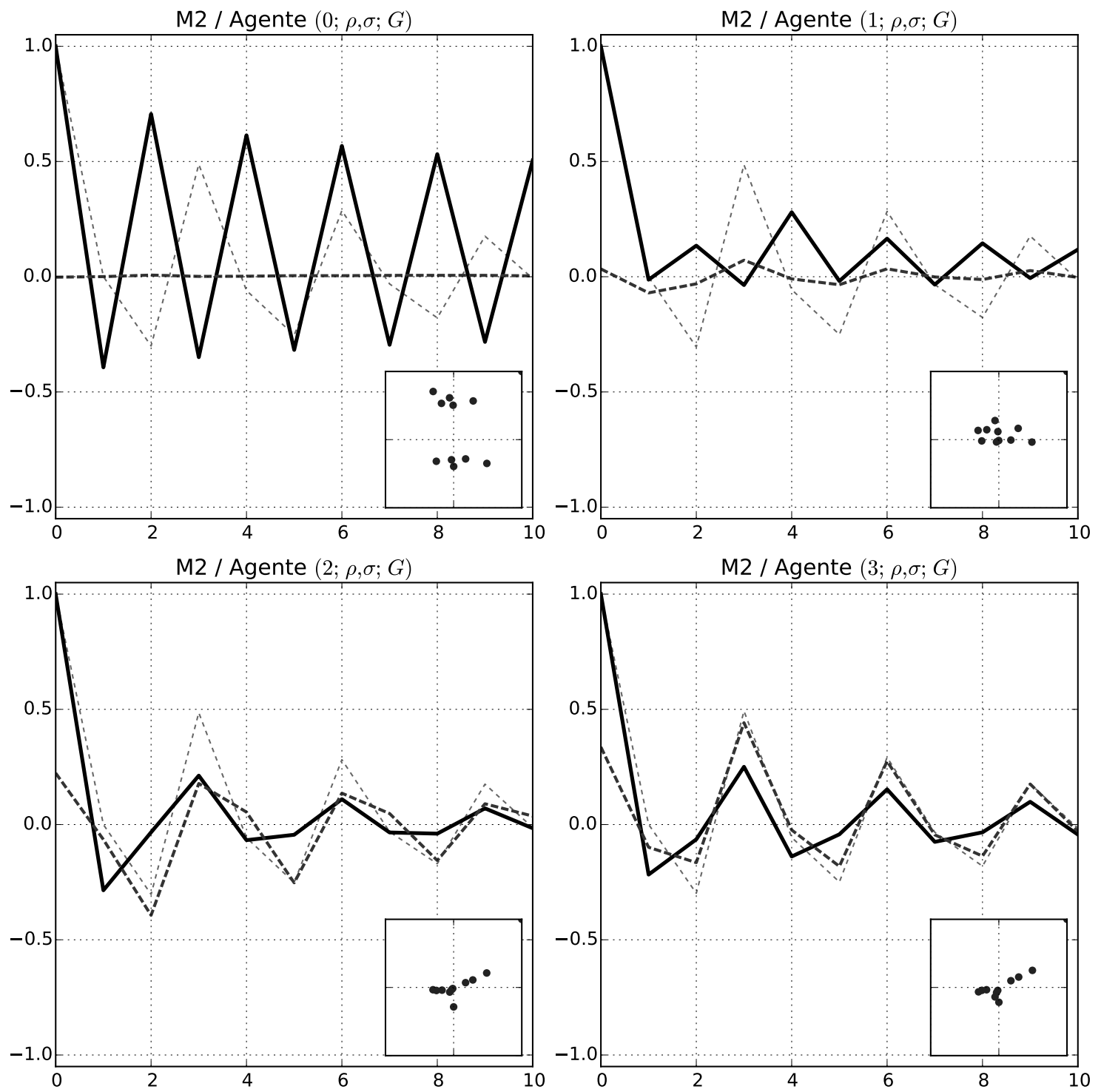

Figura 3.13: Curvas de correlação para simulações de agentes $(K ; \rho, \sigma ; G)$ contra sequências $M 2$.

Os modelos de variáveis $x$ mostraram-se em geral bastante distantes dos resultados experimentais. Em parte dos problemas eles não discordam fortemente dos modelos nas variáveis $\rho, \sigma$, porém eles não têm uma interpretação que permita variar as 'constantes de aprendizado' como é o caso de $c_{0}$ e $c_{1}$ nos modelos $\rho, \sigma$, e isso elimina a chance de modificarmos o modelo parametricamente até obter resultados mais compatíveis com os dados experimentais. Por isso, daqui em diante será dada preferência aos modelos nas variáveis $\rho, \sigma$.

Observa-se de início, na figura 3.14, que os dois primeiros grupos de crianças (de 3 a 5 anos) não apresentaram sinal algum de compreensão da regularidade na sequência, 
uma vez que se vê período 3 na autocorrelação de $x$ e período 2 na autocorrelação de $y$. Comparando tais resultados com os dos agentes simulados, vemos que os modelos que melhor reproduzem o padrão qualitativo desses indivíduos são os de variáveis $\rho, \sigma$ com memória zero, especialmente com a estimativa tipo $G$. Num ajuste mais fino, vemos que é possível variar o parâmetro $c_{1}$ para obter uma coincidência maior, apenas quando se usa a estimativa tipo $G$. Na figura 3.14 confrontamos os dois grupos com os resultados do modelo para $c_{1}=1,013$ e $c_{1}=1,011$, respectivamente.
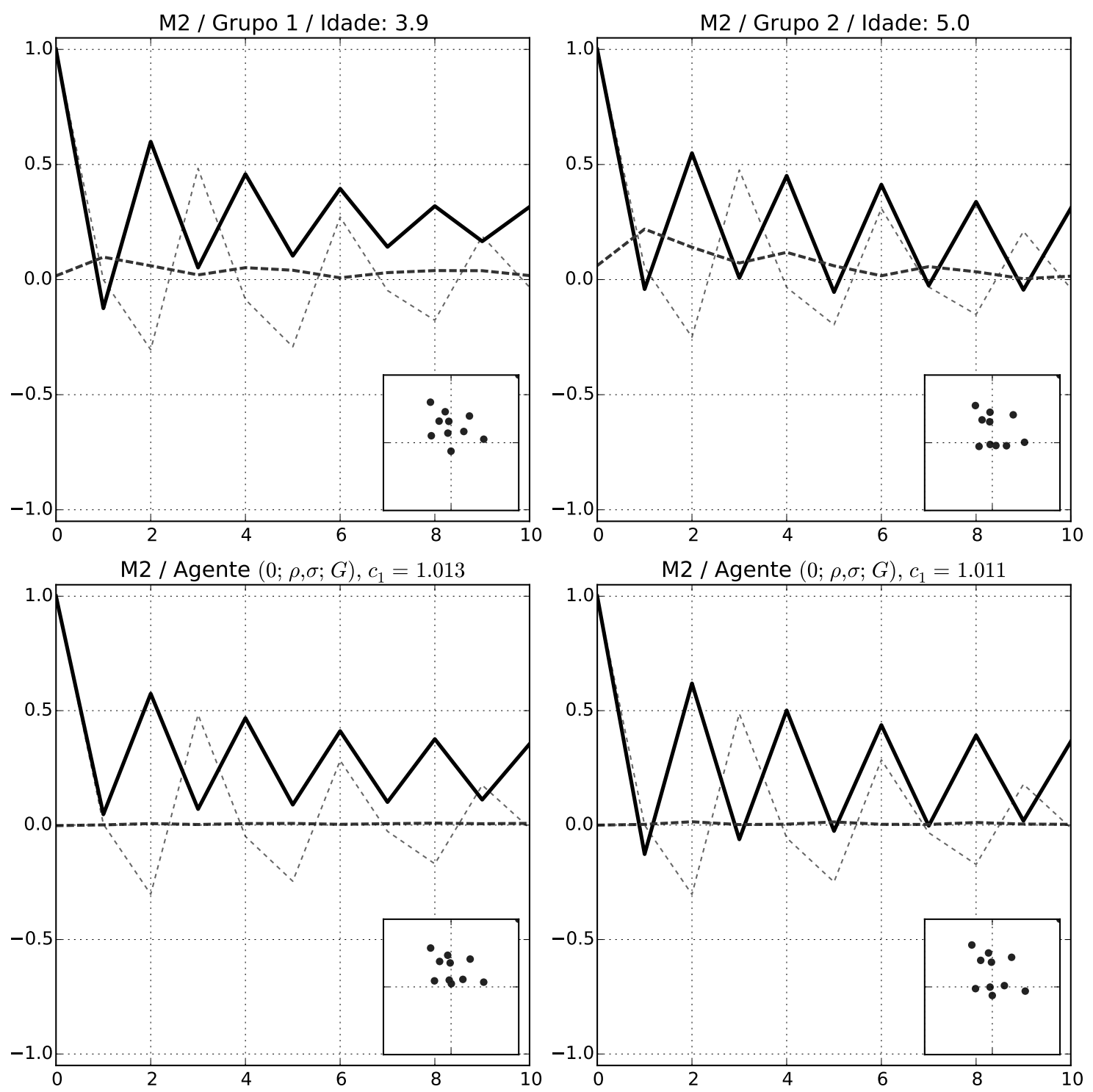

Figura 3.14: Curvas de correlação para crianças dos grupos 1 e 2 contra sequências M2.

Apesar desse ajuste, ao diminuir $c_{1}$ nos modelos de memória 2 e 3, são obtidos resultados que guardam certa semelhança com estes. Vê-se nas figuras 3.15 e 3.16 que, à 
medida que se diminui $c_{1}$, o agente perde a capacidade de aprender um padrão de período 3 , exibindo apenas oscilações de período 2. Nos modelos de memória 3, essa perda ocorre por volta de $c_{1}=0,89$; os modelos de memória 2 são mais sensíveis e apresentam essa perda em $c_{1}=0,96$. Vale notar na correlação cruzada experimental a sutil presença de um pico na ordem 1 - que sugere o emprego, parcial, de uma estratégia de "cópia da resposta anterior") - que não se mostrou em nenhuma das curvas simuladas para este tipo de sequência.
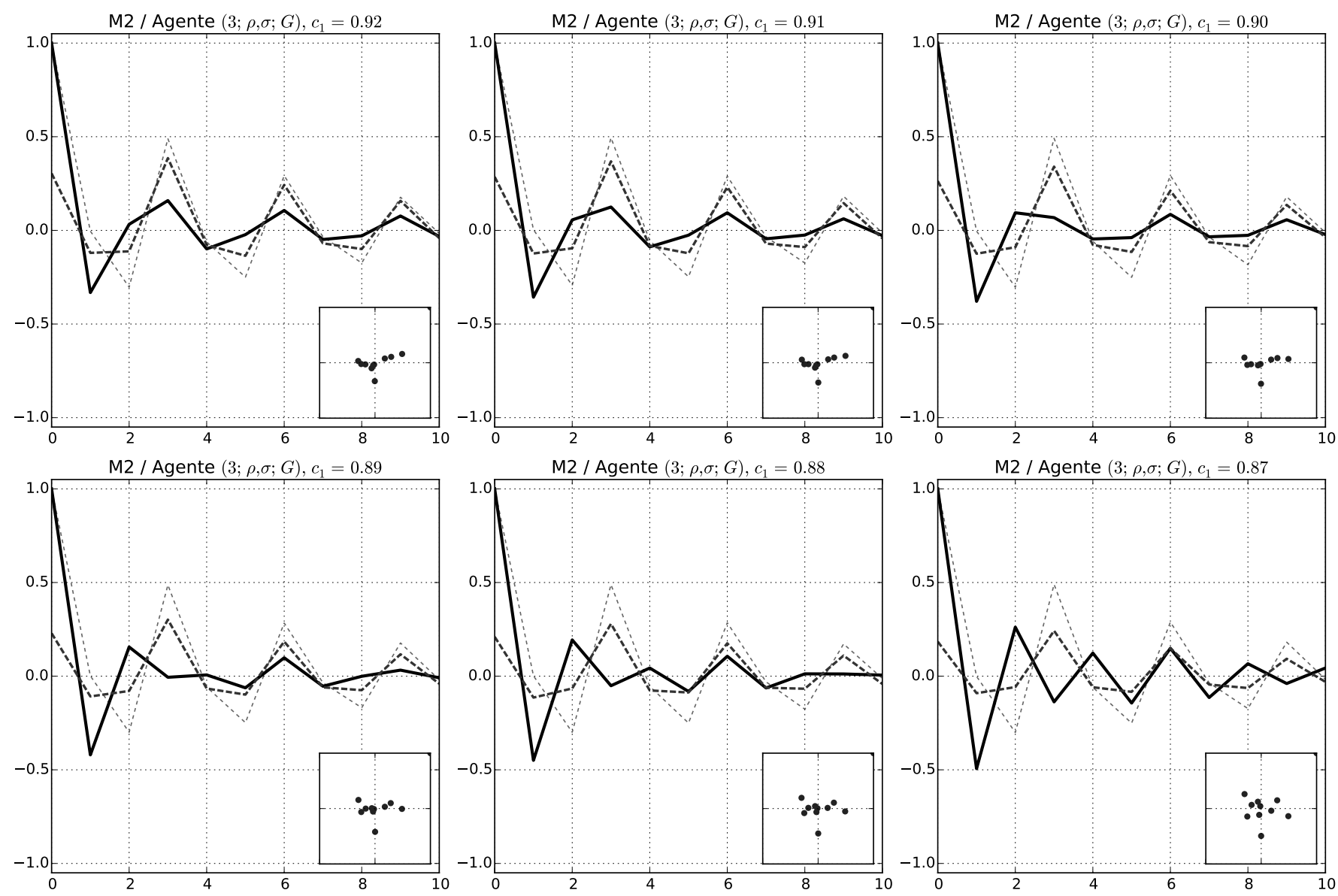

Figura 3.15: Sensibilidade dos modelos $(3 ; \rho, \sigma ; G)$, e da sua capacidade de ajustar padrões de período 3 , à variação de $c_{1}$.

Nas correlações dos grupos de 6 anos em diante (figura 3.17), começam a aparecer sutis "pegadas" dos picos correspondentes ao período 3. Os picos começam a se revelar de fato apenas no grupo 5, porém se percebe que todas as curvas desde o grupo 3 formam um conjunto bastante distinto daquele formado pelos grupos 1 e 2 .

Assim, conseguimos comparar os grupos de crianças de 6 a 12 anos a agentes com $c_{1}<1$ e memórias de ordem 2 ou 3 . Na mesma figura podemos ver os modelos de agentes 

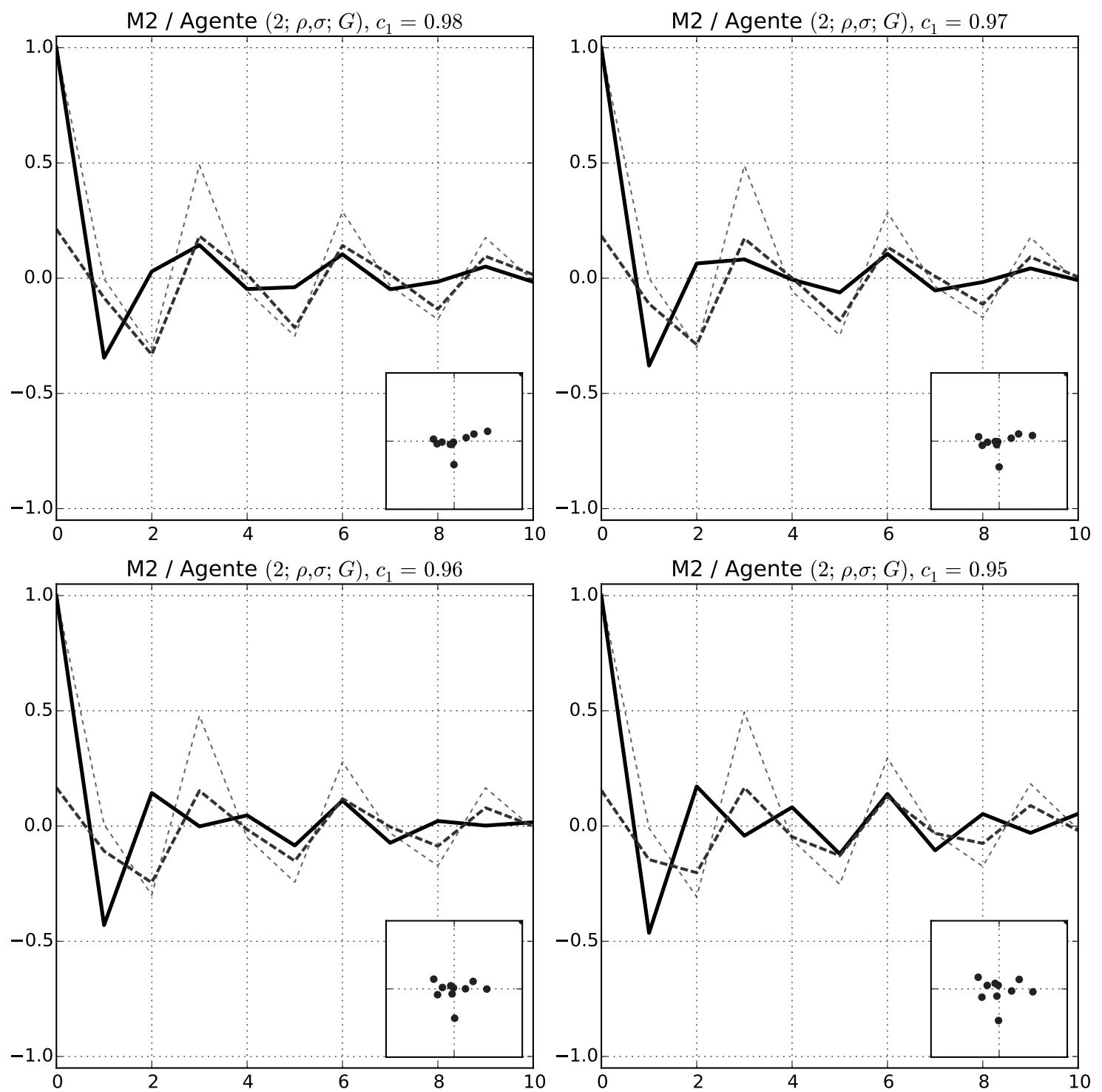

Figura 3.16: Sensibilidade dos modelos $(2 ; \rho, \sigma ; G)$, e da sua capacidade de ajustar padrões de período 3, à variação de $c_{1}$.

que foram considerados: para memória 2 , usamos $c_{1}=0,97$; para memória 3 , usamos $c_{1}=0,90$ e 0,91 . Não foi determinada uma correspondência de um para um; o conjunto de modelos foi entendido como um conjunto de possibilidades de descrição conjunta desses três grupos de indivíduos.

Em seguida, chegamos ao grupo de 20-25 anos (figura 3.18), que apresenta o melhor desempenho de todos para as sequências M2 (cerca de 70\%). É interessante notar que o perfil de autocorrelação dos sujeitos se assemelha muito ao perfil de autocorrelação dos agentes $(3 ; \rho, \sigma ; G)$, o que não ocorre com o modelo $(x ; D)$ nem com o $(\rho, \sigma ; D)$ - porém 

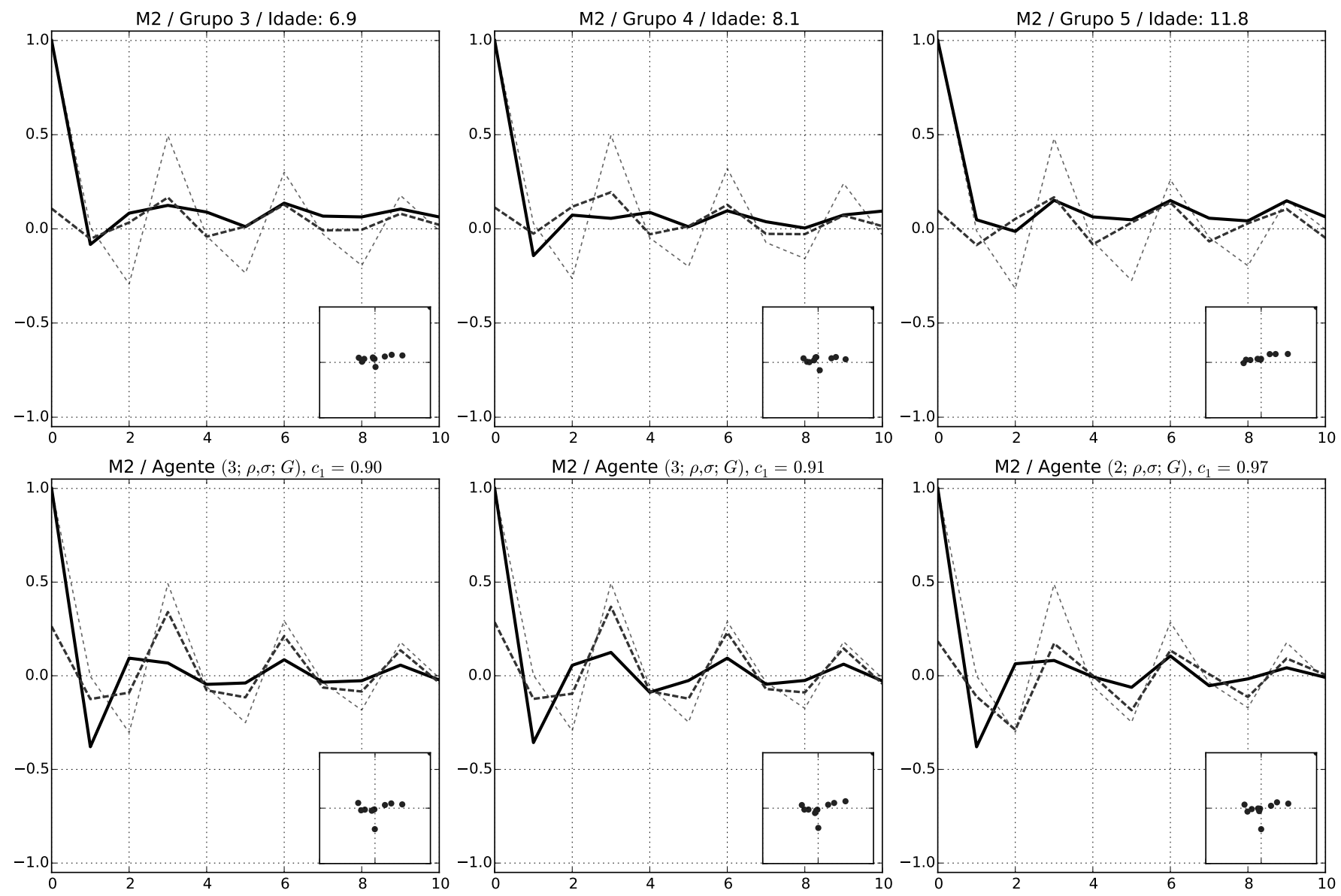

Figura 3.17: Curvas de correlação para crianças dos grupos 3, 4 e 5 contra sequências M2, e resultados de simulações para comparação.

conseguimos novamente uma grande coincidência se usarmos $c_{1}=1,1$ neste último. Na figura 3.18 vemos esses dois modelos, além de (a) uma variação sobre $(3 ; \rho, \sigma ; G)$ com $c_{1}=1,1$, que ilustra a estabilidade do ajuste nesse ponto; (b) um modelo com memória 2 , que não acompanha o formato da curva experimental e ficou longe de imitar a curva de correlação cruzada.

Do grupo 6 para o grupo 7 (figura 3.19) há uma alteração grande na curva de autocorrelação, mas que afeta principalmente a amplitude, deixando o formato muito similar ao anterior. Esse mesmo formato se mantém em grande parte nos grupos 8 e 9, havendo porém uma alteração no trecho entre as ordens 0 e 2. Apesar de essa alteração não ter sido reproduzida por nenhum modelo, as outras características do formato dessas curvas podem ser encontradas nos gráficos de agentes simulados na mesma figura. obtidos aumentando-se $c_{1}$ nos modelos analisados para o grupo 6. No entanto, outra diferença é visível: as curvas de correlação cruzada para os grupos 8 e 9 estão defasadas em uma 

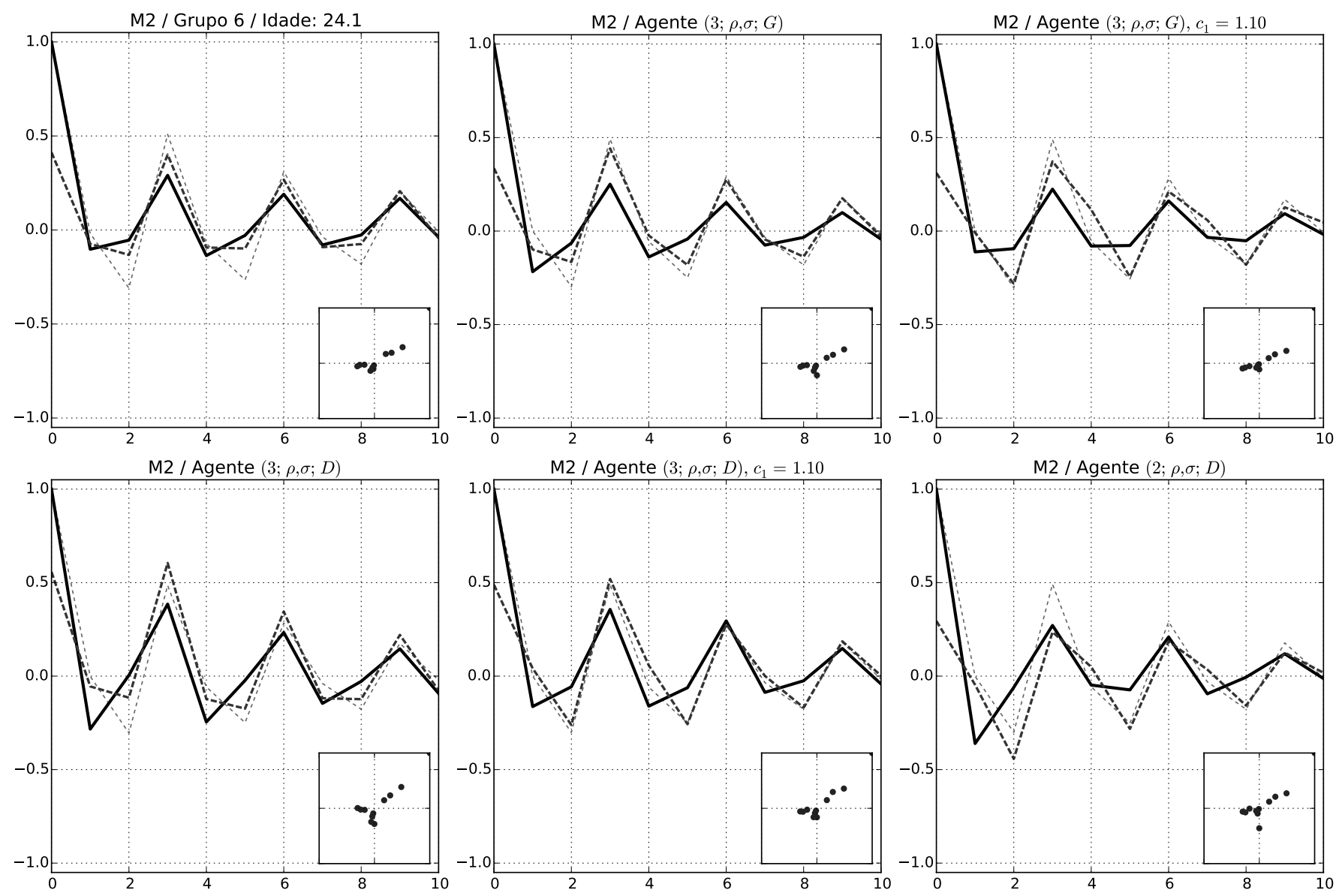

Figura 3.18: Curvas de correlação com sequências M2 para jovens do grupo 6 e simulações dos modelos para comparação.

ordem temporal - os picos que se localizavam nas ordens 0 , 3, 6, 9 estão agora localizados nas posições $1,4,7,10$. Uma possível justificativa para essa defasagem é que nesses dois grupos haja a adoção de uma estratégia de 'cópia da resposta anterior', que gera um padrão similar ao da sequência-alvo porém deslocado no tempo, conforme discutido por Victorino (2012). Lembremos também que, para haver uma estratégia pura de cópia, deveria haver coincidência entre as correlações de $x$ e $y$; por isso, por trás desses indivíduos deve haver um conjunto de estratégias mistas.

Esses resultados nos sugerem que, a partir das crianças de 6 anos, os modelos de agentes de memória 3 em geral descrevem melhor os comportamentos dos indivíduos segundo os critérios que adotamos. Os modelos de memória 2 conseguem reproduzir parte dos resultados de autocorrelações, porém em alguns casos falham nas correlações cruzadas. Também obtiveram maior acordo com os comportamentos humanos os modelos com estimativa $G$, se comparados com os com estimativa $D$. As alterações na constante 

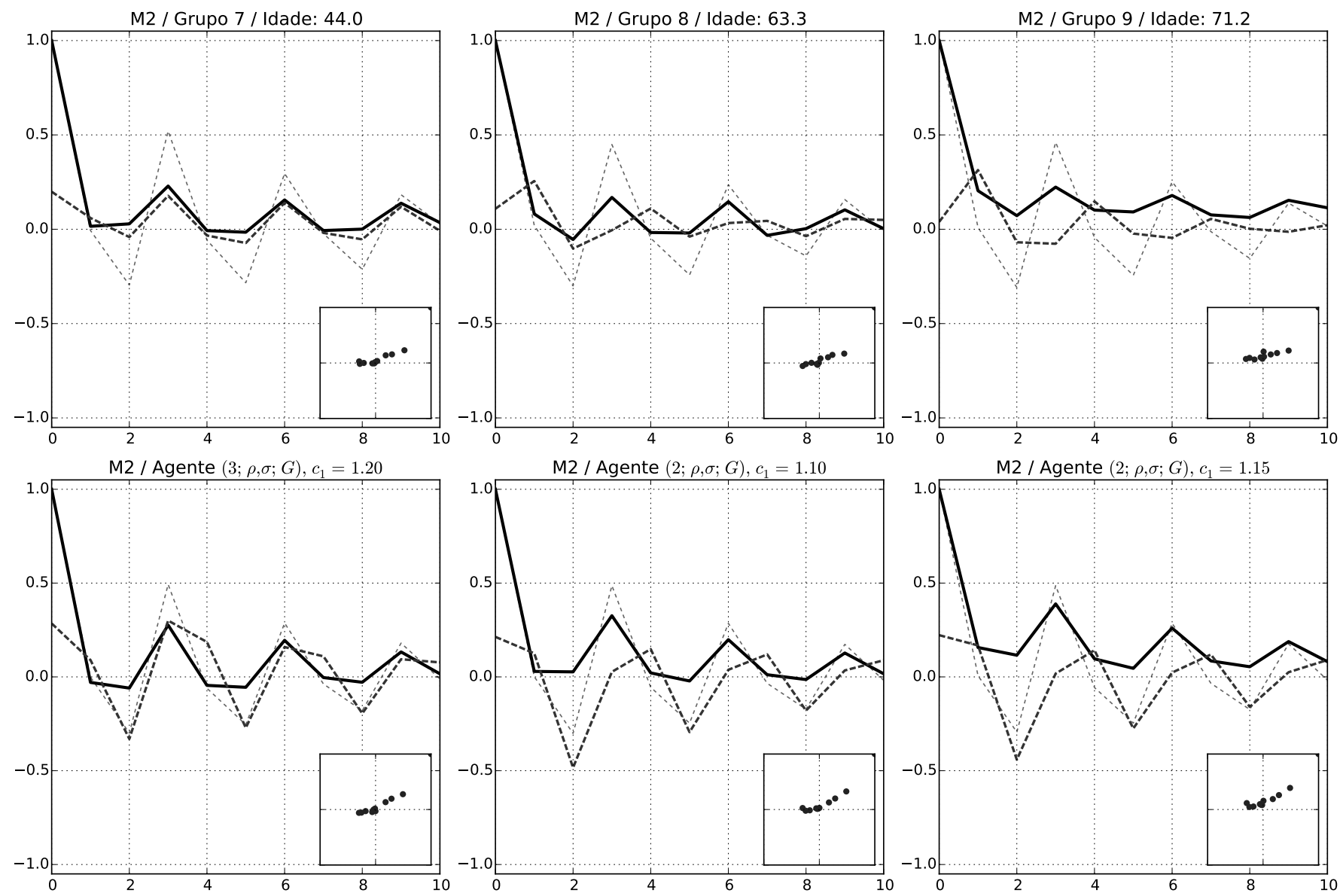

Figura 3.19: Curvas de correlação com sequências M2 para adultos dos grupos 7, 8 e 9 e para agentes simulados.

$c_{1}$ de fato se mostraram como uma maneira de aproximar os dados reais dos resultados das simulações - para os adultos acima de 40 anos, ajustaram-se valores de $c_{1}>1$, e para as crianças de 6 a 12 anos foram ajustados valores $c_{1}<1$. As crianças de menos de 6 anos não foram capazes de adotar um padrão de respostas coincidindo com a periodicidade das sequências; assim, viu-se necssário ajustar modelos com memória menor que 2, que fossem incapazes de absorver padrões de período maior do que 2. Apenas os modelos de ordem zero mostraram um aspecto compatível com os dados em questão; um ajuste fino de $c_{1}$ permitiu uma coincidência alta quando avaliada visualmente.

\section{Sequências M1}

Nas sequências M1, o período típico das autocorrelações é 2. Não há problemas com nenhum dos grupos de indivíduos em obter autocorrelações com esse mesmo período; a variação principal é na amplitude e taxa de decaimento. Veremos nos gráficos a seguir 
que, para essas sequências, o comportamento dos agentes é bem mais estável, de modo que uma gama maior de modelos pode ser ajustada a cada grupo de indivíduos. 

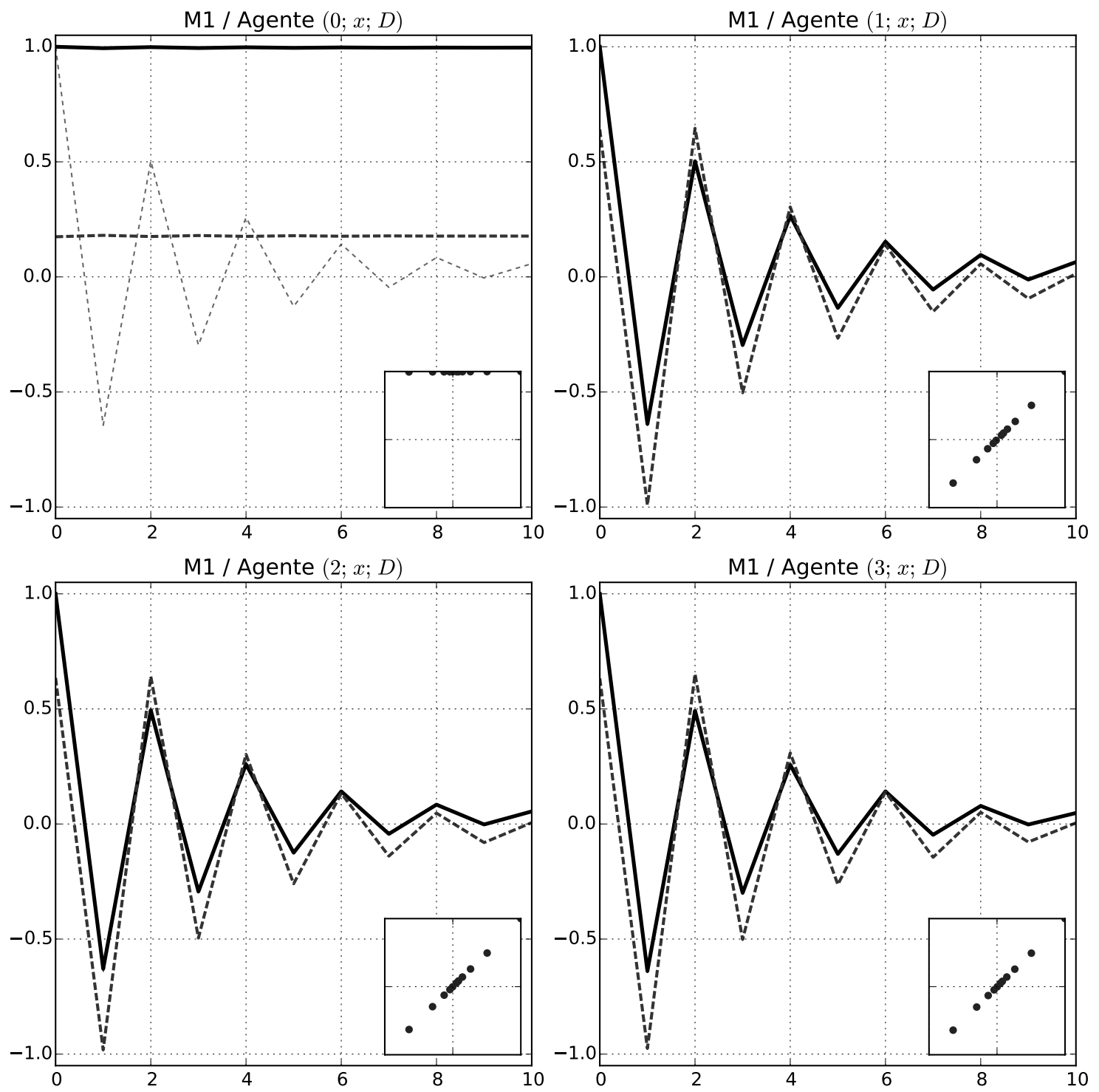

Figura 3.20: Curvas de correlação para simulações de agentes $(K ; x ; D)$ contra sequências M1. 

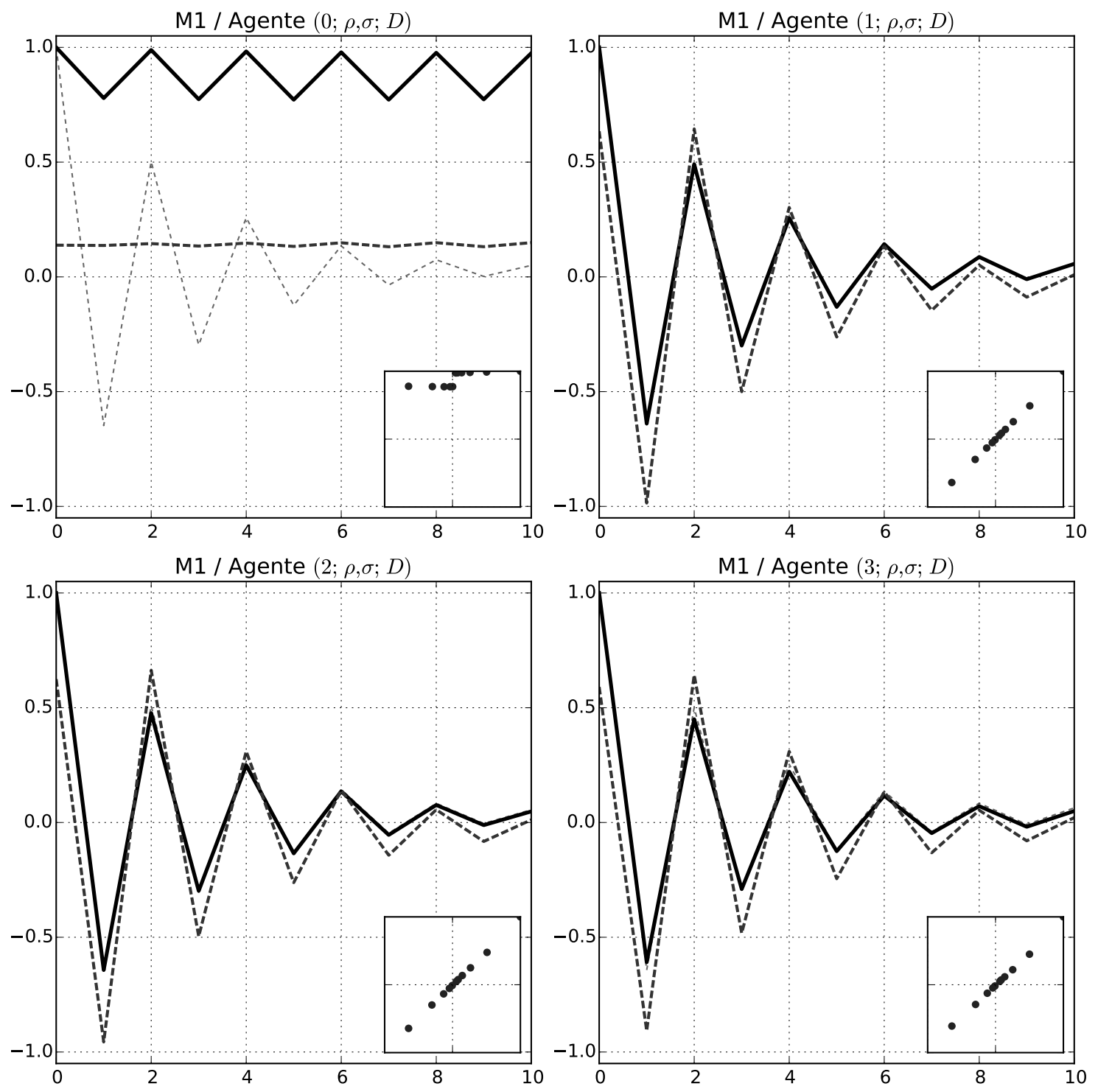

Figura 3.21: Curvas de correlação para simulações de agentes $(K ; \rho, \sigma ; D)$ contra sequências M1. 

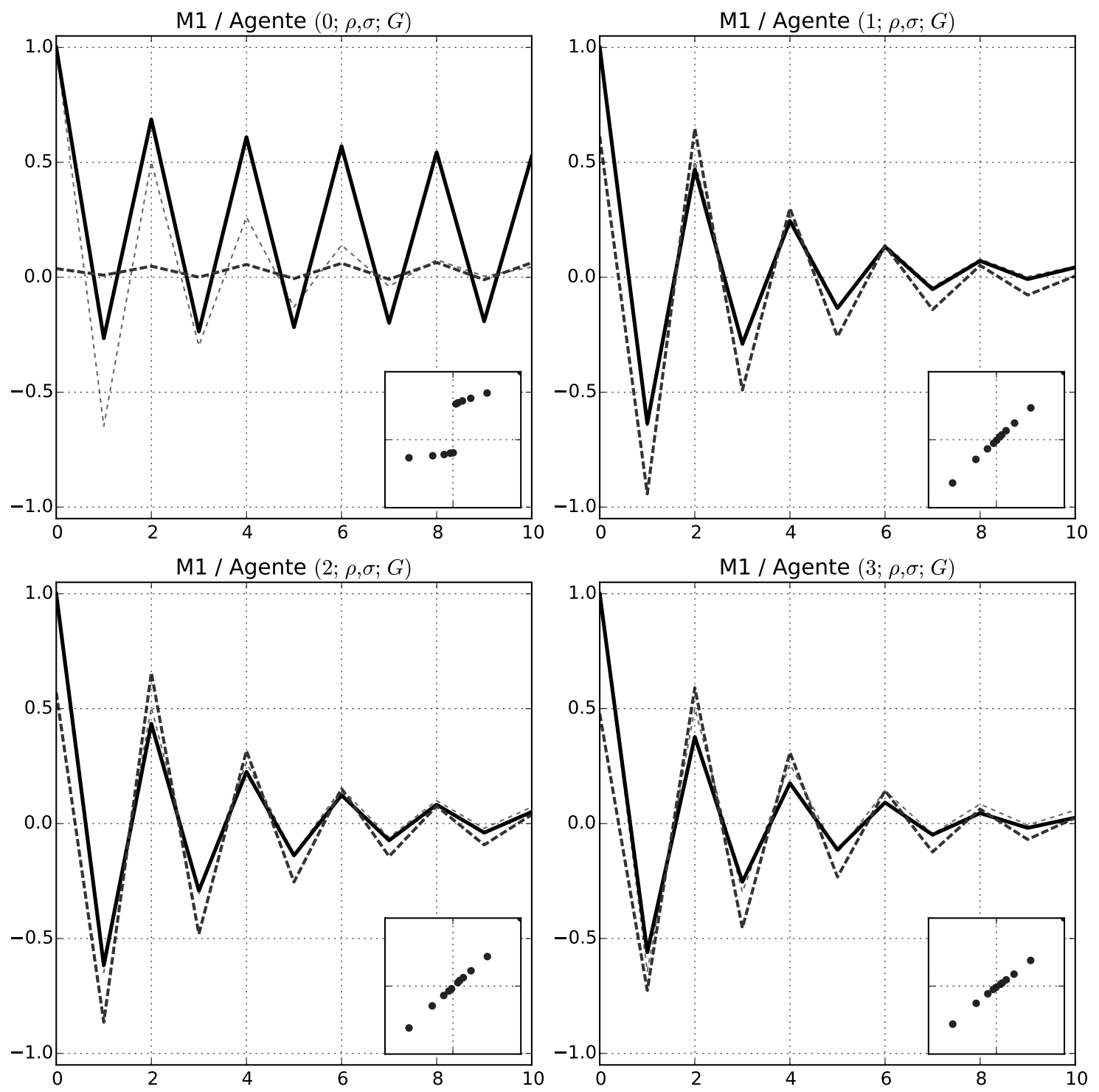

Figura 3.22: Curvas de correlação para simulações de agentes $(K ; \rho, \sigma ; G)$ contra sequências M1. 

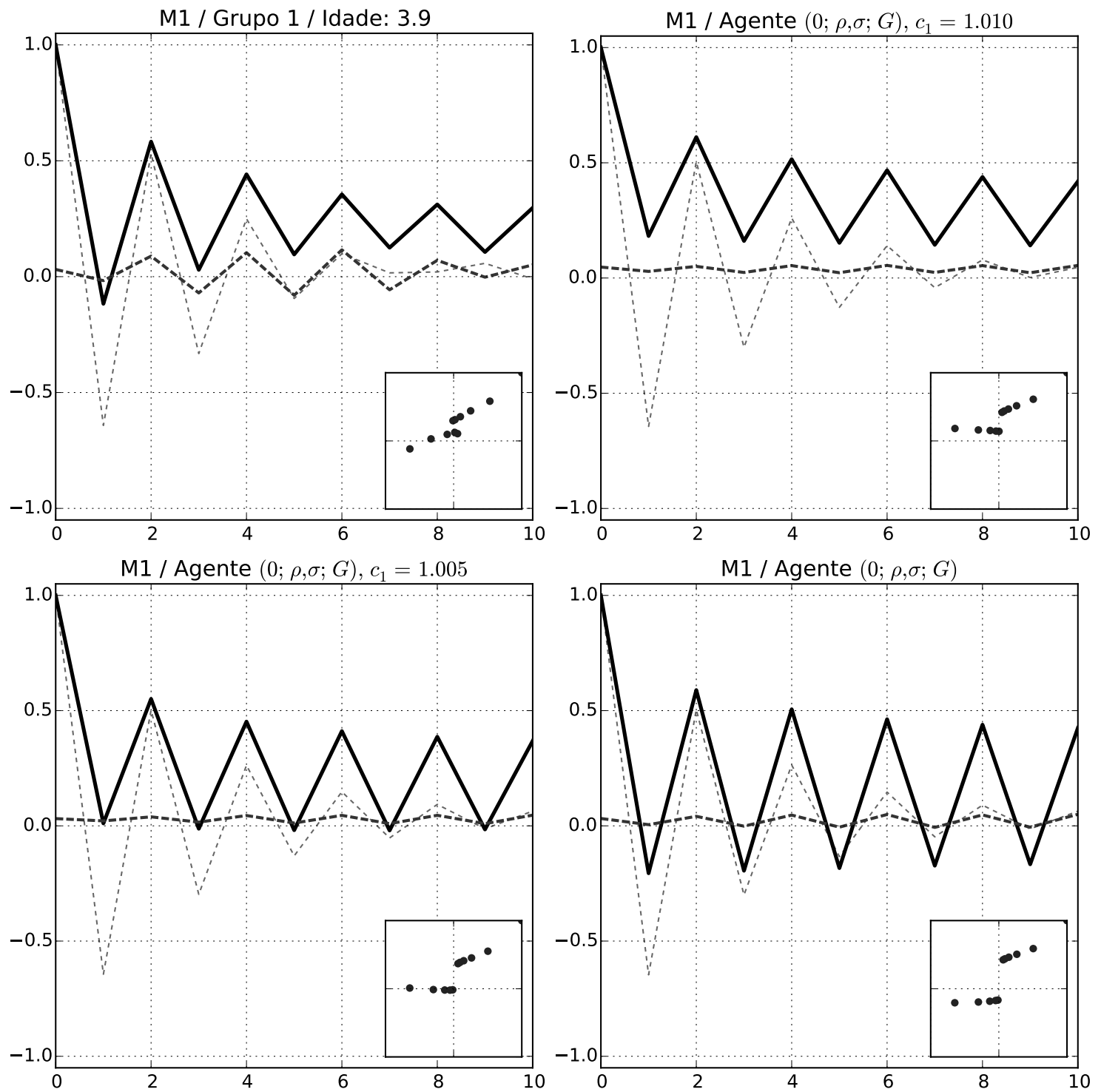

Figura 3.23: Curvas de correlação com sequências M1 para os agentes comparados ao grupo 1. 
Para o grupo 1, de crianças mais novas, viu-se novamente que o único tamanho de memória que poderia ajustar os dados era zero. O modelo "puro" (com estimativa tipo $G$ e sem ajustes nas constantes de aprendizado) difere bastante do resultado experimental; um pequeno aumento em $c_{1}$, até 1,005 ou 1,010, é suficiente para reduzir bastante essa diferença, conforme pode ser visto na figura 3.23.

No grupo 2, não foi encontrado um ajuste de modelo que conciliasse a diferença de amplitudes entre a autocorrelação e a correlação cruzada; são mostrados na figura 3.24 alguns dos modelos mais próximos dentro do repertório disponível, dando preferência ao ajuste da autocorrelação.

Entre os grupos 3, 4 e 5, conforme a figura 3.25, percebe-se que não há diferenças muito significativas que justifiquem análises separadas. Nota-se que a principal diferença em relação ao grupo 2 é o comportamento da correlação cruzada - naquele ela fica próxima do centro "neutro" $(0,5)$, enquanto nestes ela se aproxima bastante da curva de autocorrelação da cadeia de Markov. No sub-gráfico com as autocorrelações, é possível perceber que há uma mudança clara de padrão do grupo 2 para os grupos 3-5, e que estes últimos apresentam padrões compatíveis entre si.

Olhando para o conjunto dos gráficos a partir dos jovens de 20-25 anos, percebe-se uma tendência geral de aumento de $c_{1}$ conforme o crescimento da idade. Ao mesmo tempo que para o grupo 2 há uma diminuição de $c_{1}$, os grupos de 6 a 12 anos apresentam um comportamento quase especular em relação aos jovens de 20-25 anos, mostrando uma nova tendência de aumento.

Comentamos na subseção anterior que há uma tendência geral de ajuste melhor dos resultados experimentais aos modelos com estimativas do tipo $G$ em relação ao tipo $D$. No entanto, vale destacar que as diferenças entre as duas estimativas nos resultados das simulações não são fortes o suficiente para podermos afirmar alguma das duas como mais correta que a outra em termos de fidelidade ao comportamento humano que está sendo modelado. A alternância entre as duas na escolha do melhor ajuste ao longo dos grupos mostra que nossa modelagem deve omitir fatores que seriam relevantes para tal ajuste - ou possivelmente que haja um outro tipo de estimativa que descreva melhor a situação real. 

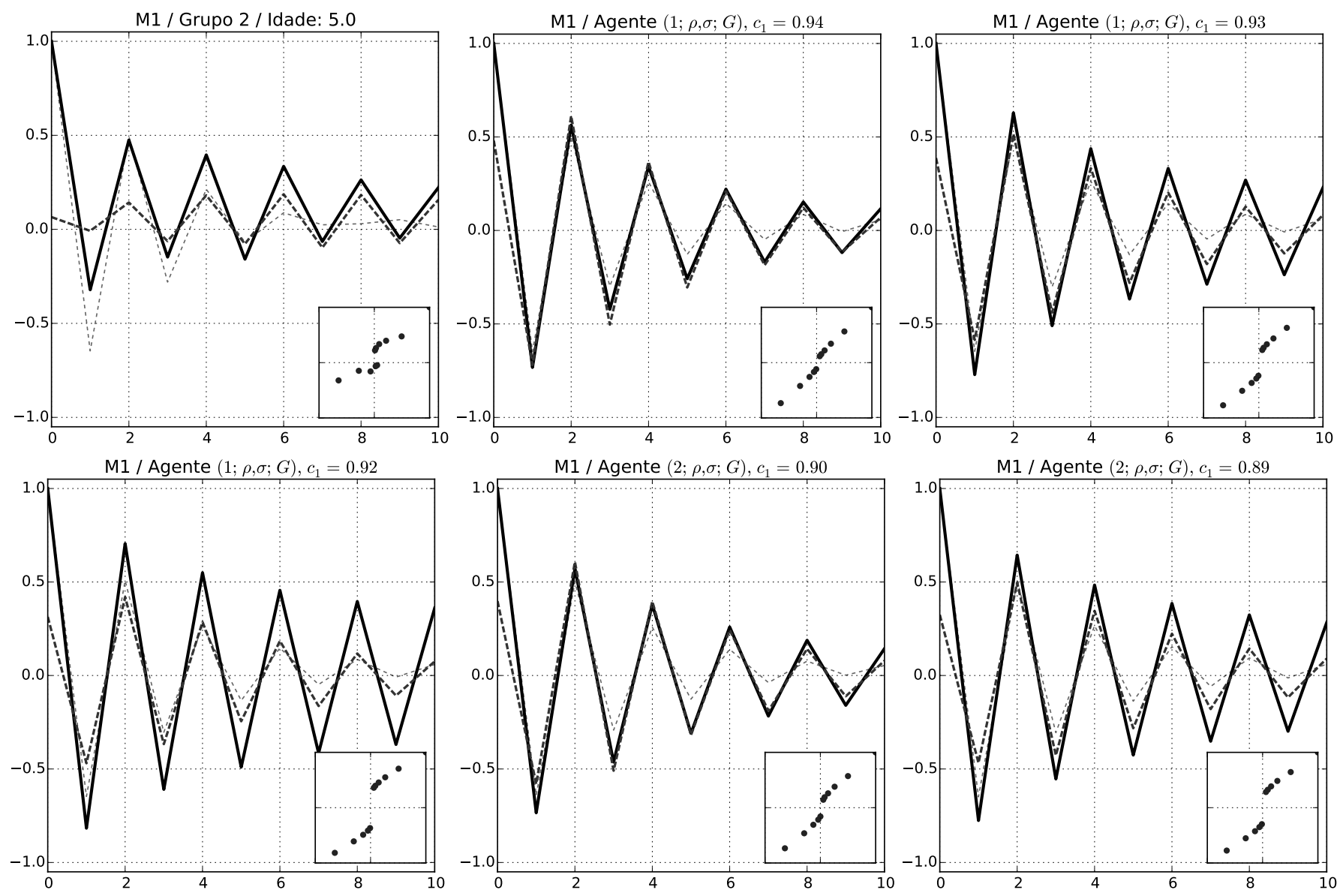

Figura 3.24: Curvas de correlação com sequências M1 para os agentes comparados ao grupo 2. 

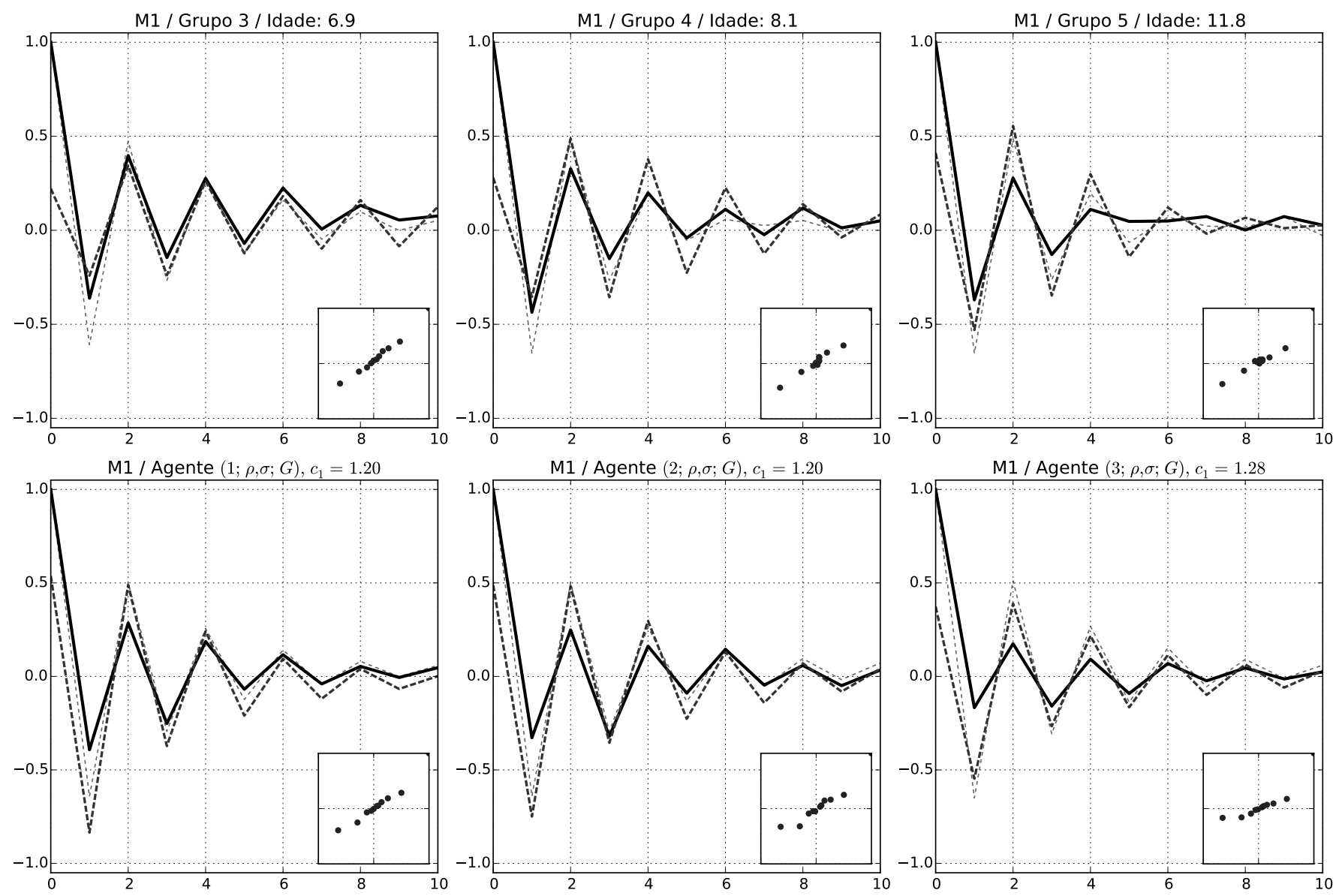

Figura 3.25: Curvas de correlação com sequências M1 para os agentes comparados aos grupos 3, $4 e$ 5. 

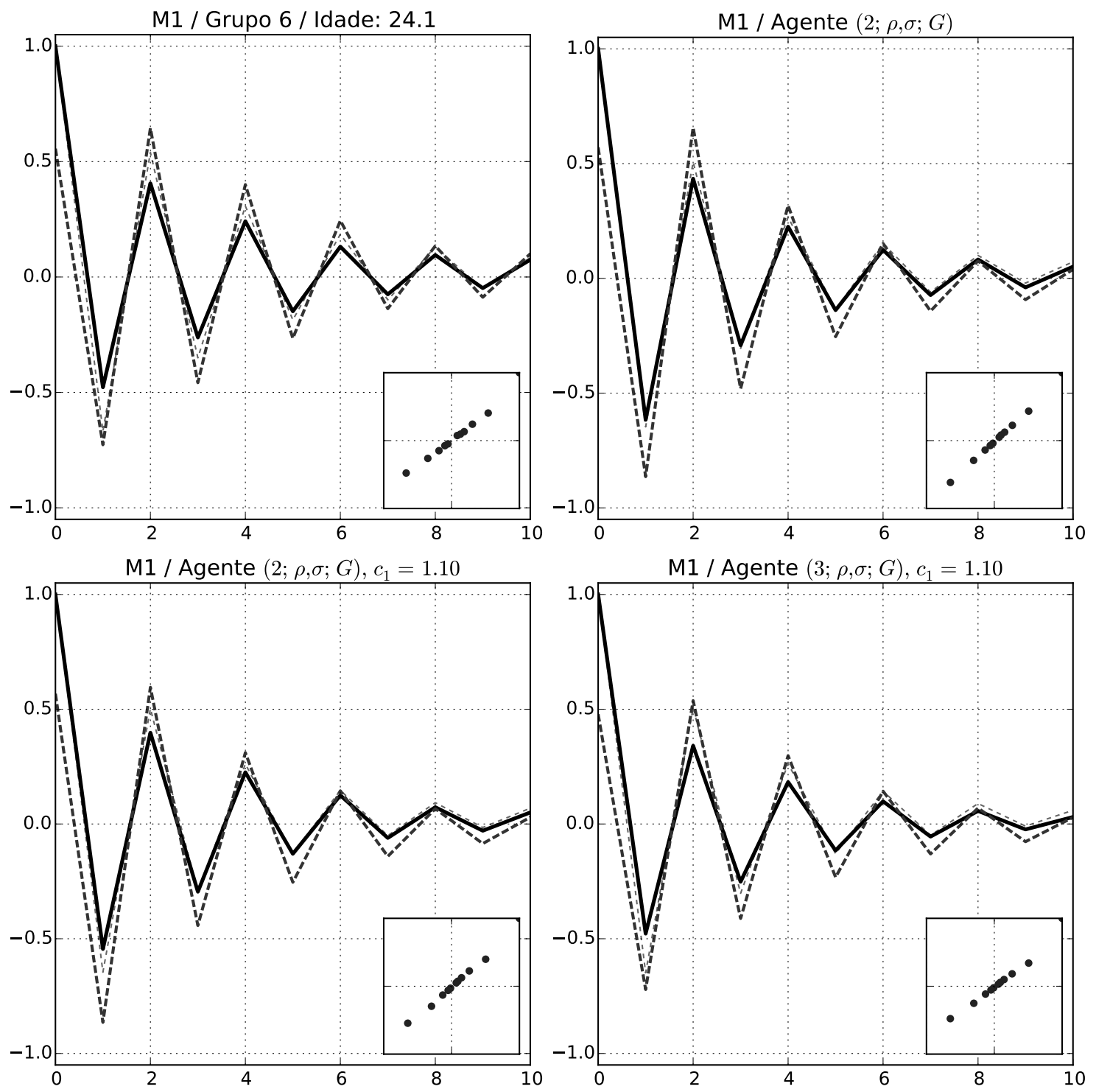

Figura 3.26: Curvas de correlação com sequências M1 para os agentes comparados ao grupo 6. 

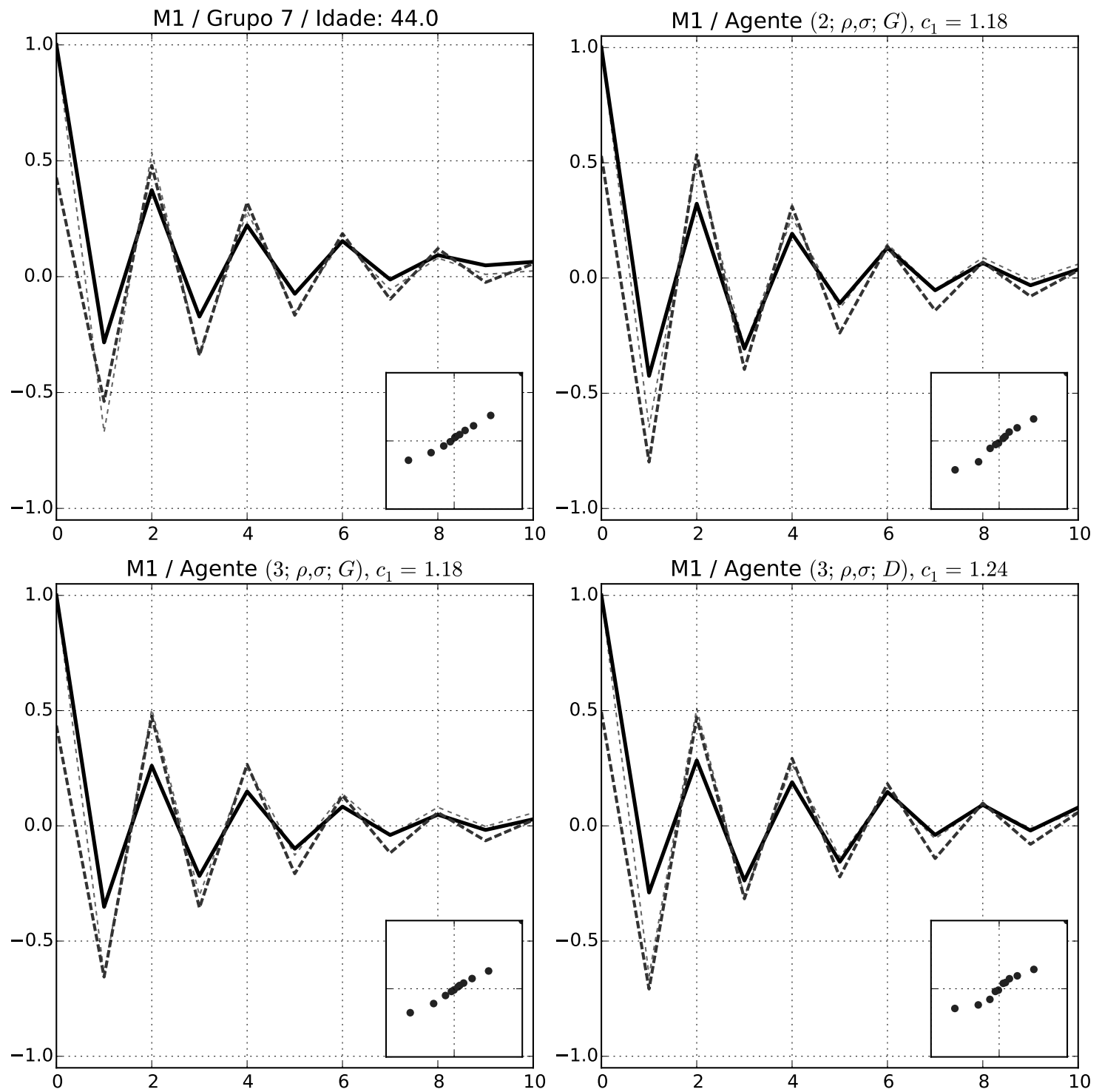

Figura 3.27: Curvas de correlação com sequências M1 para os agentes comparados ao grupo 7. 

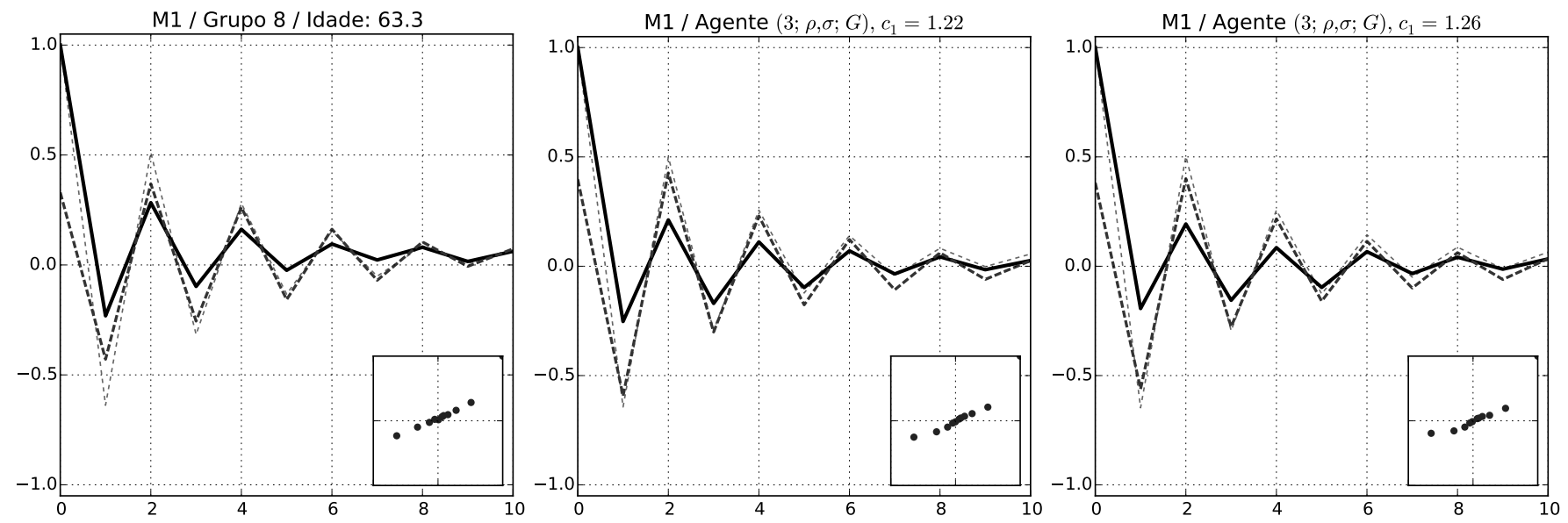

Figura 3.28: Curvas de correlação com sequências M1 para os agentes comparados ao grupo 8.
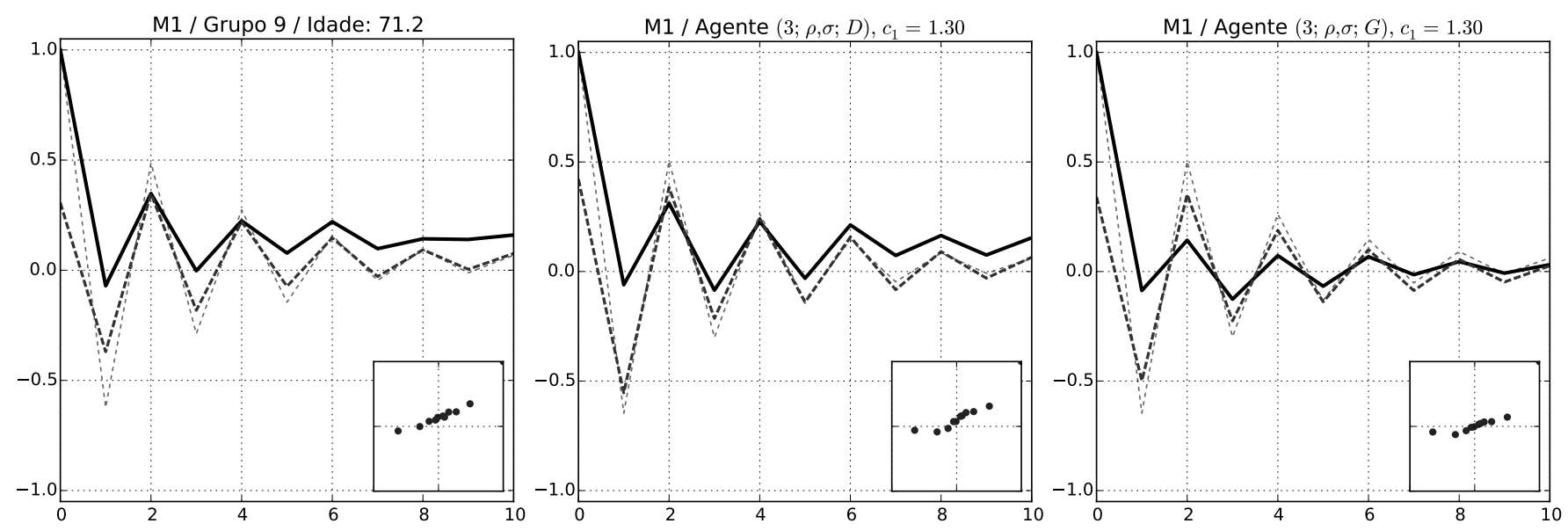

Figura 3.29: Curvas de correlação com sequências M1 para os agentes comparados ao grupo 9. 


\section{Sequências Mo}

Para as sequências de ordem 0, fica claro pela figura 3.30 que os agentes que utilizam as variáveis $x$ adotam a estratégia ideal que é persistir na estratégia mais provável. Porém claramente nenhum dos agentes humanos adota esse tipo de estratégia ou algo próximo dela, como veremos ao longo das figuras. Novamente, adotaremos apenas os modelos com variáveis $\rho, \sigma$.

As crianças mais novas, dos grupos 1 e 2, podem ser ajustadas por modelos de memórias mais curtas: o modelo de memória zero, representado na figura 3.33, pode descrever ambos os grupos. Modelos de memórias mais longas são mostrados também na mesma figura, sugerindo que as crianças do grupo 2 já apresentem sinais de uma evolução rumo a memórias mais longas.

Para os grupos 3 a 5 (crianças de 6 a 12 anos), já se vê necessidade de adotar modelos com memórias maiores - a memória zero não consegue descrever os resultados desses grupos. Na figura 3.34 esses grupos são comparados com modelos de memória 1 e 2 . O ajuste ideal, ao que parece, seria um intermediário entre os dois modelos, ao menos para os grupos 4 e 5 - o grupo 3 apresenta uma protuberância a mais na ordem 2 .

Para essas sequências, os resultados dos grupos 6, 7 e 8 (20-25, 40-45 e 60-65 anos) foram bastante similares. Embora as autocorrelações sejam bem ajustadas por modelos de memória 2 e 3 , as correlações cruzadas dos modelos de memória 3 apresentam um pico característico na ordem 3, ao passo que as correlações experimentais apresentam picos na ordem 1. Novamente o ajuste ideal aparenta ser um intermediário entre as memórias 1 e 2 .

No grupo 9, o comportamento é parecido com os grupos anteriores porém com níveis de correlação sistematicamente mais altos como observado nos outros tipos de sequências (M1 e M2). O ajuste com memória 1 parece ser mais acurado, mas foram mostrados também ajustes com memórias 2 e 3 para efeito de comparação. 

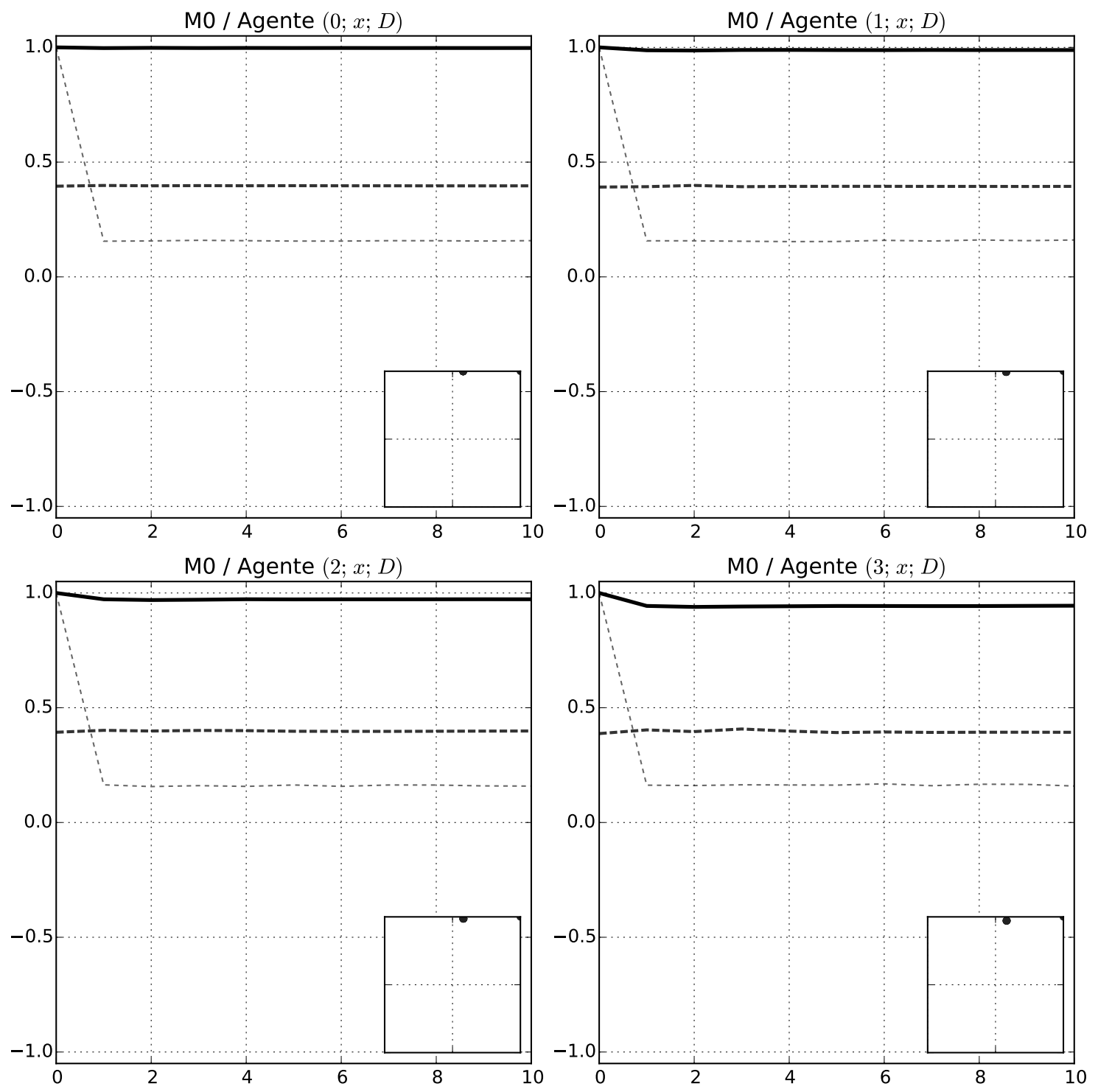

Figura 3.30: Curvas de correlação para simulações de agentes $(K ; x ; D)$ contra sequências M0. 

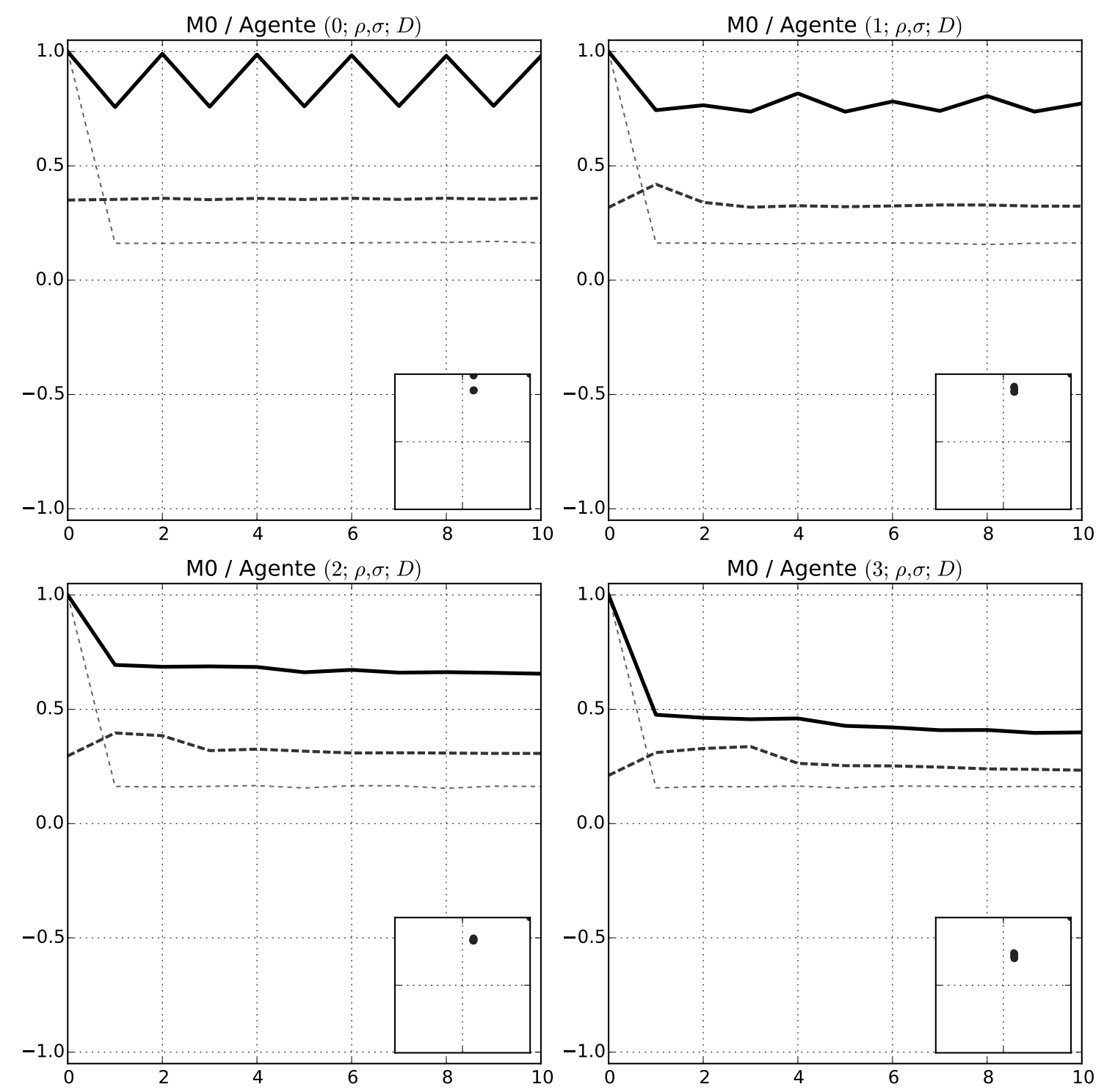

Figura 3.31: Curvas de correlação para simulações de agentes $(K ; \rho, \sigma ; D)$ contra sequências Mo. 

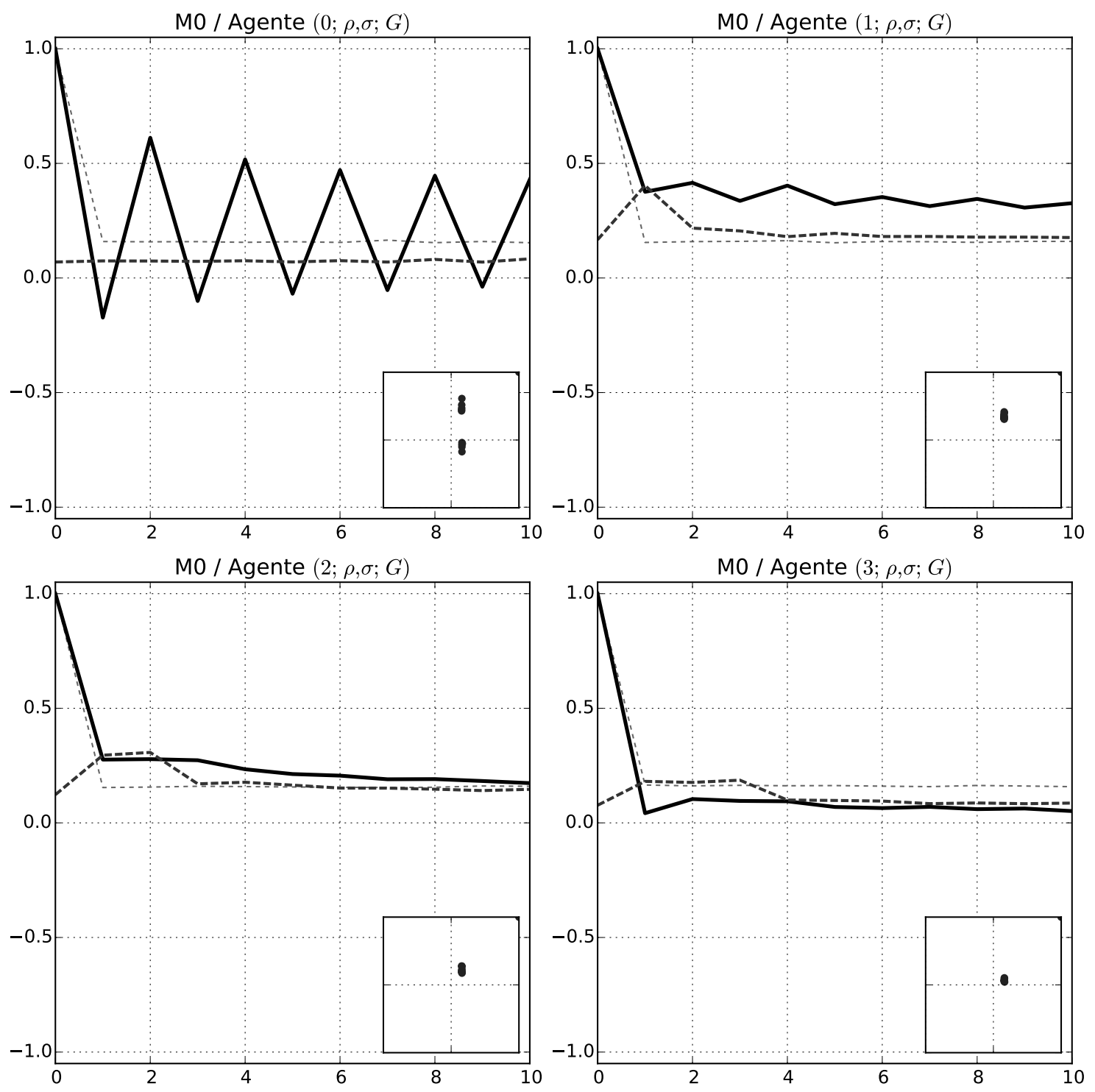

Figura 3.32: Curvas de correlação para simulações de agentes $(K ; \rho, \sigma ; G)$ contra sequências Mo. 

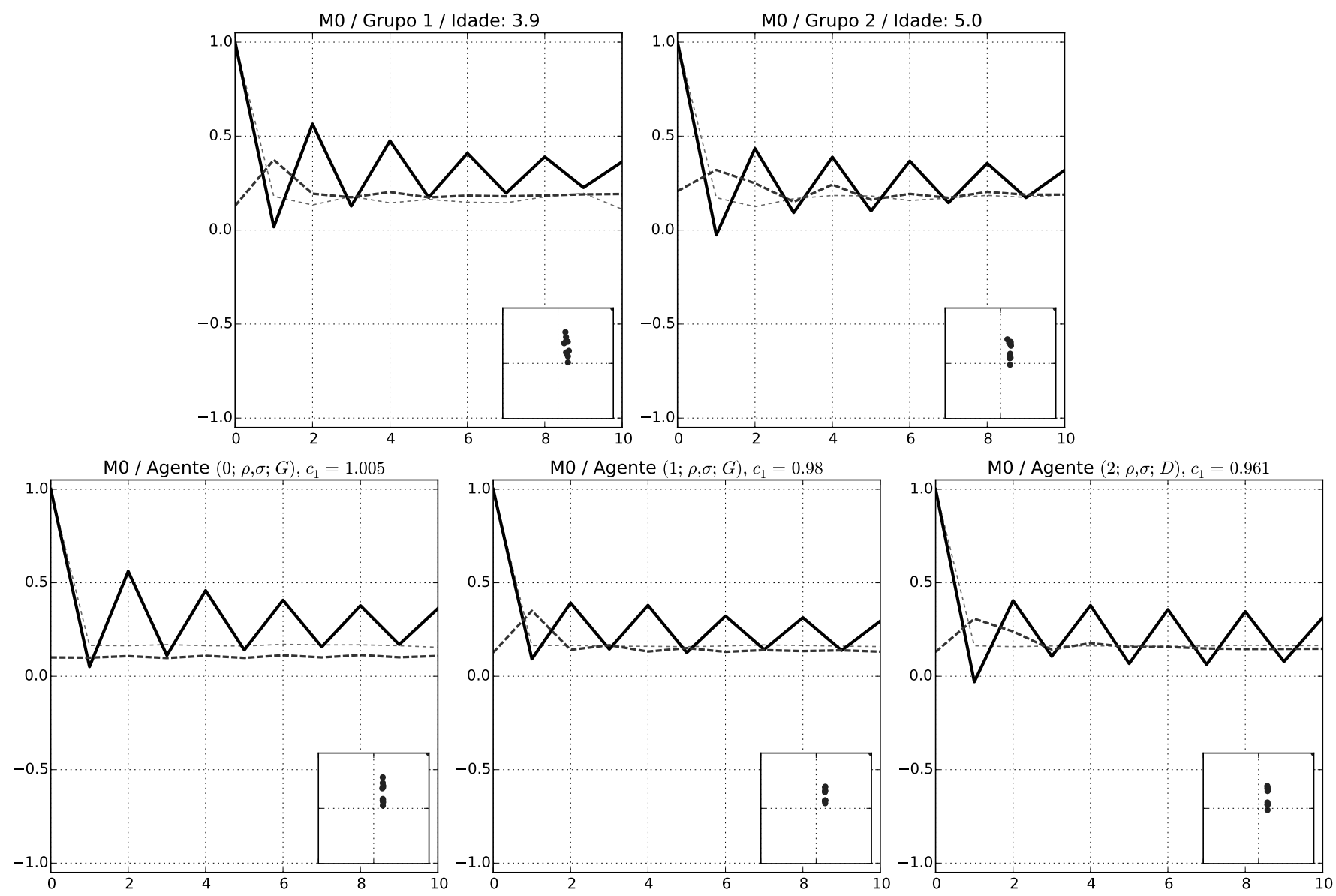

Figura 3.33: Curvas de correlação com sequências Mo para os agentes comparados aos grupos 1 e 2 . 

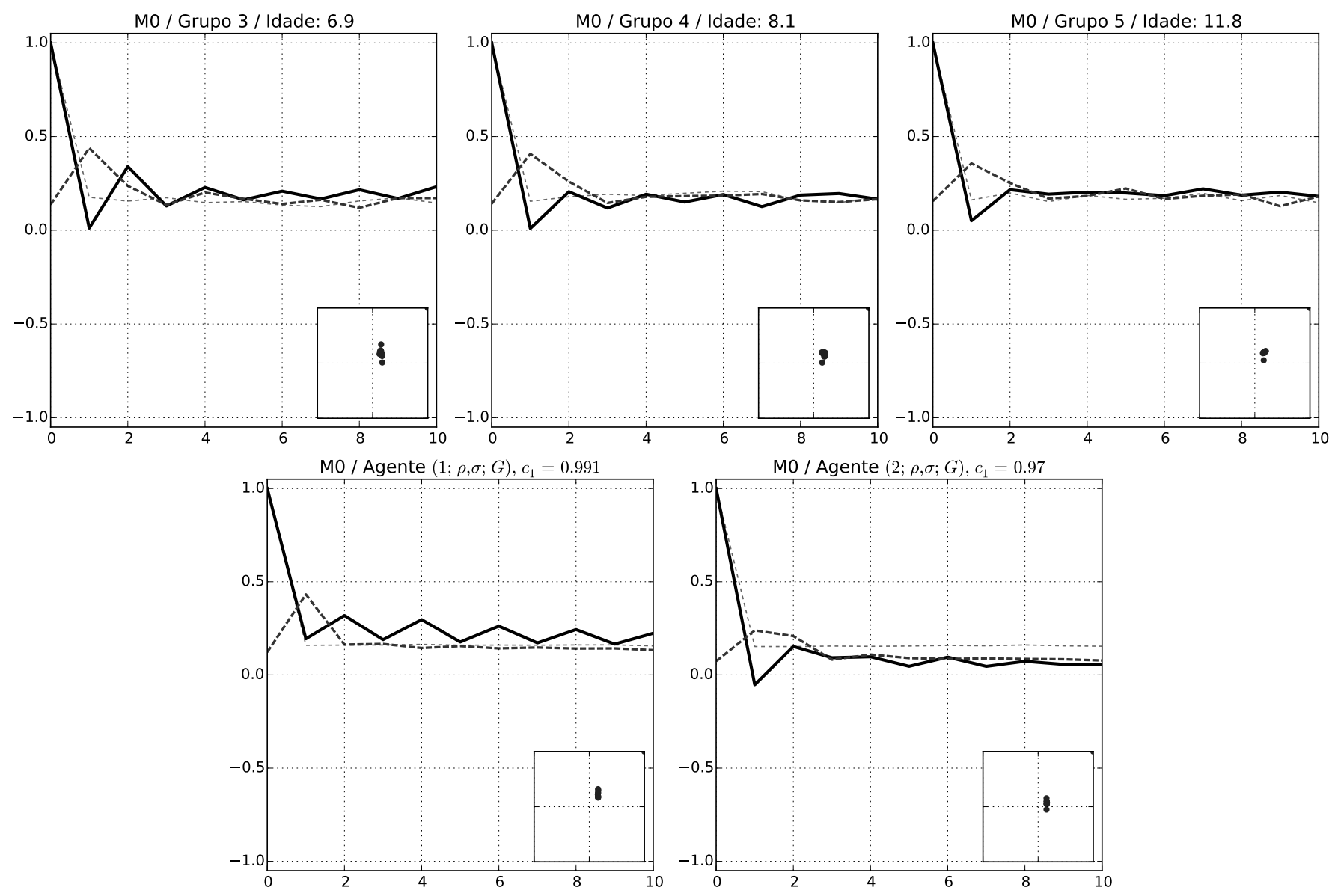

Figura 3.34: Curvas de correlação com sequências Mo para os agentes comparados aos grupos $3,4 e$ 5. 

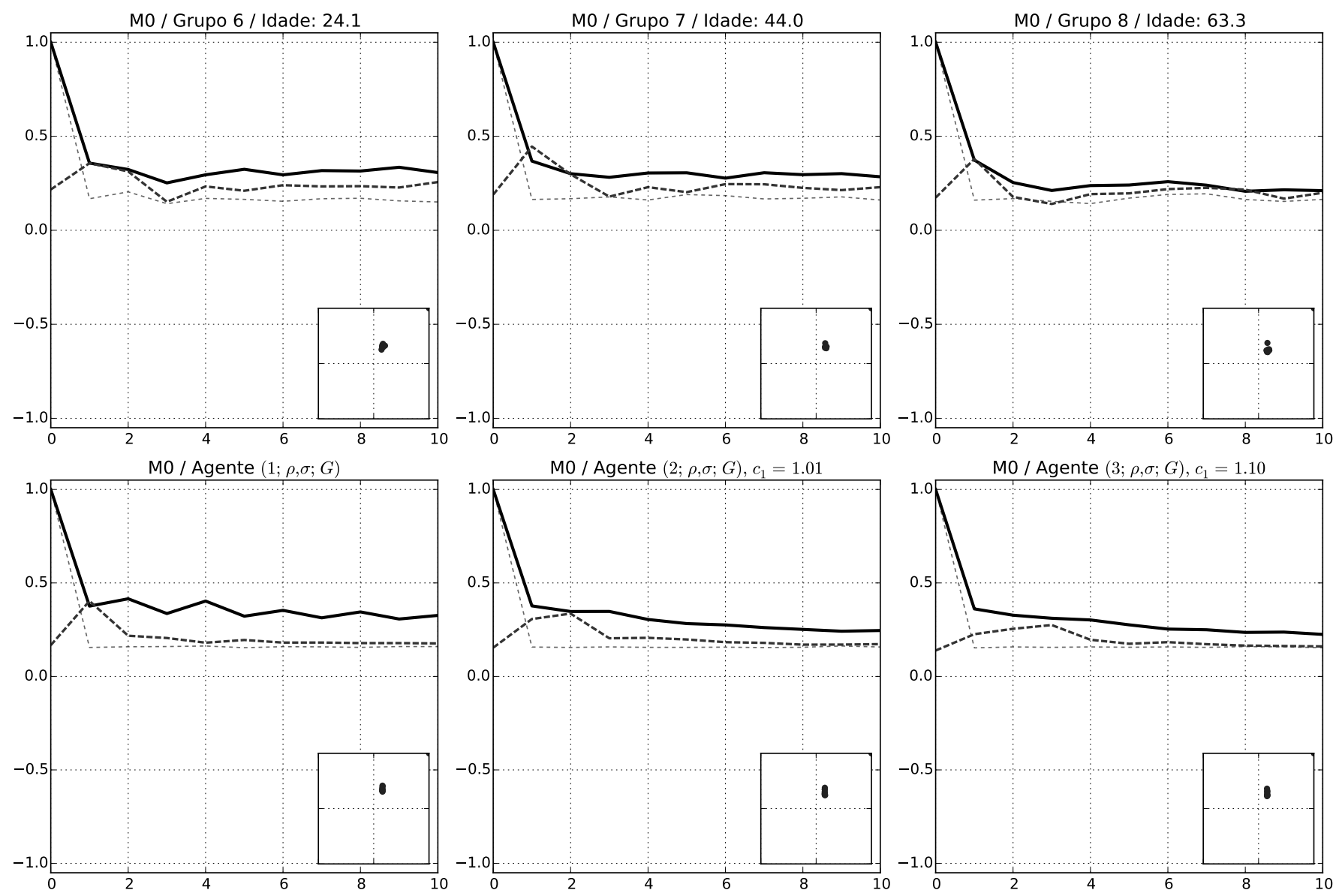

Figura 3.35: Curvas de correlação com sequências M0 para os agentes comparados aos grupos 6, $7 e$ 8. 

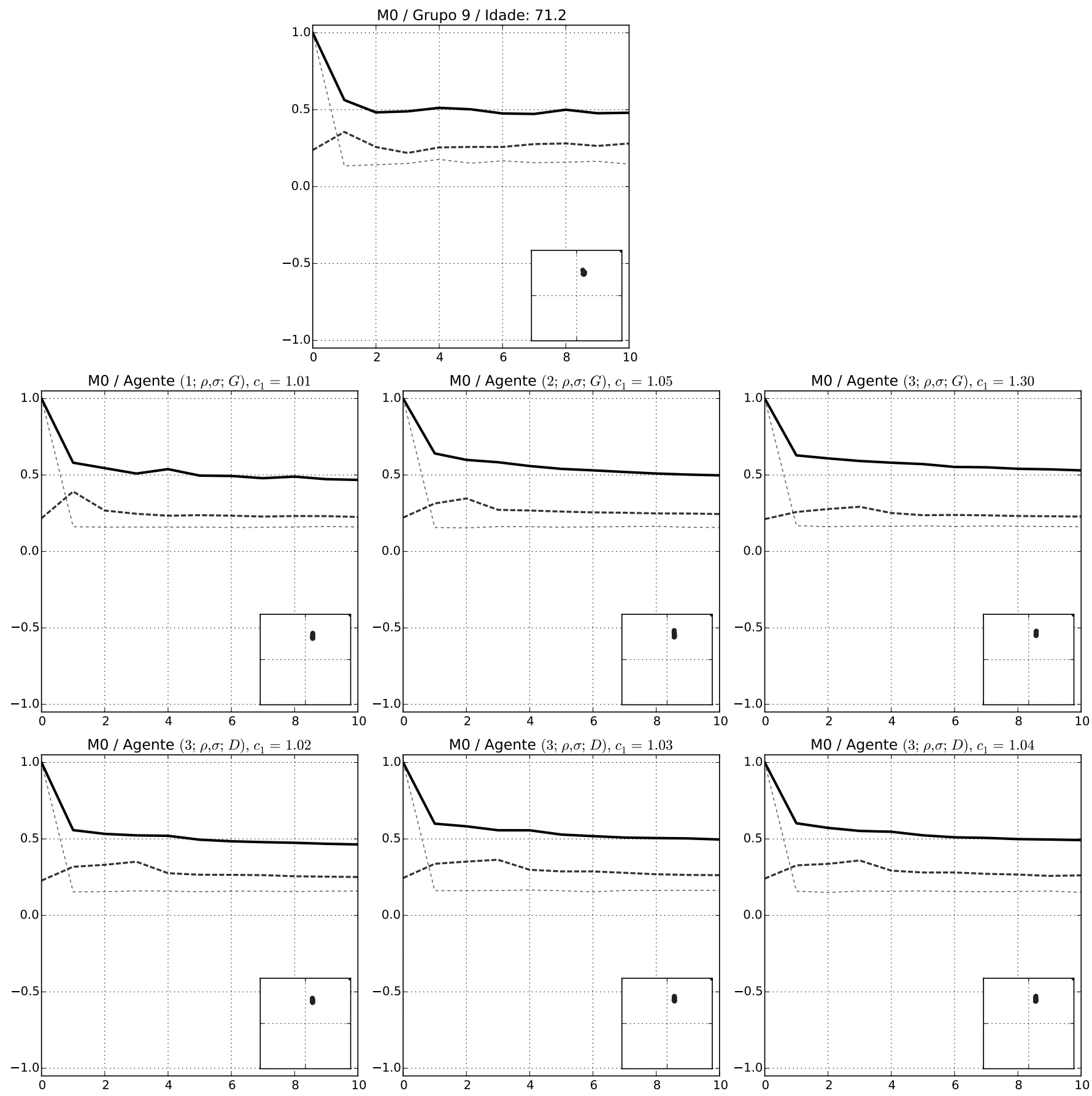

Figura 3.36: Curvas de correlação com sequências M0 para os agentes comparados ao grupo 9. 


\section{Capítulo 4}

\section{Conclusões}

Os modelos probabilísticos estudados foram comparados qualitativamente aos resultados para humanos voluntários de um experimento, e foi possível extrair alguns padrões e tendências das comparações:

- Crianças mais jovens, de 3 até 5 anos, são melhor descritas por modelos de memória mais curta -0 ou 1. Isso não é inesperado, pois percebe-se a partir dos resultados experimentais que essas crianças têm menor capacidade de compreensão de padrões, e portanto a descrição de sua estratégia deve ter uma complexidade baixa.

- Crianças de 6 a 12 anos já se aproximam dos modelos de memória 2, tendo comportamentos bastante próximos a esses ou intermediários entre esses e os de memória 1. Esse resultado seria coerente com o anterior na hipótese de o tamanho da memória para esse tipo de estratégia ser parte do desenvolvimento do sistema nervoso.

- Crianças de 3 até 12 anos tendem a se ajustar melhor a modelos em que a constante $c_{1}$ de reforço do aprendizado foi diminuída em relação à unidade; porém, esse resultado se inverte quando os indivíduos são confrontados com cadeias de Markov de ordem 1.

- A faixa etária de 20 a 25 anos se aproximou bastante dos resultados obtidos com modelos em que as constantes de reforço do aprendizado foram mantidas como 1, tendo o melhor desempenho entre todos os grupos em todas as tarefas.

- Nas faixas etárias de 40 anos e acima, a tendência geral é um aumento da constante $c_{1}$ de reforço em relação à unidade. Unindo esse resultado às observações anteriores, percebe-se uma tendência de "movimento" dessa constante, que cresceria até 1 no ápice do desenvolvimento e depois passaria a cair - esse tipo de comportamento pode estar relacionado com capacidades de absorção e liberação de neurotransmissores que são moduladas ao longo de uma vida.

Com os resultados obtidos, é possível dizer que o modelo desenvolvido fornece, com sua simplicidade, uma primeira aproximação válida para um comportamento que pode apresentar uma alta complexidade. Além de considerar a diferença nos resultados como consequência de mudanças de ordem neurocognitiva ao longo da vida, devemos lembrar que podem existir desvios de distintas naturezas nesses comportamentos. As estratégias que modelamos foram imaginadas como de natureza instintiva, possíveis 
de serem encontradas em outros seres vivos até certo ponto. No caso de humanos, os desvios em relação a essas estratégias podem ter explicações emocionais e/ou psicológicas, consequências de tentativas de racionalização do processo; cansaço em relação à tarefa pode também resultar em alterações que tendem a piorar o desempenho na tarefa. Mas, como lembra Kahneman (2011), pode também haver desvios cognitivos, que são de fato incontroláveis pelo indivíduo.

A continuidade deste trabalho pode ser imaginada seguindo alguns caminhos diferentes: no caminho da modelagem, podem ser usadas outras combinações de variáveis no mecanismo interno do agente. No caminho experimental, seria extremamente útil conhecer padrões de resultados para indivíduos portadores de doenças que afetam o sistema de recompensas e outras partes responsáveis pelo aprendizado; esse estudo seria muito valioso para entender a relação dos parâmetros aqui utilizados com estruturas biológicas. 


\section{Glossário}

\section{agente}

Elemento de um modelo que realiza ações, tais como a tomada de decisões.

\section{iteração, repetição, rodada, tentativa}

Termos usados alternadamente para expressar cada sub-problema de uma tarefa de decisão; em cada sub-problema, o agente toma uma decisão e em seguida observa se previu corretamente a resposta que deveria ter dado.

\section{marginalização}

Processo que remove a dependência em uma ou mais variáveis de uma probabilidade conjunta ou condicional, somando sobre todos os valores possíveis dessas variáveis. Por exemplo, a probabilidade $P(A)$ pode ser obtida das probabilidades $P(A \mid B)$ somando-se sobre todos os valores de $B$, ponderando por cada probabilidade $P(B)$. 



\section{Bibliografia}

Behrend, E. e M. Bitterman (1961). "Probability-matching in the fish". Em: American Journal of Psychology 74.4, pp. 542-551.

Bogacz, R. et al. (2006). "The physics of optimal decision making: A formal analysis of models of performance in two-alternative forced-choice tasks." Em: Psychological Review 113.4, pp. 700-765. ISSN: 0033-295X. DOI: 10.1037/0033-295x.113.4.700.

Kahneman, D. (2011). Thinking, Fast and Slow. Farrar, Straus and Giroux.

Kahneman, D. e A. Tversky (1979). "Prospect theory: An analysis of decision under risk". Em: Econometrica: Journal of the Econometric Society, pp. 263-291.

Marsaglia, G. (2003). "Xorshift RNGs". Em: Journal of Statistical Software 8.14, pp. 1-6. ISSN: $1548-7660$.

Martin, R. (2004). “The St. Petersburg Paradox". Em: Stanford Encyclopedia of Philosophy. Ed. por E. N. Zalta. Stanford University.

Savage, L. (1972). The Foundations of Statistics. Dover Books on Mathematics. Dover Publications. ISBN: 0486623491.

Victorino, C. G. (2012). "Estudo do desenvolvimento de estratégias decisionais em escolhas binárias repetidas”. Dissertação (Mestrado em Fisiologia Humana) - Instituto de Ciências Biomédicas. Universidade de São Paulo. 